UNIVERSIDADE ESTADUAL PAULISTA “JÚLIO DE MESQUITA FILHO”

Programa de Pós-Graduação em Ciência e Tecnologia de Materiais

César Rodnei de Oliveira

\title{
Alteração das Propriedades Superficiais do Alumínio via Eletrólise a Plasma
}


César Rodnei de Oliveira

\title{
Alteração das Propriedades Superficiais do Alumínio via Eletrólise a Plasma
}

\begin{abstract}
Dissertação apresentada como requisito à obtenção de título de Mestre à Universidade Estadual Paulista "Júlio de Mesquita Filho" - Programa de Pós-Graduação em Ciência e Tecnologia de Materiais, área de concentração Ciência e Engenharia de Interfaces, sob a orientação do Prof. Dr. Nilson Cristino da Cruz.
\end{abstract}

Sorocaba, 18 de janeiro de 2010

Banca Examinadora:

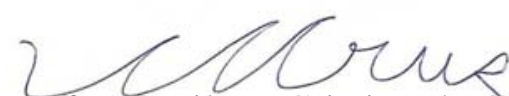

Prof. Dr. Nilson Cristino da Cruz (orientador)

Instituição: Universidađe Estadual Paulista Júlio de Mesquita filho - UNESP - Sorocaba

Prof. Dr. Mário Antonio Bica de Morais

Instituição: Universidade Estadual de Campinas - UNICAMP - Campinas<smiles>CCCCCCCCCCCCCC</smiles>

Prof. Dr. Tersio Guilherme de Souza Cruz

Instituição: Universidade Federal de São Carlos - UFSCAR - Sorocaba 
Oliveira, César Rodnei de.

Alteração das Propriedades Superficiais do Alumínio via Eletrólise a Plasma / César Rodnei de Oliveira, 2009.

$122 \mathrm{f}$.

Orientador: Nilson Cristino da Cruz

Dissertação (Mestrado)-Universidade Estadual Paulista. Faculdade de Ciências, Bauru, 2010

1. Plasma Eletrolítico. 2. Proteção Contra Corrosão. 3. Micro descargas. I. Universidade Estadual Paulista. Faculdade de Ciências. II. Título. 


\title{
FOLHA DE APROVAÇÃO
}

\section{Une UNIVERSIDADE ESTADUAL PAULISTA "JÚLIO DE MESQUITA FILHO" CAMPUS DE BAURU \\ FACULDADE DE CIENCIAS DE BAURU}

\begin{abstract}
ATA DA DEFESA PÚBLICA DA DISSERTAÇÃO DE MESTRADO DE CESAR RODNEI DE OLIVEIRA, DISCENTE DO PROGRAMA DE PÓS-GRADUAÇÃO EM CIÊNCIA E TECNOLOGIA DE MATERIAIS, DO(A) FACULDADE DE CIENCIAS DE BAURU.
\end{abstract}

Aos 18 dias do mês de janeiro do ano de 2010, às 14:00 horas, no(a) Campus Experimental UNESP / Sorocaba, reuniu-se a Comissão Examinadora da Defesa Pública, composta pelos seguintes membros: Prof. Dr. NILSON CRISTINO DA CRUZ do(a) Coordenadoria Executiva / Unidade de Sorocaba, Prof. Dr. MARIO ANTONIO BICA DE MORAIS do(a) Instituto de Física Gleb Wataghin UNICAMP, Prof. Dr. TERSIO GUILHERME DE SOUZA CRUZ do(a) Campus de Sorocaba I Universidade Federal de Sao Carlos, sob a presidência do primeiro, a fim de proceder a argüição pública da DISSERTAÇÃO DE MESTRADO de CESAR RODNEI DE OLIVEIRA, intitulado "ALTERAÇÃO DAS PROPRIEDADES SUPERFICIAIS DO ALUMÍNIO VIA ELETRÓLISE A PLASMA". Após a exposição, o discente foi argüido oralmente pelos membros da Comissão Examinadora, tendo recebido o conceito final: $\triangle P R Q V A D Q$ . Nada mais havendo, foi lavrada a presente ata, que, após lida e aprovada, foi assinada pelos membros da Comissão Examinadora.

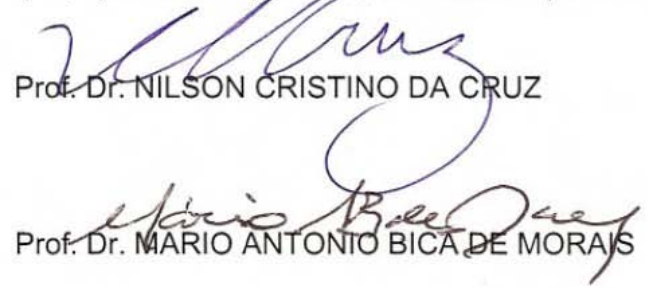

Prof. Dr. THRSIO GUILHERME DE SOUZA CRUZ 


\section{AGRADECIMENTOS}

Gostaria de expressar os meus mais sinceros agradecimentos primeiramente a Deus, meu Senhor e meu maior ajudador nas horas mais difíceis de minha vida.

A minha esposa e filha pela paciência e pelo carinho que tiveram por mim durante todo o período em que me dediquei à realização deste projeto.

Ao meu orientador, o prof. Dr. Nilson Cristino da Cruz pela orientação, pelo apoio, pela oportunidade que me ofereceu para desenvolver este trabalho, pela paciência demonstrada e por todo conhecimento transmitido, sendo que sem seu apoio não seria possível a realização deste trabalho.

À prof. Dra. Elidiane C. Rangel pelo grande apoio demonstrado ao longo do período em que permaneci no laboratório e pelos incentivos dispensados em momentos difíceis.

Aos meus pais, Maria Aparecida de Oliveira e Salvador Oliveira, por toda a preocupação, compreensão, ajuda, incentivo e lições de vida dispensadas.

Ao meu irmão Robson de Oliveira pela preciosa ajuda prestada na montagem que compõem o aparato experimental e pelo apoio recebido.

Ao meu grande amigo César Augusto Antonio pelo grande auxílio no desenvolvimento do projeto, pelo trabalho em equipe e pelas palavras de conforto e otimismo em momentos de difíceis escolhas.

A minha grande amiga Rita de Cássia Rangel pela ajuda prestada e pelo constante apoio recebido, sempre presente e tentando auxiliar a resolver todos os problemas.

À Prof. Dra. Maria Eliziane Pires de Souza pelas análises de espectroscopia de impedância e polarização, pelo apoio e pelas correções. 
Aos professores Antônio Riul Junior, Prof. Dr. Steven F. Durrant, Prof. Dr. José Roberto Bortoleto e Prof. Dr. Sandro Donnini Mancini e Profa. Dra. Maria Lúcia Pereira Antunes (Malu) pelo apoio demonstrado ao longo de todo o período de tempo em que permaneci no laboratório e pela constante paciência.

Ao prof. Dr. Carlos Frederico de Oliveira Graeff, pela sensibilidade e compreensão e fundamental apoio para tornar possível a realização deste trabalho.

Ao amigo Renato Raposo Trindade pelo auxilio e prontidão em oferecer seu auxílio na correção do resumo em inglês.

Ao Sr. Ricardo Cumino da empresa Schaeffler Brasil Ltda-Divisão INA por permitir a utilização do MEV e EDS, especialmente ao Sr. Gilvan pela grande atenção e dedicação aos ensaios realizados em minhas amostras.

Ao Sr. Carlos Fernando Ricci de Oliveira da empresa Rontan Eletro Metalúrgica Ltda por permitir a utilização do equipamento de névoa salina e especialmente ao Sr. Carlos Eduardo Leal do departamento de metrologia pela grande atenção prestada e pela análise das minhas amostras.

Ao amigo Guilherme Fernandes Nielsen pelo apoio nos ensaios de infravermelho.

A amiga Daniela Branco Tavares Mascagni por todo o incentivo e prontidão em me auxiliar na interpretação dos resultados de impedância eletroquímica.

Ao amigo Péricles Lopes Sant'Ana pelo incentivo e apoio recebidos.

À Prof. Dra. Célia Marina Alvarenga Freire por permitir a utilização do Laboratório de Engenharia de Corrosão do Departamento de Engenharia de Materiais da Faculdade de Engenharia Mecânica da UNICAMP.

A todo o pessoal da secretaria da POSMAT, principalmente à Andressa por toda a tolerância e grande ajuda prestada. 
"Eu sou a videira, vós as varas; quem está em mim, e eu nele, esse dá muito fruto; porque sem mim nada podeis fazer".

S. João, cap. 15 verso 5. 
Oliveira, C. R. Alteração das Propriedades Superficiais do Alumínio via Eletrólise a Plasma. 2009. 122f. Dissertação (Mestre em Ciência e Tecnologia de Materiais) UNESP, Sorocaba, 2009.

\section{RESUMO}

A proteção de superfícies metálicas é um assunto de grande interesse científico e econômico. As vultosas quantias empregadas regularmente em manutenção e conservação motivam estudos para a obtenção de materiais com maior durabilidade e manutenção de seu aspecto estético. Neste trabalho é proposto o desenvolvimento de um dispositivo de geração de plasma via eletrólise e a investigação de sua aplicabilidade no aumento da resistência a corrosão da liga de alumínio 2024. A alteração da resistência à corrosão conferida pelo filme ao substrato foi investigada através de ensaios de névoa salina e de impedâncias eletroquímica e de polarização. A composição e a estrutura química dos revestimentos foram analisadas por espectroscopia de absorção no infravermelho. Perfilometria e o método de correntes parasitas foram empregados na determinação da espessura das camadas depositadas, enquanto alterações da molhabilidade das superfícies foram avaliadas por medidas de ângulo de contato. Os resultados mostram que, sob determinadas condições, o tratamento aumentou em cerca de 145 vezes, em comparação com substratos sem tratamento, a resistência das amostras a exposição à névoa salina.

Palavras-chave: Plasma Eletrolítico, Filmes Finos a Plasma, Liga de Alumínio 2024, Proteção Contra Corrosão, Camada Cerâmica de Óxido, PEO (do inglês, Plasma Electrolytic Oxidation), PED (do inglês, Plasma Electrolytic Deposition), EPP (do inglês, Electrolytic Plasma Processing), Micro descargas; MAO (do inglês, Micro-arc Oxidation). 
Oliveira, C. R. Modification of the Superficial Properties of the Aluminum by Plasma Electrolysis. 2009. 122f. Dissertation (Mastering Degree on Material Science and Technology) - UNESP, Sorocaba, 2009.

\begin{abstract}
The protection of metallic surfaces is a subject of great scientific and economical interests. The huge amounts of money regularly employed in maintenance and conservation motivate investigations on the production of materials with larger durability, preserving the esthetic aspect. In this work, it is proposed the development of an electrolytic plasma device and the investigation of its applicability on the improvement of the resistance to corrosion of 2024 aluminum alloy coupons. Modifications in corrosion resistance conferred by the films to the substrates have been evaluated through salt spray tests and electrochemical and polarization impedances. Fourier infrared absorption spectroscopy has been employed to assess composition and chemical structure of the coatings. Layer thickness has been determined by profilometry and the eddy current method, while modifications in surface wettability have been evaluated through contact angle measurements. It has been observed that, under certain experimental conditions, the treatments have enhanced the resistance to salt spray corrosion up to 145 times, as compared to the pristine substrates.
\end{abstract}

Keywords: Electrolytic Plasma, Thin Films by Plasma, 2024 Aluminum Alloy, Protection Against Corrosion, Oxide Ceramic Layers, PEO (Plasma Electrolytic Oxidation), PED (Plasma Electrolytic Deposition), EPP (Electrolytic Plasma Processing), Microdischarge; MAO (Micro-arc Oxidation). 


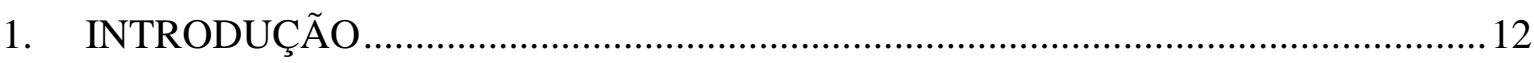

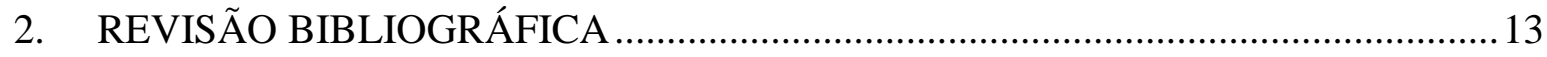

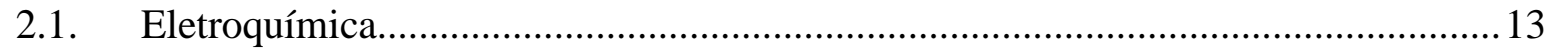

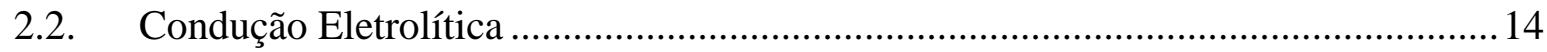

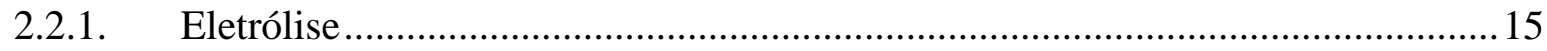

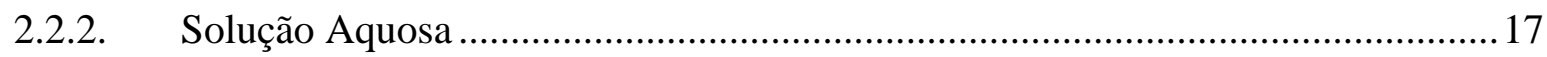

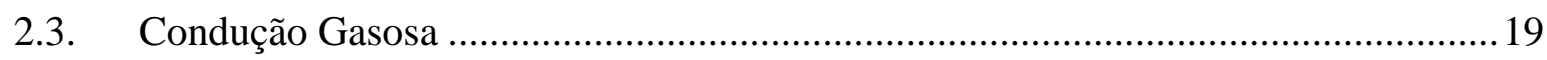

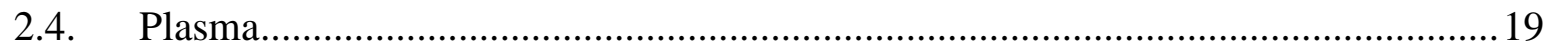

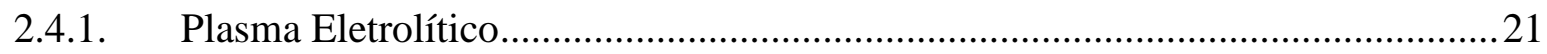

2.4.1.1. O Processamento via Plasma Eletrolítico …………………………………....22

2.4.1.2. Monitoramento de processo em PEO …………………………....................29

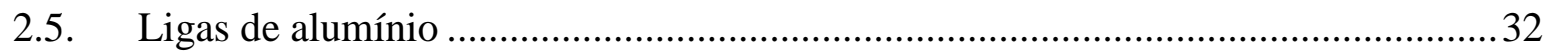

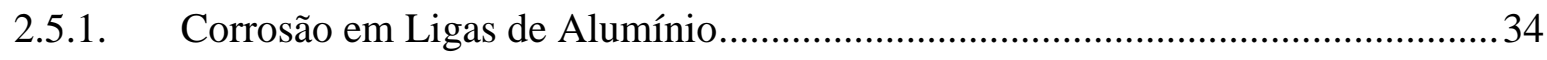

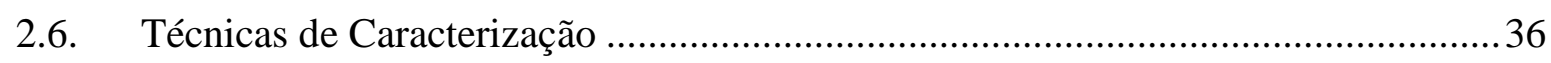

2.6.1. Ângulo de Contato e Energia de Superfície …………………………………......36

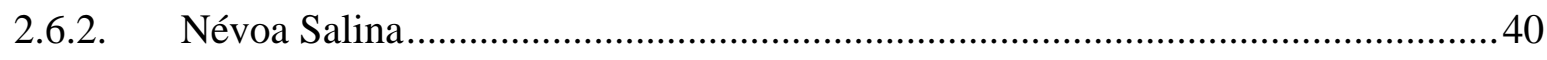

2.6.3. Microscopia Eletrônica de Varredura............................................................... 41

2.6.4. Espectroscopia de impedância eletroquímica.......................................................42

2.6.5. Polarização Potenciodinâmica.......................................................................... 48

2.6.6. Espectroscopia de Infravermelho ...............................................................50

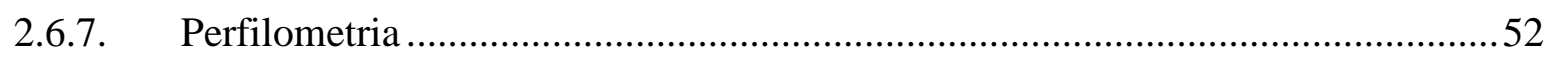

2.6.8. Medição da Espessura do Revestimento por Correntes Parasitas ..........................53

3. PROCEDIMENTOS EXPERIMENTAIS ……………………………………….....55

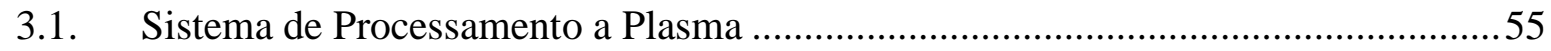

3.2. Preparação das amostras ......................................................................................59

3.3. Preparação da solução ……………………………………………………....59

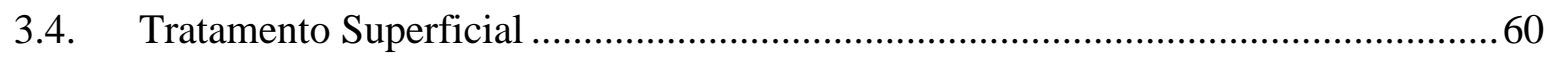

3.5. Técnicas de Caracterização dos Filmes Produzidos .................................................62

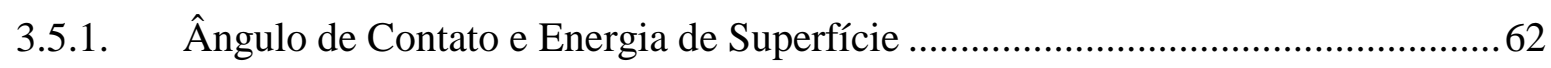

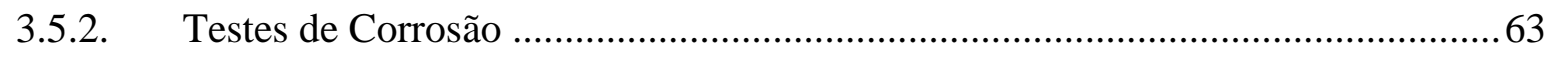

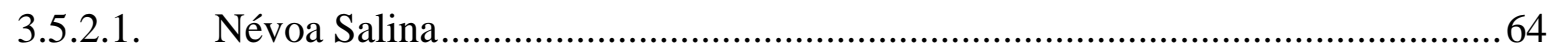


3.5.2.2. Espectroscopia de impedância eletroquímica...............................................67

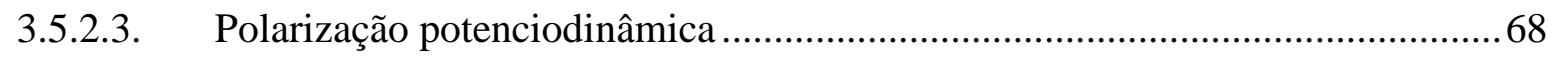

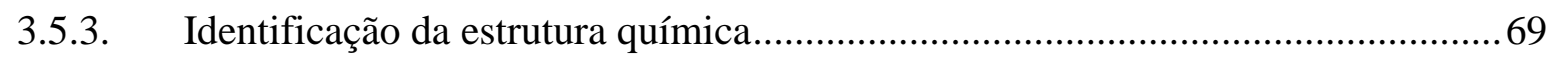

3.5.4. Microscopia Eletrônica de Varredura............................................................. 70

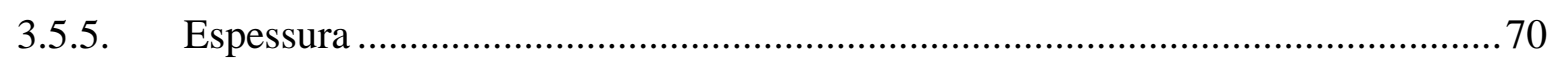

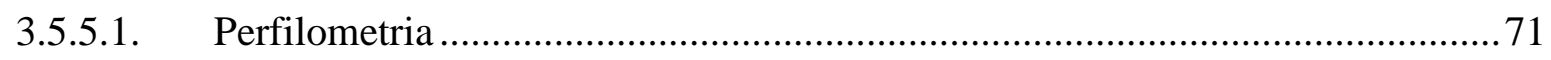

3.5.5.2. Medição por Correntes Parasitas ...................................................................... 72

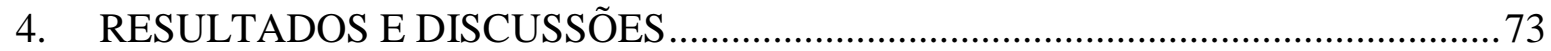

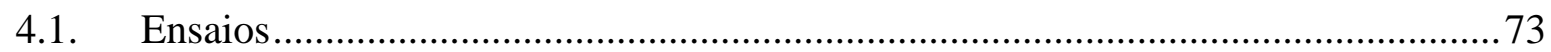

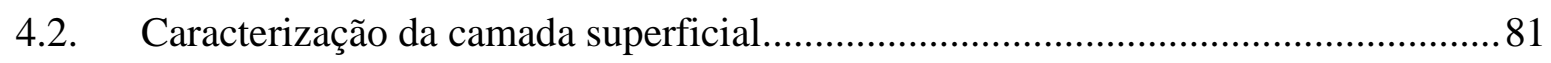

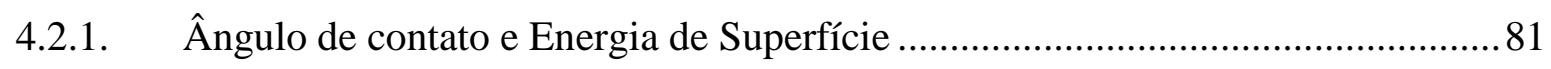

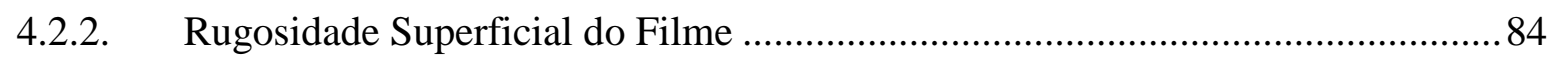

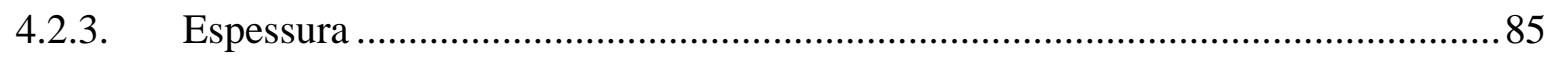

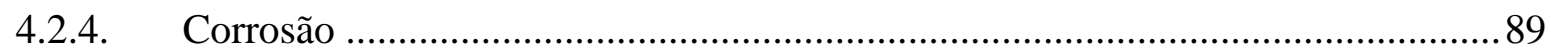

4.2.5. Microscopia Eletrônica de Varredura e Análise de Energia Dispersiva ............. 103

4.2.6. Análise da Estrutura Molecular por Espectroscopia no Infravermelho.............. 111

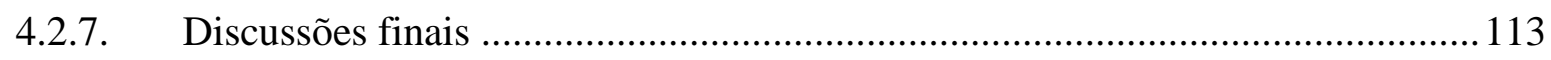

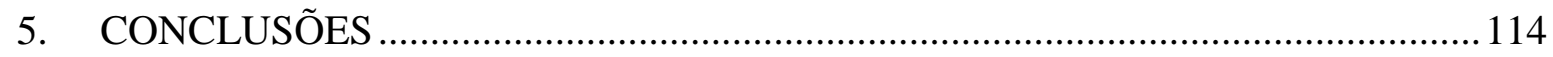

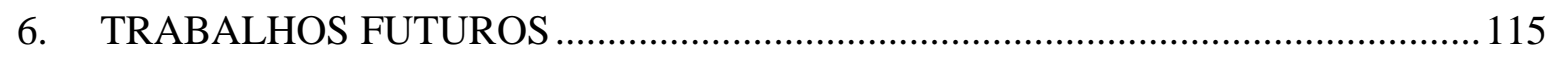

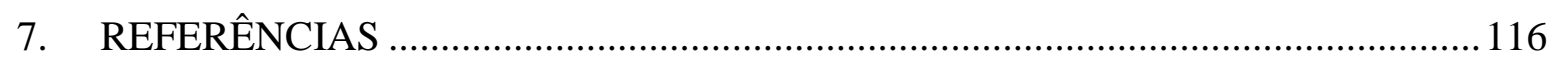




\section{INTRODUÇÃO}

A modificação de superfícies geralmente é realizada nos materiais com o objetivo de conferir a estes características não encontradas em sua forma natural e, desta forma, ampliar suas possibilidades de aplicação. Dos parafusos às complexas naves espaciais, o tratamento de superfícies merece maior destaque a cada dia, não só pelo desempenho que oferece aos produtos e materiais, aumentando sua vida útil e protegendo contra agressões ambientais, como também pela possibilidade de ampliação das opções de uso pela estética que proporciona.

Particularmente em ligas de alumínio, o uso de pré-tratamentos é uma tecnologia essencial em alguns setores industriais. A corrosão em ligas de alumínio ocorre principalmente em função da sua composição. Por exemplo, a presença de cobre em ligas AA-2024-T3, aumenta a propensão à corrosão por pite devido à formação de pares galvânicos na superfície. Assim, estudos sobre revestimentos alternativos que eliminem ou minimizem a formação desses pares galvânicos são de suma importância [1]. Entretanto, embora esses pré-tratamentos sejam necessários para assegurar um bom desempenho do material e aumentar sua vida útil, normalmente causam algum tipo de degradação ambiental devido à utilização de solventes ou cromatos, podendo causar danos à saúde por possuírem agentes cancerígenos [2].

O desenvolvimento tecnológico envolvendo plasmas tem fundamental importância nas indústrias eletrônica, aeroespacial, metalúrgica, biomédica e de tratamento de resíduos e detritos e pode ser uma atraente alternativa de processamento de materiais para a obtenção de filmes finos protetivos em ligas metálicas [3].

Alguns resultados obtidos na indústria moderna só foram possíveis graças à técnicas que utilizam plasmas e que foram desenvolvidas, em sua maior parte, nas 
últimas décadas. Diversas aplicações de plasma têm se tornado cada vez mais importantes por reduzir, em muitos casos, a produção de resíduos e o consumo de energia em vários processos industriais [2,3].

O objetivo deste trabalho é investigar o tratamento de superfícies metálicas, mais precisamente o alumínio, por meio da técnica de eletrólise a plasma. Através da caracterização deste filme será observada a mudança que este conferiu a superfície do substrato metálico e principalmente se houve modificação no processo de oxidação do metal.

Para possibilitar o tratamento destes substratos de alumínio, foi desenvolvido um dispositivo para criação do plasma em meio aquoso. Os parâmetros adotados neste trabalho para desenvolvimento deste equipamento, bem como para a geração do plasma foram baseados em resultados relatados em artigos periódicos que tratam do assunto, uma vez que não foram encontrados livros publicados para consulta.

\section{REVISÃO BIBLIOGRÁFICA}

\subsection{Eletroquímica}

A eletroquímica é o ramo da química que estuda a relação entre a corrente elétrica e as reações químicas. Em outras palavras, é o estudo do uso de reações químicas espontâneas para produzir eletricidade, e o uso da eletricidade para forçar as reações químicas não-espontâneas [5]. Os elementos envolvidos em uma reação eletroquímica são caracterizados pelo número de elétrons que têm. O número de oxidação de um íon é o número de elétrons que este aceitou ou doou quando comparado 
com seu estado neutro (que é definido como tendo número de oxidação igual a zero). Se um átomo ou íon doa elétrons em uma reação química, seu número de oxidação aumenta, se aceita um elétron seu número diminui. A perda de elétrons por uma substância é chamada oxidação e o ganho é chamado de redução [5]. Como princípio geral nas reações de oxi-redução estabelece-se que havendo oxidação, necessariamente haverá redução [5]. Uma reação eletroquímica na qual, através da passagem de corrente elétrica entre eletrodos separados por uma distância finita ocorre oxidação e redução é chamada de reação redox [5].

\subsection{Condução Eletrolítica}

A condução eletrolítica, ou condução iônica, é aquela que ocorre no interior das soluções de ácidos, bases ou sais ou nos sais fundidos. Nessas soluções, é possível o movimento líquido de íons carregados, o que produz uma corrente elétrica. Essa corrente é constituída pelo deslocamento dos íons presentes na solução resultantes da dissociação de moléculas.

Quando se dissolve um sal, um ácido ou uma base em água, os íons que compõem a molécula deste sal, ácido ou base se separam. Essa separação dos íons que compõem esta molécula é chamada de dissociação. Os íons separados ficam então dispersos aleatoriamente na solução, sem se movimentarem em uma direção definida. Quando se aplica um campo elétrico a essa solução, os íons positivos se deslocam no sentido do campo elétrico e espécies carregadas negativamente se deslocam no sentido oposto. A corrente elétrica é então estabelecida pelo movimento das espécies carregadas nos dois sentidos. Nesses meios condutores, ocorre então uma transferência de massa associada a essa passagem de corrente [5]. 


\subsubsection{Eletrólise}

A eletrólise é um processo de condução eletrolítica no qual se força uma reação química a ocorrer em uma direção não-espontânea através do uso da corrente elétrica [5]. É caracterizada principalmente pela ocorrência de reações de oxi-redução em uma solução condutora ao se aplicar uma diferença de potencial entre eletrodos mergulhados nesta solução.

Um sistema eletroquímico é composto por pelo menos dois eletrodos imersos em uma solução eletrolítica, conforme ilustrado na Figura 1.

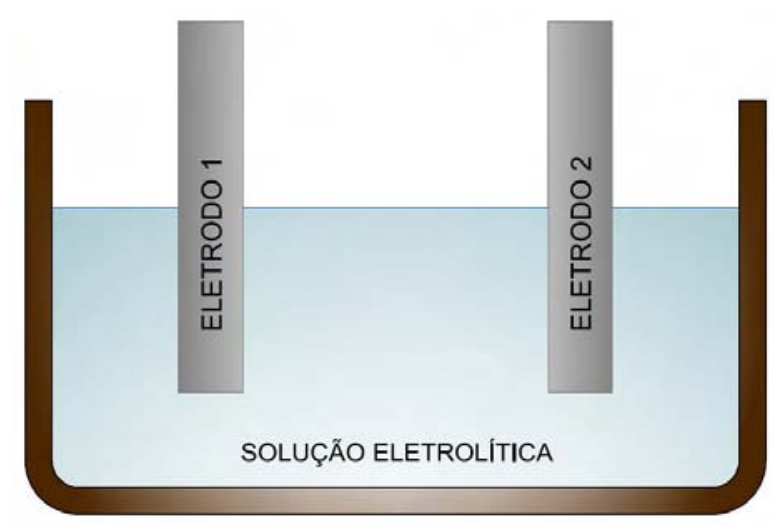

Figura 1 - Configuração esquemática de um sistema eletroquímico

A denominação "solução eletrolítica", designada para qualquer solução aquosa condutora de eletricidade, deriva deste processo.

A água pura tem resistência alta, se comportando como um isolante elétrico. No entanto, os solutos em água podem ser classificados de acordo com a condutividade das soluções que eles formam, sendo divididos em dois tipos: não-eletrólitos e 
eletrólitos [6]. Os não-eletrólitos são aqueles que formam soluções aquosas que não conduzem eletricidade. Tipicamente, estas substâncias são moleculares quando puras e dissolvem-se liberando moléculas. Como as moléculas são neutras, elas não podem migrar sob a ação de um campo elétrico e, portanto, não conduzem eletricidade. Os eletrólitos são solutos sob a forma de íons em solução e, portanto, conduzem eletricidade.

É chamado de célula eletrolítica o dispositivo onde se processa a eletrólise. Nela, além da solução eletrolítica, são colocados os eletrodos onde é aplicada a diferença de potencial responsável pelo processo. A Figura 2 ilustra esquematicamente os componentes de uma célula eletrolítica.

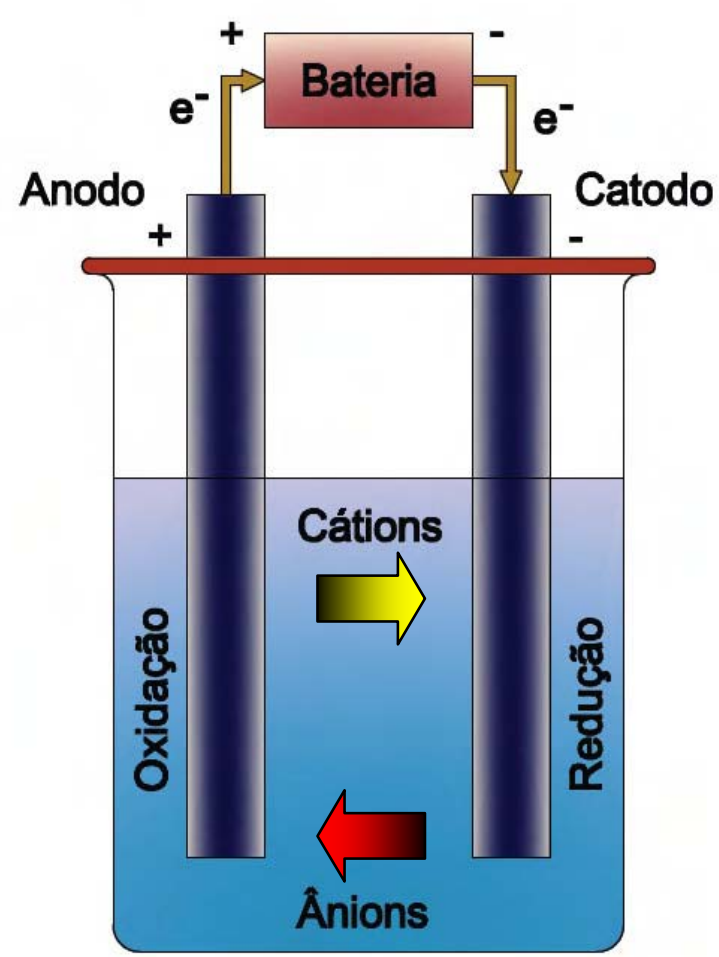

Figura 2 - Diagrama esquemático de uma célula eletrolítica 
Para um melhor entendimento, pode-se dividir a eletrólise em três fases distintas:

Ionização: É a fase antes da aplicação de uma diferença de potencial. Para que ocorra a eletrólise é necessário que o eletrólito esteja na forma de íons, que são obtidos por dissolução ou fusão do material.

Orientação: Nesta fase, uma vez aplicada uma diferença de potencial entre os eletrodos, os íons se dirigem, segundo suas cargas elétricas até os pólos positivos e negativos correspondentes.

Descarga: Os ions negativos cedem elétrons ao anodo (+) e os ions positivos recebem elétrons do catodo (-). O total de elétrons perdidos no anodo sempre será igual ao total de elétrons recebidos no catodo.

Na eletrólise aquosa, a auto-ionização da água não é desprezível e, portanto deve-se considerar as prioridades de descarga. Os íons em solução deverão competir com os íons da água $2 \mathrm{H}^{+}$e $2 \mathrm{OH}^{-}$.

$$
2 \mathrm{H}_{2} \mathrm{O} \rightarrow 2 \mathrm{H}^{+}+2 \mathrm{OH}^{-}
$$

\subsubsection{Solução Aquosa}

Solução aquosa é o nome dado à solução que utiliza a água como solvente. Se esta solução possuir íons livres presentes em seu meio, torna-se capaz de conduzir a corrente elétrica. O cloreto de sódio é um exemplo familiar de um eletrólito. Na forma sólida, $\mathrm{NaCl}$ consiste em $\mathrm{Na}^{+}$e $\mathrm{Cl}^{-}$. Ao serem dissolvidos em água, estes íons ficam livres e a solução dita solução eletrolítica, conduz energia elétrica [6]. O processo de separação em que compostos iônicos têm seus íons separados é chamado de dissociação 
iônica. Estes íons podem voltar a recombinar-se e dar origem ao composto original. O processo de solução do cloreto de sódio, por exemplo, pode ser representado por:

$$
\mathrm{NaCl}_{(s)} \rightarrow \mathrm{Na}_{(a q)}^{+}+\mathrm{Cl}_{(a q)}^{-}
$$

Os índices (s) e (aq) representam os estados físicos sólido e líquido, respectivamente.

Alguns eletrólitos comumente usados para produção de camadas de óxido em ligas de alumínio são descritos por Yerokhin et al. em seu trabalho sobre tratamento superficial via plasma eletrolítico [7]. Alguns destes elementos permitem que a voltagem de ignição da centelha seja mais facilmente alcançada e são mais eficazes na produção de camadas através do plasma eletrolítico de oxidação, PEO. Soluções coloidais de silicato de sódio ou de potássio, por exemplo, são extensamente usadas em processamentos PEO [7]. O tratamento de ligas de alumínio com soluções de silicato dissolvido tem resultado em filmes com densas camadas internas constituídas principalmente de alumina e algumas complexas fases de Al-Si-O presentes [7].

O eletrólito utilizado neste trabalho foi o silicato de sódio dissolvido em água. Além de ser um elemento de baixo custo, também é facilmente encontrado comercialmente. Os silicatos são feitos pela fusão a cerca de $1400{ }^{\circ} \mathrm{C}$ do carbonato de sódio e sílica (areia) em um forno parecido com o da fabricação de vidro. A principal utilização é na fabricação de catalisadores, à base de sílica e de sílica-gel. Entre outros empregos importantes estão a fabricação de sabões e detergentes de pigmentos e de adesivos, a limpeza de metais e o tratamento da água e de papel [8]. O metassilicato de sódio existe na forma hidratada e é vendido como sólido. 


\subsection{Condução Gasosa}

$\mathrm{Na}$ condução em meio gasoso, assim como na condução eletrolítica, a corrente elétrica é constituída pelo movimento de espécies carregadas positivamente em um sentido e de espécies carregadas negativamente no sentido oposto. Essas espécies são provenientes da ionização das moléculas de gás. Essas moléculas, entretanto, não se ionizam sozinhas, como é o caso das soluções eletrolíticas. A corrente elétrica, em geral, se inicia com o movimento de elétrons livres. Esses elétrons, chocando-se com as espécies presentes no gás, promovem a ionização dessas espécies. Essas espécies ionizadas, por sua vez, vão ionizando novas espécies através de colisões. A esse gás ionizado, chamamos plasma [9].

\subsection{Plasma}

A palavra plasma é de origem grega e significa material moldável. $\mathrm{Na}$ medicina é utilizada para apontar perturbação ou estado não distinguível, como por exemplo: o plasma sanguíneo. Plasma, na física, é conhecido como o quarto estado da matéria [9]. Foi utilizado pela primeira vez pelo físico americano, Irving Langmuir, em 1929, quando estudava descargas elétricas em gases. Langmuir notou que os plasmas exibiam um comportamento diferente dos gases não ionizados e era obviamente diferente dos líquidos e dos sólidos.

O termo "plasma" também se refere à descarga elétrica e descarga gasosa e pode ser aplicado a um gás contendo espécies neutras e espécies eletricamente carregadas como elétrons, íons positivos, íons negativos, átomos e moléculas [10]. Na média, o plasma é eletricamente neutro, sendo que qualquer desbalanceamento de carga 
resultará em campos elétricos que tendem a restabelecer o equilíbrio. Como resultado, a densidade de elétrons mais a densidade de íons negativos devem ser iguais à densidade de íons positivos.

De acordo com a definição clássica, plasma é um gás ou vapor consideravelmente ionizado que conduz a eletricidade e é, ao mesmo tempo, eletricamente neutro, fluídico, quente e viscoso [11]. A definição moderna, menos restritiva, denota que plasma é um gás consideravelmente ionizado [11]. Ou seja, um complexo composto de elétrons, íons (positivos e negativos), átomos e/ou moléculas do gás no estado fundamental ou excitado e fótons.

O plasma pode ser criado por uma variedade de meios. De um modo geral quando uma molécula é submetida a uma condição severa, tal como, calor intenso ou uma diferença de potencial elevada o suficiente, a ionização da molécula pode ocorrer.

De forma geral, em laboratório, o plasma é gerado por combustão, chamas, descargas elétricas, reações nucleares controladas e choques. Devido ao fato do plasma perder energia para o meio principalmente pela radiação e pelo choque com as paredes do recipiente que o contém, é necessário para manter continuamente o estado de plasma, um sistema que forneça energia ininterruptamente. Existem vários meios para manter essa energia, o plasma empregado neste trabalho é mantido por uma corrente elétrica.

Os processos a plasma envolvem reações físicas e químicas que ocorrem entre partículas e superfícies sólidas em contato com o plasma. Alguns exemplos são: erosão por plasma, deposição de filmes finos, proteção e endurecimento e implantação iônica [10]. 


\subsubsection{Plasma Eletrolítico}

A eletrólise em solução aquosa é acompanhada por uma série de processos que acontecem nos eletrodos, em particular a liberação de oxigênio e/ou a oxidação do metal que ocorre na superfície do anodo [7].

Embora os fenômenos de descarga elétrica em solução aquosa tenham sido descobertos há muitos anos atrás, a eletrólise a plasma é composta por um grupo de técnicas de processamento a plasma relativamente novas. Esta técnica associa os princípios amplamente difundidos da eletrólise convencional com os fenômenos de plasma à pressão atmosférica [7].

Devido à rapidez de tratamento e ao fato destes equipamentos serem construtivamente bem semelhantes aos de banhos eletrolíticos clássicos, estes processos são potencialmente úteis para a produção em série de componentes complexos, pois o plasma criado na interface metal-solução eletrolítica envolve todas as superfícies expostas do substrato [7]. A Figura 3 ilustra o envelope de plasma criado ao redor do anodo.

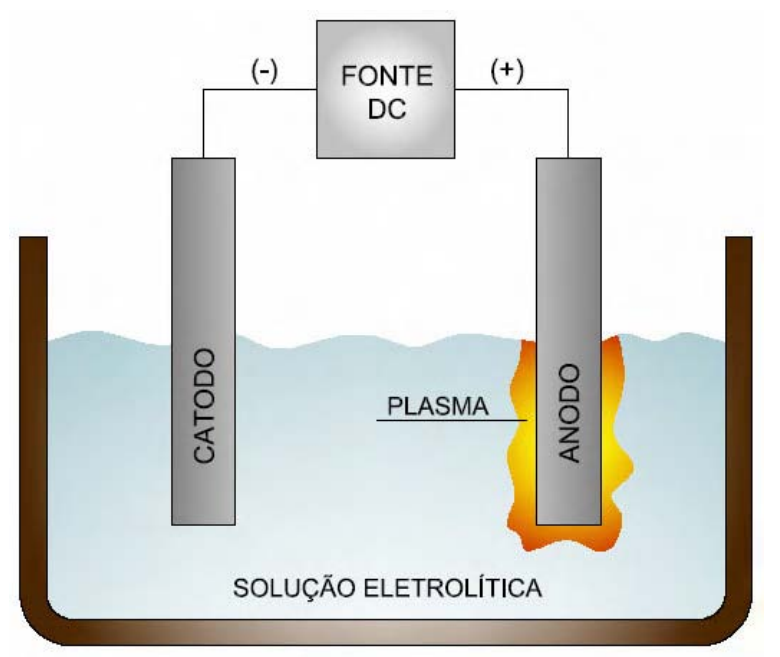

Figura 3 - Envelope de plasma em meio aquoso 


\subsubsection{O Processamento via Plasma Eletrolítico}

A técnica de processamento de materiais metálicos via plasma eletrolítico (EPP, do inglês, "Electrolytic Plasma Processing") é uma técnica na qual o plasma é criado dentro de uma solução eletrolítica à pressão atmosférica. O primeiro trabalho significante neste campo foi desenvolvido por Kellogg [12]. Depois, Hickling e Ingram conduziram também vários estudos em plasma de descarga luminescente, "Glow Discharge Plasma" (GDP) [12].

Em virtude da presença de espécies reativas e energéticas, os plasmas podem ser utilizados para modificar a superfície de sólidos [13]. O grau de alteração induzido na superfície é dependente das características do plasma que incluem fatores como a concentração de elétrons, íons, espécies em estados neutros e suas energias [14]. Variando-se tais parâmetros, chamados de parâmetros intrínsecos do plasma, obtêm-se diferentes interações plasma-superfície e, por conseguinte, diferentes graus de modificação [14].

As características microscópicas são dependentes de fatores experimentais macroscópicos, chamados de parâmetros de excitação. Estes englobam a composição química e concentração da solução eletrolítica, a diferença de potencial aplicada aos eletrodos, a distância entre os eletrodos, entre outros. Com isto, as características do plasma eletrolítico podem ser ajustadas para a obtenção dos resultados desejados em um determinado processamento. O grande número de parâmetros que podem ser ajustados em um processamento a plasma eletrolítico gera um amplo leque de modificações que são possíveis de serem implementadas, de acordo com os objetivos de cada tratamento. 
Vários estudos têm sido conduzidos mundialmente em EPP, buscando variações da ciência básica para aplicações práticas [12]. Todos os estudos independentes revelam uma observação comum, que para certo valor de diferença de potencial entre dois elétrodos em uma solução eletrolítica aquosa, há divergência significante do regime da eletrólise normal de Faraday [6]. A aplicação de potencial elétrico é significativamente maior quando comparada à eletrólise convencional e conduz a um fenômeno anormal de evolução do excesso de gás produzido nos eletrodos, conduzindo à formação de um "envelope" de gás contínuo ao redor do cátodo ou do ânodo acompanhado por uma descarga luminosa. Os principais fatores que influenciam a formação deste "envelope" ou invólucro de plasma contínuo incluem o potencial aplicado, a temperatura do eletrólito, a geometria do eletrodo, a natureza e propriedades da solução eletrolítica e a dinâmica de fluxo [12].

Entre as diversas técnicas de eletrólise a plasma estão as do grupo de deposição ou plasma eletrolítico para deposição, PED [7]. Estas técnicas de deposição podem ser desenvolvidas tanto em configuração anódica como catódica em pressão atmosférica [7,12]. As técnicas PED são compostas pelos métodos PEO, Plasma Eletrolítico de Oxidação e PES, Plasma Eletrolítico de Saturação, este último incluindo plasmas para carbonetação e nitretação, entre outros [7]. Nas técnicas PED, as camadas superficiais são formadas como resultado da modificação do processo eletrolítico básico, eletrólise clássica, através de reações químicas realçadas pela presença do plasma e por processos de difusão na superfície do eletrodo. O princípio básico do sistema de deposição via plasma eletrolítico é a aplicação de uma diferença de potencial entre dois eletrodos imersos em uma solução eletrolítica aquosa. Inicia-se então a formação de subprodutos gasosos da eletrólise, que envolvem a amostra. A partir de um determinado valor de tensão estes gases começam a ser ionizados, surgindo uma luminescência característica 
em toda a superfície da amostra imersa na solução. O filme é então depositado sobre o eletrodo mediante a constituição do plasma produzido na solução aquosa. Utilizando o plasma em configuração anódica, com o substrato disposto no anodo, o processo é tecnicamente chamado Plasma Eletrolítico de Oxidação (PEO) [7]. A Figura 4 ilustra a relação entre os principais processos físico-químicos que acontecem na eletrólise a plasma e os processos básicos de eletrodo que ocorrem na eletrólise clássica.

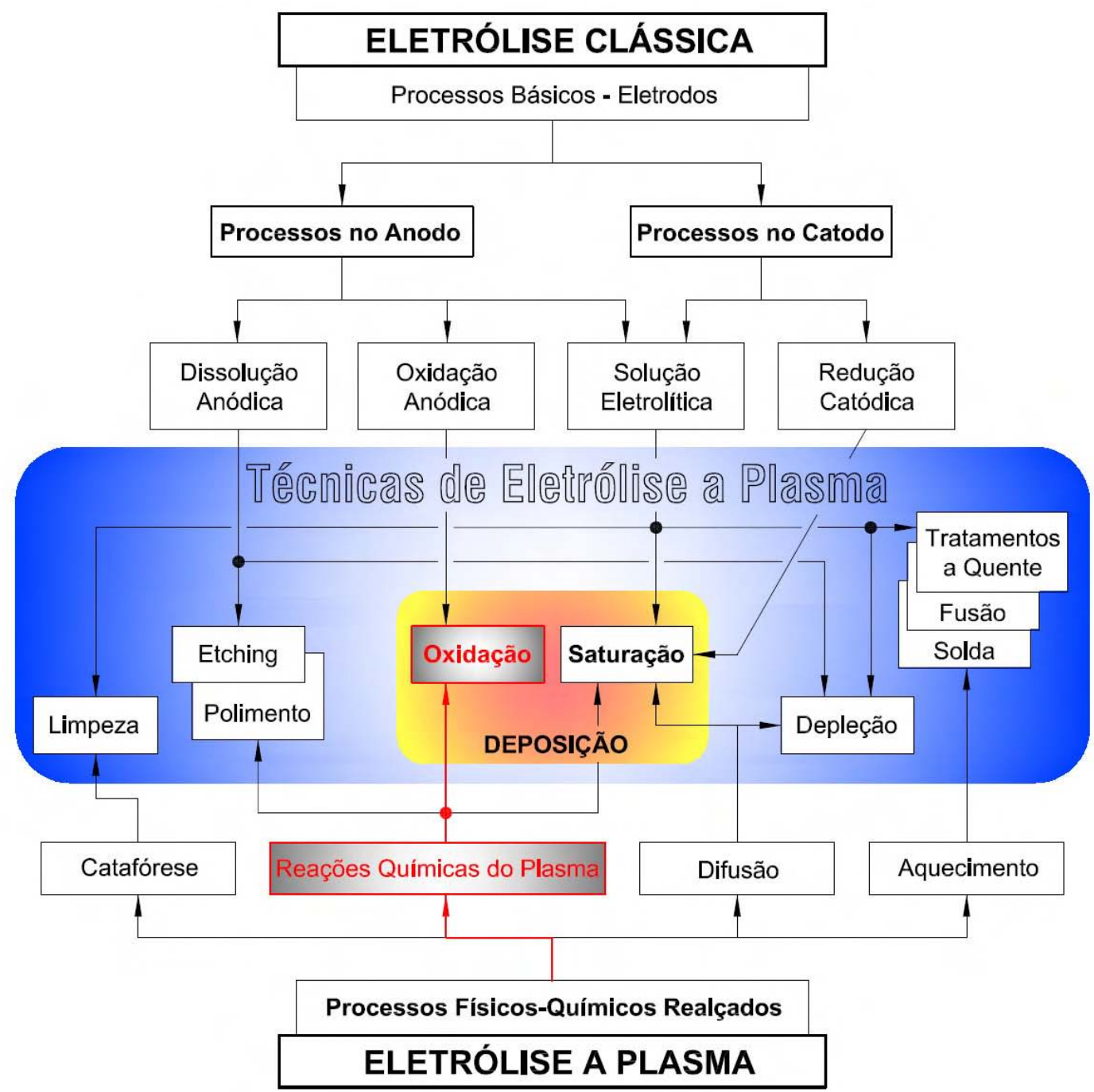

Figura 4 - Relação entre os principais processos físico-químicos que acontecem na eletrólise a plasma e os processos básicos de eletrodo que ocorrem na eletrólise clássica. Adaptado de [7] 
A oxidação eletrolítica a plasma, ou plasma de eletrolítico de oxidação, PEO, é uma técnica de criação de plasma em meio aquoso que utiliza os princípios já conhecidos de tratamento eletroquímico e pode ser utilizada para converter a superfície de metais em uma camada de óxido cerâmico $[15,16]$. Através deste sistema é possível a produção de filmes aderentes de óxido tal como alumina, sílica ou titânia [7,15].

Várias terminologias têm sido utilizadas para se referir àquilo que, essencialmente é a mesma técnica. Alguns exemplos são:

- Oxidação de micro-plasma;

- Eletrólise de centelha anódica;

- Plasma eletrolítico de tratamento anódico;

- Oxidação anódica sob descarga de centelha.

Estes são alguns exemplos típicos de terminologias utilizadas para descrever o que tecnicamente aqui chamamos de plasma eletrolítico de oxidação.

No processamento a plasma eletrolítico, o campo elétrico é maior na região do eletrodo e induz um forte aquecimento em sua vizinhança. Este aquecimento ativa a formação de uma bainha de vapor ao redor do eletrodo. Como a condutividade elétrica desta bainha é muito menor que a condutividade elétrica da solução líquida, uma queda de tensão acontece primariamente dentro desta bainha de vapor, induzindo um forte campo elétrico dentro das bolhas separadas [17]. Se a diferença de potencial aplicada for suficientemente alta, o campo elétrico, dentro das bolhas causará a ignição de uma descarga luminescente dentro da bolha. Aumentando a diferença de potencial, o plasma estende-se ao longo da superfície do substrato, passando a cobri-la por inteiro. A intensidade de tensão aplicada, bem como as características físicas do plasma, dependerão da composição química e da resistência elétrica da solução [17]. Estas 
descargas luminescentes induzem a dissociação do eletrólito vaporizado e a formação de uma camada contínua no substrato [17].

Estudos realizados por Yerokhin e outros pesquisadores em tecnologia de plasma eletrolítico observam que, a baixas tensões, a corrente aumenta linearmente com o aumento da tensão, seguindo os princípios da lei de Faraday observados em processos eletrolíticos convencionais e as características de corrente e tensão da célula variam de acordo com a lei de Ohm, sendo este regime acompanhado pela presença de gás. [7,12]. Esta região é compreendida entre os pontos "0-U1" e "0-U4" representados nas Figuras 5 e 7, respectivamente. Diferenças de potencial superiores a $90 \mathrm{~V}$ ganharam a atenção de cientistas que estudam os processos de plasma eletrolítico. Esta região é caracterizada pela de presença de um gás luminoso não estável e por uma quantidade significante de oscilação de corrente. Na Figura 5, esta região é compreendida entre os pontos “U1-U2”. A elevação de corrente é limitada por uma ação de proteção parcial dos produtos de reação dos gases $\left(\mathrm{O}_{2}\right.$ ou $\left.\mathrm{H}_{2}\right)$ sobre a superfície do eletrodo. Em áreas onde o elétrodo permanece em contato com o líquido, porém, a densidade de corrente continua subindo, causando uma vaporização da solução eletrolítica nas adjacências do elétrodo. A formação do gás luminoso tem sido atribuída à vaporização da solução eletrolítica ao redor do eletrodo devido ao aquecimento [12].

Acima do ponto "U2" ilustrado na Figura 5, o eletrodo é envolvido por um contínuo envelope de vapor com plasma de baixa condutividade elétrica. Quase toda a tensão fornecida à célula se concentra agora dentro desta fina região próxima ao eletrodo. Esta região é aquecida através de avalanches de elétrons com temperaturas de até $10^{4} \mathrm{~K}$ [18]. O forte campo elétrico dentro desta região chega a alcançar valores entre $10^{6}$ e $10^{8} \mathrm{~V} / \mathrm{m}$ que são suficientes para iniciação de processos de ionização no invólucro de vapor $[7,18]$. 
O plasma gerado dentro deste envelope gasoso produz uma série de espécies ativas que bombardeiam a superfície do substrato e asseguram o fluxo difusional dentro desta crescente camada superficial [19]. Este processo de ionização pode ser inicialmente observado através de rápidas centelhas que se espalham nas bolhas de gás e então se transformam em um brilho uniforme distribuído ao longo do envelope de vapor.

Com a estabilização hidrodinâmica do envelope de vapor, na região U2-U3 da Figura 5, a corrente diminui. Acima do ponto U3, a descarga luminescente se transforma em um intenso arco acompanhado por uma emissão acústica característica de baixa freqüência [7].

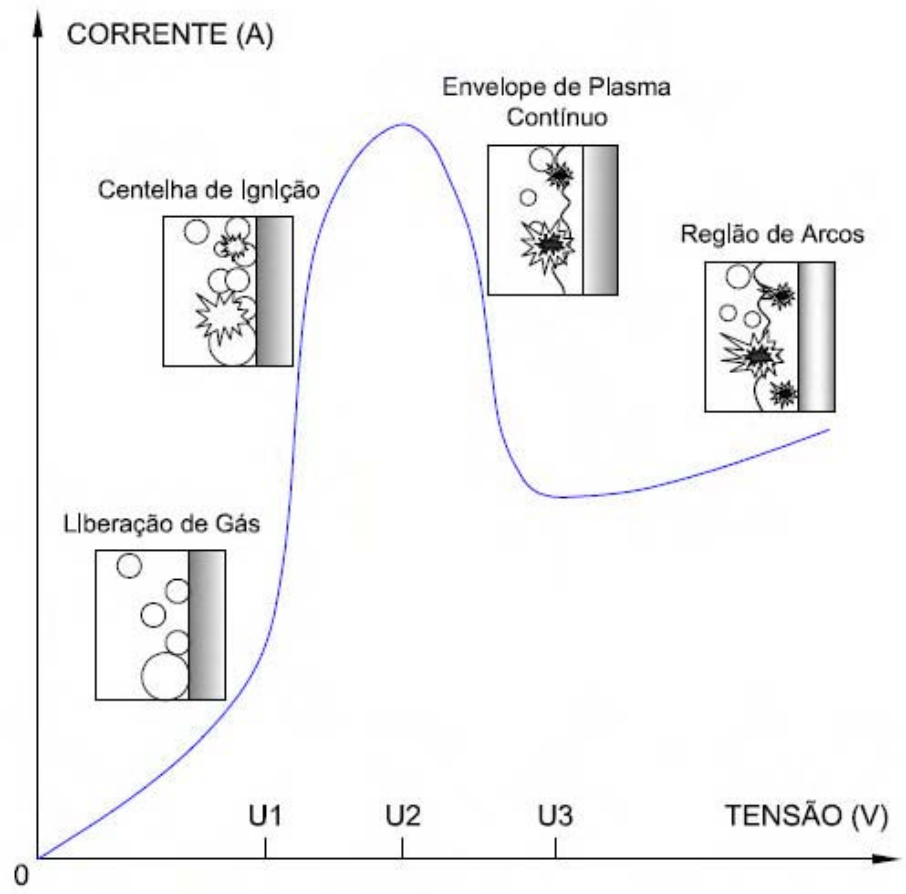

Figura 5 - Diagrama “Tensão x Corrente” para processos a plasma eletrolítico - Desenvolvimento dos fenômenos de descarga nas proximidades do eletrodo. Adaptado de [7, 48]. 
De uma forma geral, os processos a plasma são limpos, e de fácil execução. A versatilidade de um sistema a plasma, permite que outros tipos de experimentos sejam realizados no mesmo sistema. Simples alterações nas condições de processamento permitem induzir diferentes tipos de tratamentos superficiais, como por exemplo, a incorporação de espécies químicas nestas superfícies [3].

A Figura 6 ilustra um modelo de formação de micro descargas em um eletrodo de alumínio, onde o envelope de vapor é gerado pelas bolhas de gás que acompanham o processo de oxidação. A descarga aparece como se desintegrando em uma série de micro arcos ao longo de todo o envelope de gás [20].

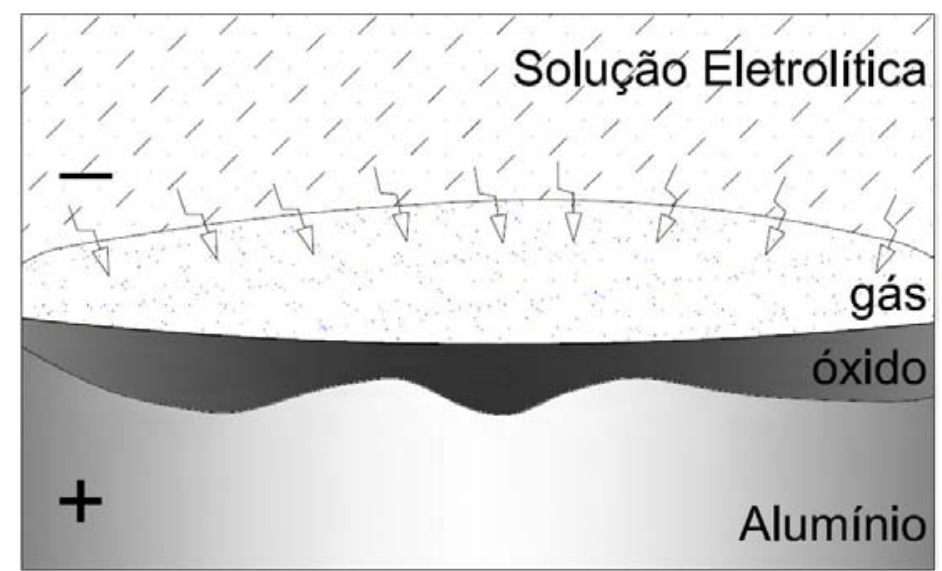

Figura 6 - Ilustração esquemática de micro descargas na presença de um filme de óxido na superfície do alumínio. Adaptado de [20].

De acordo com Yerokhin et. al. [20], a condição normalmente comum para a iniciação de descarga é a emissão de elétrons da superfície da solução eletrolítica, que age como uma espécie de catodo parcial, para dentro da fase gasosa, em vez da desagregação do crescimento do filme de óxido. Os elétrons livres aparecem inicialmente na interface entre o filme de óxido e a solução eletrolítica sob forte campo 
elétrico, independente da presença de qualquer fase de gás/vapor, devido à ionização dos ânions e das moléculas da água [20]. Estes participam então de uma série de reações com água, resultando na formação de produtos gasosos $\left(\mathrm{H}_{2}\right.$ e $\left.\mathrm{O}_{2}\right)$, provendo as condições necessárias para a manutenção de um ambiente de descarga de plasma estável [20].

\subsubsection{Monitoramento de processo em PEO}

A densidade de corrente é o principal parâmetro a ser monitorado na rotina de processamento em PEO [21]. Normalmente, para se alcançar as condições exigidas para a eletrólise a plasma, a densidade de corrente deve estar dentro de uma faixa que varia de 0,01 a $0,3 \mathrm{~A} / \mathrm{cm}^{2}$ [7]. A taxa de crescimento da camada de revestimento normalmente é definida de acordo com a $1^{\mathrm{a}}$ lei de Faraday para a eletrólise que afirma que "a massa de qualquer elemento depositado em um dos eletrodos por efeito da eletrólise é diretamente proporcional à carga elétrica que passa pela solução”, considerando-se que a carga elétrica é o produto da intensidade da corrente pelo tempo [22, 23]. Enquanto o revestimento cresce, a princípio a tensão aumenta rapidamente, em seguida, uma vez que as condições de estado de equilíbrio de plasma foram estabelecidas, a tensão passa a aumentar lentamente.

Inicialmente, a fina camada de óxido que se forma naturalmente sobre a superfície do alumínio começa a dissolver, ponto "U4" da Figura 7. Na prática, este ponto corresponde ao potencial de corrosão do material [7]. Na região compreendida entre os pontos "U4 -U5" da Figura 7, um filme de óxido começa a crescer.

A taxa crítica de tensão, que corresponde à mudança do estabelecimento da centelha de descarga de plasma na superfície do eletrodo é observada no ponto "U5" e 
tem uma forte dependência com as características da combinação metal-solução. Neste ponto são observadas pequenas centelhas luminescentes se movendo rapidamente por toda a superfície do filme de óxido, facilitando seu contínuo crescimento [7]. A diferença de potencial é dependente da combinação metal-solução, entretanto, normalmente está compreendida entre 120 a $350 \mathrm{~V}$ [7], valores bem superiores aos de tensão normalmente requeridos para os principais processos clássicos de anodização, que utilizam grandezas normalmente variando entre 24 a $100 \mathrm{~V}$, com densidades de corrente entre 0,1 e $3,6 \mathrm{~A} / \mathrm{dm}^{2}[1]$.

As centelhas que são observadas nesta fase do processo, são como luzes brancas uniformes e que envolvem todo o eletrodo. Sequencialmente, estas luzes mudam sua cor para uma série de centelhas amarelas separadas e que se movem rapidamente por toda a superfície do eletrodo, ponto "U6". Neste ponto, o mecanismo de ionização por impacto é apoiado pelo início do processo de ionização térmica. Surgem então descargas de arco maiores, porém mais lentas [7]. A cor da luz emitida, entretanto, depende na natureza dos íons presentes na solução. As cores são vistas principalmente devido à descarga na superfície do substrato, onde diferentes elementos produzem diferentes comprimentos de onda de luz [12].

$\mathrm{Na}$ região entre os pontos "U6 -U7" a densidade da centelha reduz gradativamente e a ionização térmica vai sendo parcialmente bloqueada pelo acúmulo de carga negativa que engrossa a maior parte do filme de óxido e ocasiona a diminuição da descarga no substrato. Este efeito determina a relativa baixa potência e duração das descargas de arco resultantes, e das micro-descargas que são chamadas de micro arcos [7].

Devido à ação destas micro-descargas, o filme é gradualmente fundido e incorporado no substrato, juntamente com os elementos contidos na solução eletrolítica. 
Um pequeno arco vermelho como uma mancha se movendo lentamente por toda a superfície pode ser visto, no ponto "U7" da Figura 7. Acima deste ponto, as microdescargas de arco que acontecem ao longo do filme penetram através do substrato e se transformam em arcos intensos. Estes intensos arcos conduzem a oscilações de corrente e podem causar danos ao revestimento como, por exemplo, trincas [7].

$\mathrm{Na}$ prática, vários processos podem acontecer concorrentemente nas áreas adjacentes da superfície do eletrodo. O modelo simplificado de duas fases normalmente encontrado na eletrólise convencional deve ser substituído então por um sistema mais complexo de quatro fases (metal, filme isolante, gás e solução eletrolítica) com vários limites de fase possíveis.

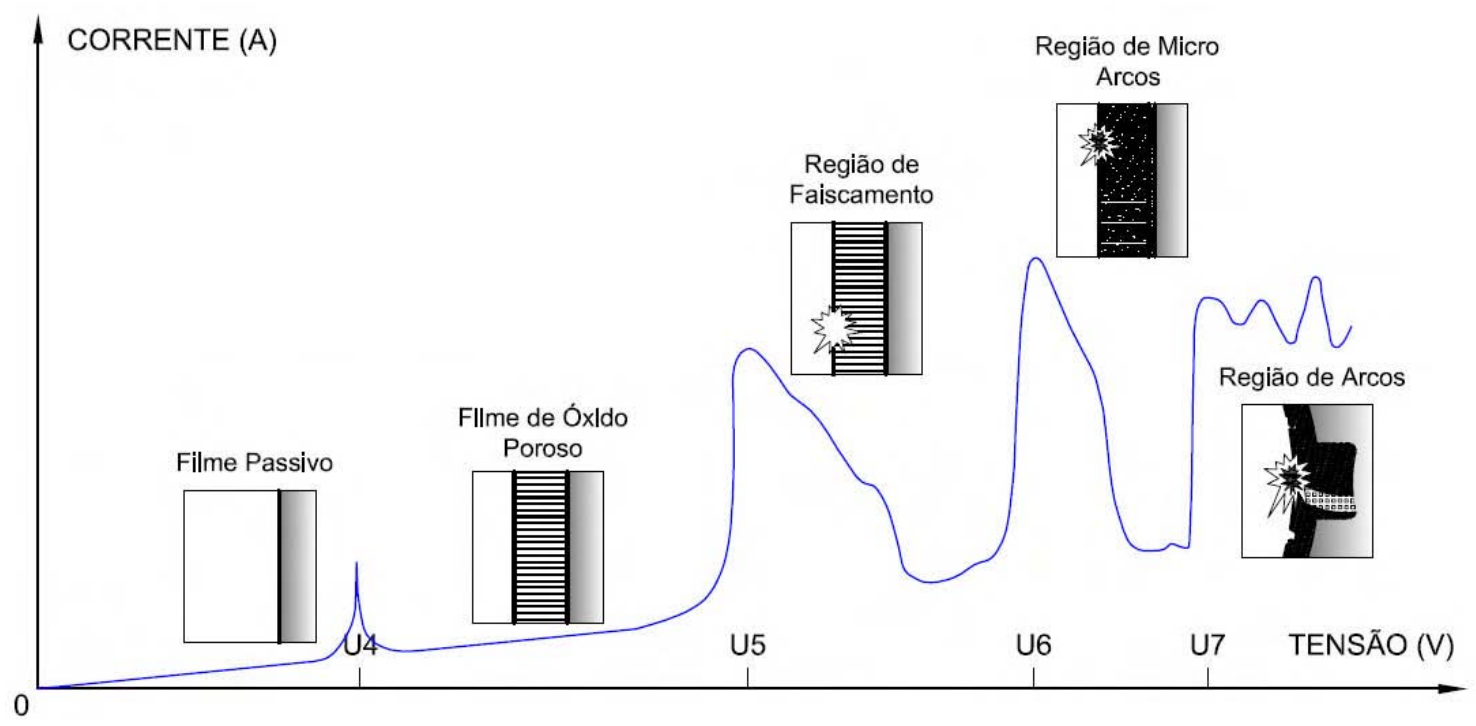

Figura 7 - Diagrama “Tensão x Corrente" para processos a plasma eletrolítico - Desenvolvimento dos fenômenos de descarga no filme dielétrico formado na superfície do eletrodo. Adaptado de [7].

Particularmente, quando um sistema eletroquímico acontece sobre as voltagens críticas "U1", Figura 5 e "U5", Figura 7, são formadas duas fases de baixa 
condutividade (dielétrico e gás), onde a principal queda de tensão está concentrada. Como a resistência destas fases varia continuamente, é muito difícil discernir em que fase os fenômenos de ionização iniciam [7]. Portanto, a divisão de sistemas eletroquímicos nos dois tipos não é distinta.

\subsection{Ligas de alumínio}

O alumínio é tanto estrategicamente como estruturalmente um importante material utilizado na indústria moderna. É o metal mais abundante da crosta terrestre [24]. É extremamente versátil devido a suas propriedades como baixa densidade, boa resistência mecânica, boa propriedade de resistência à corrosão e à oxidação, boa condutividade térmica e elétrica, boa conformabilidade e, em algumas ligas, boa capacidade de endurecimento por processos térmicos e/ou mecânicos. Adicionalmente, ao contrário das ligas ferrosas comuns, as ligas de alumínio são caracterizadas pela capacidade de manter as propriedades de resistência mecânica, tenacidade à fratura e fadiga, mesmo em baixas temperaturas, o que, aliado às propriedades descritas acima, torna o metal o mais usado pela indústria aeroespacial [24].

As ligas de alumínio encontram aplicações nos mais diversos setores da indústria, tais como automobilístico, naval, aeroespacial, eletrotécnico, construção civil, metal-mecânico, de embalagens, entre outros. A Tabela 1 resume algumas das diversas aplicações em função das diferentes composições de cada grupo de ligas. 
Tabela 1 - Sistema de Classificação do Alumínio segundo a “Aluminum Association” e suas principais Aplicações. Adaptado de [24, 25].

\begin{tabular}{|c|c|c|c|}
\hline LIGAS & CLASSE & $\begin{array}{c}\text { PRINCIPAIS } \\
\text { ELEMENTOS DE } \\
\text { LIGA }\end{array}$ & APLICAÇÃO \\
\hline \multirow{8}{*}{ 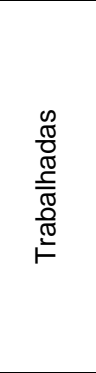 } & $1 \mathrm{xxx}$ & Puro $(>99 \% \mathrm{Al})$ & Tubulações, chapas finas, componentes elétricos \\
\hline & $2 x x x$ & Al-Cu e Al-Li & Elementos estruturais, estruturas de aviões \\
\hline & $3 x x x$ & Al-Mn & Chapas finas, estruturais, latas para bebidas \\
\hline & $4 x x x$ & Al-Si e Al-Mg-Si & Metal de preenchimento para solda \\
\hline & $5 x x x$ & Al-Mg & Carrocerias de automóveis, componentes de navios, tampas para latas de bebidas \\
\hline & $6 x x x$ & $\mathrm{Al}-\mathrm{Mg}-\mathrm{Si}$ & Tubos e conexões, estruturas de automóveis, vagões ferroviários e embarcações \\
\hline & $7 x x x$ & Al-Mg-Zn & Estruturas aeroespaciais \\
\hline & $8 x x x$ & Al-Li, Sn, Zr ou B & Estruturas aeroespaciais \\
\hline \multirow{7}{*}{$\begin{array}{l}\frac{\pi}{2} \\
\frac{\pi}{0} \\
\frac{0}{0} \\
5 \\
5\end{array}$} & $1 \mathrm{xx}$ & Al Puro comercial & - \\
\hline & $2 x x$ & $\mathrm{Al}-\mathrm{Cu}$ & Tubos e válvulas de distribuição. Base de ferro elétrico, carcaças de transmissão \\
\hline & $3 x x$ & Al-Si-Cu e Al-Si-Mg & Carcaças de motores, acessórios p/ aeronaves \\
\hline & $4 x x$ & Al-Si & Equipamento para manuseio de alimentos, \\
\hline & $5 x x$ & Al-Mg & Peças p/ decoração, conexões, componentes p/ \\
\hline & $7 x x$ & Al-Mg-Zn & Uso geral, onde se exige boa usinabilidade, \\
\hline & $8 x x$ & Al-Sn & Mancais \\
\hline
\end{tabular}

As ligas de alumínio dividem-se em dois grupos principais: as fundidas e as trabalháveis mecanicamente por processos como laminação, trefilação, extrusão e forjamento. As ligas de alumínio ainda podem ser divididas entre as tratáveis termicamente e as não-tratáveis termicamente [24].

A resistência mecânica do alumínio puro é muito baixa e, por isto os elementos de liga são adicionados ao metal para lhe conferir melhores propriedades mecânicas através de formação de solução sólida ou de precipitados de segunda fase. Dentre estes elementos, destacam-se o cobre, magnésio, manganês, zinco, lítio e silício. Nas ligas fundidas, alguns elementos de liga são adicionados principalmente para melhorar a reologia do processo de fundição [24].

No sistema de classificação proposto pela Aluminum Association (AA) e também adotado pela norma brasileira ABNT NBR 6835, as ligas de alumínio são 
identificadas por um número de quatro dígitos, conforme mostra a Tabela 1 . O primeiro dígito identifica os principais elementos de liga. O segundo dígito indica modificações da liga original ou dos limites de impurezas e os dois últimos dígitos identificam a composição química da liga e/ou grau de pureza do alumínio. As ligas fundidas possuem uma vírgula entre os dois últimos dígitos e se o último for zero, muitas vezes, na prática, ele não é usado na identificação [25].

Após os quatro dígitos que identificam a liga de alumínio existe uma letra separada por um hífen que identifica se a liga está no estado como fabricado (F), recozido $(\mathrm{O})$, trabalhado a frio $(\mathrm{H})$, solubilizado $(\mathrm{W})$ ou endurecido por envelhecimento (T). À frente das letras, pode-se encontrar até quatro dígitos que identificam o tipo de tratamento térmico e/ou mecânico ao qual a liga foi submetida.

\subsubsection{Corrosão em Ligas de Alumínio}

O alumínio é um metal quimicamente muito ativo, entretanto, desenvolve rapidamente um filme natural isolante de alumina $\left(\mathrm{Al}_{2} \mathrm{O}_{3}\right)$ em sua superfície quando exposto ao oxigênio. Este filme, por sua vez, é capaz de proteger o metal contra corrosão em ambientes neutros porque esta camada de óxido não permite que os elétrons produzidos por reações de oxidação atinjam a interface entre o óxido e o meio, evitando que reações catódicas ocorram.

Quando se adiciona os elementos de liga, como $\mathrm{Cu}, \mathrm{Mg}, \mathrm{Mn}, \mathrm{Zn}$ e Si ao metal, estes formam compostos intermetálicos, resultando em efeitos deletérios às propriedades de corrosão do material, devido à formação de um filme de óxido mais fino e mais condutor que acaba permitindo que reações catódicas ocorram. A Figura 8 ilustra de forma esquemática como ocorrem estas reações. 


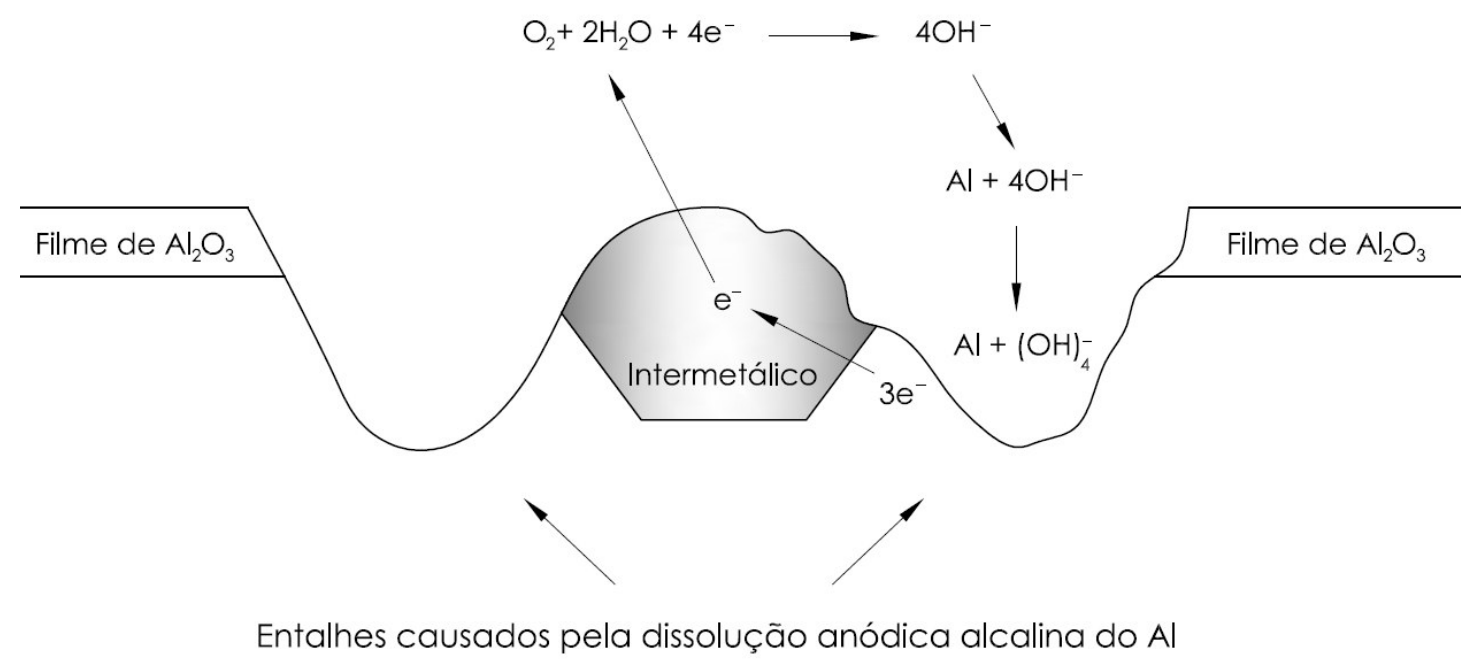

Figura 8 - Processo de corrosão por ponto (pitting) em ligas de alumínio.

$\mathrm{Na}$ interface das partículas intermetálicas, ocorrem reações catódicas que ocasionam o aumento do $\mathrm{pH}$ da solução ao redor. Os ânions hidroxila $\left(\mathrm{OH}^{-}\right)$que se formam dissolvem o filme de óxido, expondo o metal e permitindo que o processo de oxidação prossiga. Em meios aquosos contendo cloretos, esta descontinuidade do filme de óxido faz com que a superfície exposta fique ainda mais vulnerável à corrosão [16].

As ligas da série 2xxx, mais particularmente as de alumínio-cobre, além de permitirem tratamentos térmicos, apresentam como atraente característica a combinação de elevada resistência mecânica com baixa densidade. Na liga 2024, amplamente utilizada pela indústria aeroespacial $[24,26]$ e empregada neste trabalho, a adição de cobre e magnésio para melhora das propriedades mecânicas, conduz à formação de precipitados que embora confiram propriedades mecânicas desejáveis à liga também propiciam os mecanismos de corrosão através de processos galvânicos [16]. A presença de ferro como uma impureza na liga leva à formação de inclusões $\mathrm{Al}-\mathrm{Cu}-\mathrm{Fe}-\mathrm{Mn}$ e $\mathrm{Al}-$ 
$\mathrm{Cu}-\mathrm{Fe}-\mathrm{Si}-\mathrm{Mn}$, durante o durante o processo de solidificação [26] . Algumas características da liga de alumínio 2024 são apresentadas na Tabela 2:

Tabela 2 - Composição química, densidade e propriedades térmicas da liga 2024. Adaptado de [28].

\begin{tabular}{cl}
\hline \multicolumn{2}{c}{ LIGA DE ALUMíNIO 2024 } \\
\hline \multirow{2}{*}{$\begin{array}{c}\text { Composição } \\
\text { Química }\end{array}$} & $\begin{array}{l}\text { M3,5\% Al; 4,5\% Cu; } 1,5 \% \mathrm{Mg} ; 0,6 \% \\
\text { de liga na ordem de 0,05\%, como } \\
\text { vanádio, silício, ferro, titânio e zinco. }\end{array}$ \\
\hline Densidade & $2,77 \mathrm{~g} / \mathrm{cm}^{3}$ a $20{ }^{\circ} \mathrm{C}$ \\
\hline Propriedades & Temperatura de fusão: $502{ }^{\circ} \mathrm{C}$ \\
\cline { 2 - 2 } Térmicas & Temperatura de evaporação: $638^{\circ} \mathrm{C}$ \\
\cline { 2 - 2 } & Calor específico: $875 \mathrm{~J} / \mathrm{kg} . \mathrm{K} \mathrm{a} 20^{\circ} \mathrm{C}$ \\
\hline
\end{tabular}

\subsection{Técnicas de Caracterização}

As alterações superficiais provocadas nas placas de alumínio empregadas após a exposição dos substratos ao plasma de eletrólise foram avaliadas através das seguintes técnicas:

\subsection{1. Ângulo de Contato e Energia de Superfície}

Uma gota de um determinado líquido apresenta formatos diferentes para cada superfície na qual estiver em contato, pois o modo como o volume deste líquido se acomoda depende das interações entre a água e a superfície do material em que foi depositada [27]. Esta interação pode ser estudada através da medida do ângulo de molhabilidade, ou ângulo de contato, $\theta$, que a gota forma com a superfície sólida. Este ângulo é definido como sendo o ângulo formado na interseção entre um plano tangente à gota e a superfície onde o líquido se encontra depositado, conforme ilustra a Figura 9. 


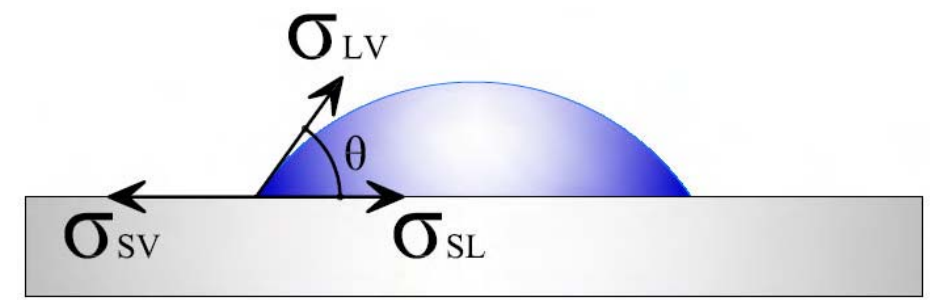

Figura 9 - Ângulo de contato e tensões superficiais.

É, portanto, possível medir o ângulo com que uma gota fica na superfície e com isto verificar a interação desta com o líquido. $\mathrm{O}$ valor igual a $0^{\circ}$ é um caso extremo de máxima afinidade química entre a superfície e o líquido e, portanto, haverá espalhamento completo do líquido no sólido. Neste caso, a superfície molha completamente, como ilustrado na Figura 10, e é chamada super-hidrofílica. Se esse ângulo, contudo, for superior a 165 graus ou for igual a 180 graus, conforme ilustra a Figura 10, o líquido não apresenta qualquer interação com a superfície e esta é chamada de super-hidrofóbica [27].

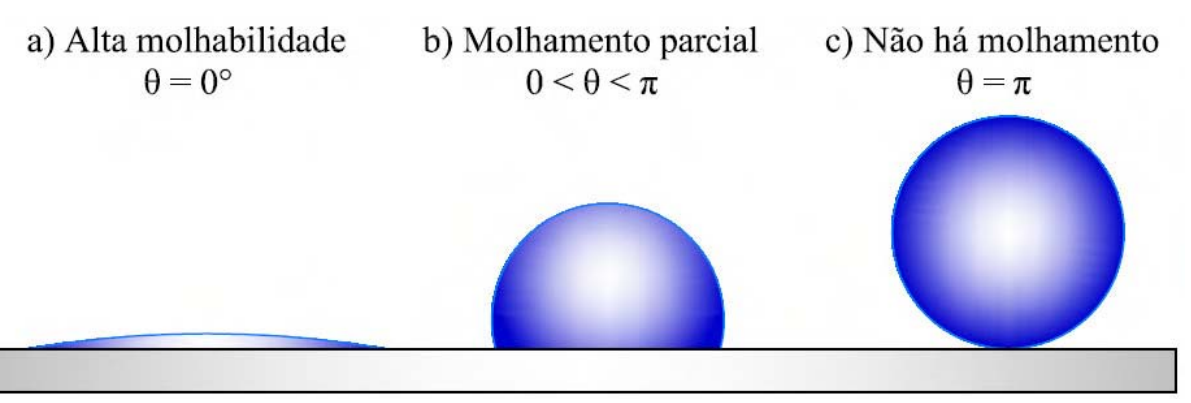

Figura 10 - Interação gota-superfície. 
Quando o ângulo de contato é menor que $90^{\circ}$, a superfície é chamada de hidrofílica; se o ângulo de contato é maior que 90 graus, a superfície é chamada de hidrofóbica [27].

Considerando uma gota líquida em equilíbrio depositada sobre uma superfície sólida horizontal e as tensões superficiais resultantes das interações nas interfaces sólido-vapor, $\sigma_{\mathrm{SV}}$, sólido-líquido, $\sigma_{\mathrm{SL}}$, e, líquido-vapor, $\sigma_{\mathrm{LV}}$, como ilustrado na Figura 9, o ângulo de contato é determinado a partir do balanço de forças devido a essas interações, através da chamada Equação de Young [27]:

$$
\sigma_{L V} \cos \theta=\sigma_{S V}-\sigma_{S L}
$$

O ângulo de contato é então dado por:

$$
\theta=\cos ^{-1} \frac{\left(\sigma_{S V}-\sigma_{S L}\right)}{\sigma_{L V}}
$$

Modificações na superfície dos materiais podem ser usadas para aumentar ou diminuir o ângulo de contato, influenciando assim o molhamento do sólido pelo líquido. As espécies presentes em um líquido interagem entre si de várias maneiras. Uma delas é a atração ou repulsão elétrica, se estiverem carregadas ou se suas cargas positivas e negativas não estiverem igualmente distribuídas no espaço. Além disso, sofrem a ação da gravidade e da agitação térmica [27].

Se o líquido estiver em um recipiente, as forças de atração preponderam e impedem que as moléculas se espalhem pelo espaço. O líquido, neste caso, ocupa um 
volume determinado, formando uma superfície bem definida entre ele e o ar circundante. Surge daí uma diferença clara entre as moléculas da superfície e as que ficam internas no líquido. As que ficam dentro interagem com as demais em todas as direções. Em média, portanto, essas interações (ou forças) se anulam mutuamente. Já as que ficam na superfície só podem interagir com as que estão do lado de dentro. Do lado de fora só existe o ar e as moléculas do ar estão tão separadas uma das outras que seu efeito imediato sobre a superfície líquida pode ser desprezado.

O resultado é que a película que fica na superfície sofre uma atração para dentro do próprio líquido. Essa tendência é contrabalançada pela resistência das moléculas de dentro que só podem ceder espaço até certo ponto. Quando o equilíbrio é alcançado a tendência das moléculas superficiais de penetrarem no líquido é equilibrada pela resistência das demais que estão no interior. A diferença entre as energias das espécies na superfície e no interior do material se denomina tensão interfacial ou energia de superfície [27].

A Figura 11 ilustra de forma esquemática a interação das espécies no interior e na superfície de um líquido.

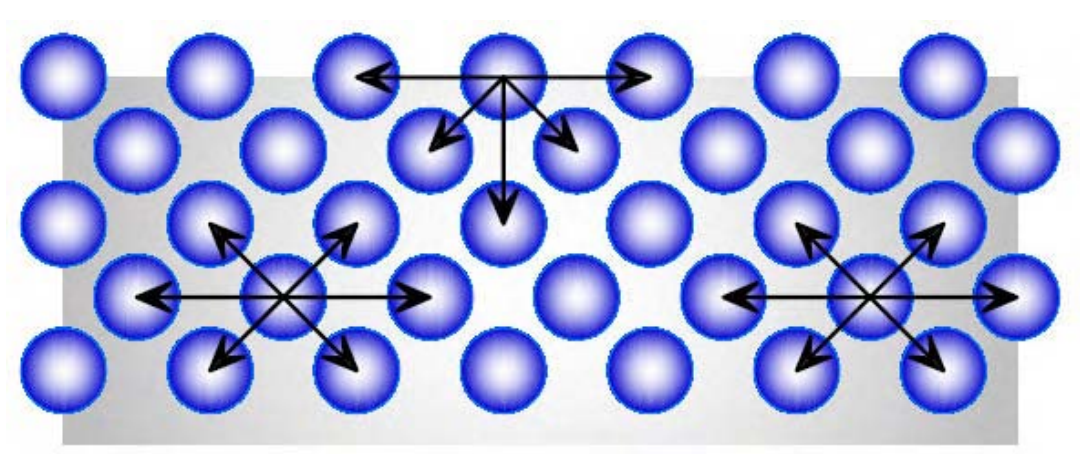

Figura 11 - Interação entre espécies no interior e na superfície de um material. Adaptado de [28]. 
Fowkes [30] propõe em seu trabalho que a energia de superfície pode ser descrita como a soma de contribuições de interações dispersivas ou apolares $\left(\sigma_{\mathrm{D}}\right)$ e não dispersivas, ou polares, $\left(\sigma_{\mathrm{P}}\right)[31,32]$. As componentes polares incluem todas as interações entre o sólido e o líquido, tais como dipolo - dipolo, dipolo induzido dipolo, pontes de hidrogênio, etc. De acordo com o principio da menor energia, a natureza tende sempre a um estado de mínima energia. É por esta razão que uma gota de água tende à forma esférica, pois esta é a forma geométrica de mesmo volume com a menor área superficial.

\subsubsection{Névoa Salina}

Materiais resistentes à oxidação sempre são de grande interesse para diversos tipos de aplicações tecnológicas. O comportamento de um material quando exposto às condições atmosféricas agressivas pode ser simulado em laboratório através da exposição de substratos a testes de corrosão em uma câmara de névoa salina, ou salt spray test, como é mais comumente conhecido. Este equipamento possibilita simular no equipamento um ambiente marinho extremamente severo, com concentração de sal e temperatura controlados, de forma que os testes podem ser realizados de forma acelerada. Os testes realizados em névoa salina, entretanto, não levam em consideração a presença de poluentes atmosféricos, ciclos de umidade e radiação ultravioleta, normalmente presentes na atmosfera real. Os resultados obtidos são portanto comparativos [33]. 


\subsubsection{Microscopia Eletrônica de Varredura}

A microscopia eletrônica de varredura é uma técnica de análise utilizada para caracterizar materiais a partir da produção de imagens de alta resolução da superfície de uma amostra.

O princípio de funcionamento do microscópio eletrônico de varredura é a emissão de feixes de elétrons a partir de filamento capilar de tungstênio (eletrodo negativo), mediante a aplicação de uma diferença de potencial que pode variar de 0,5 a $30 \mathrm{KV}$. Essa variação de voltagem permite a alteração da aceleração dos elétrons, e também provoca o aquecimento do filamento. A parte positiva do aparelho, em relação ao filamento, atrai fortemente os elétrons gerados, resultando numa aceleração em direção ao eletrodo positivo. A correção do percurso dos elétrons é realizada por lentes condensadoras que alinham os feixes em direção à abertura da objetiva [34]. A objetiva ajusta o foco dos feixes de elétrons antes dos elétrons atingirem a amostra analisada.

Este feixe de elétrons gerado pelo instrumento interage com a amostra de através de colisões que podem ser elásticas ou inelásticas. Nas colisões elásticas, os elétrons são afetados apenas em sua trajetória, sem alteração significativa em sua energia. Ao incidirem na amostra podem retornar a superfície após sucessivas colisões, como elétrons retroespalhados. Em colisões inelásticas, os elétrons acelerados transferem sua energia para o alvo, que por sua vez, pode emitir elétrons secundários, elétrons Auger, raios- $\mathrm{X}$ característicos e catodo luminescência [35]. As imagens fornecidas pelo equipamento são visualizadas através do monitor do aparelho através da transcodificação da energia emitida pelos elétrons e apresentam um aspecto tridimensional, sendo muito úteis para avaliação da estrutura superficial de uma 
determinada amostra. As imagens são geradas a partir de feixe de elétrons que incide sobre a superfície do substrato, permitindo uma ampliação de até 100.000 vezes [36] e uma resolução de 5 a $200 \mathrm{~nm}$. O microscópio eletrônico de varredura pode ser utilizado para caracterizar diversos tipos de materiais sejam estes orgânicos ou inorgânicos.

A Figura 12 apresenta de forma ilustrativa as interações de um feixe de elétrons incidindo em uma amostra e suas respectivas profundidades de zonas de emissões características.

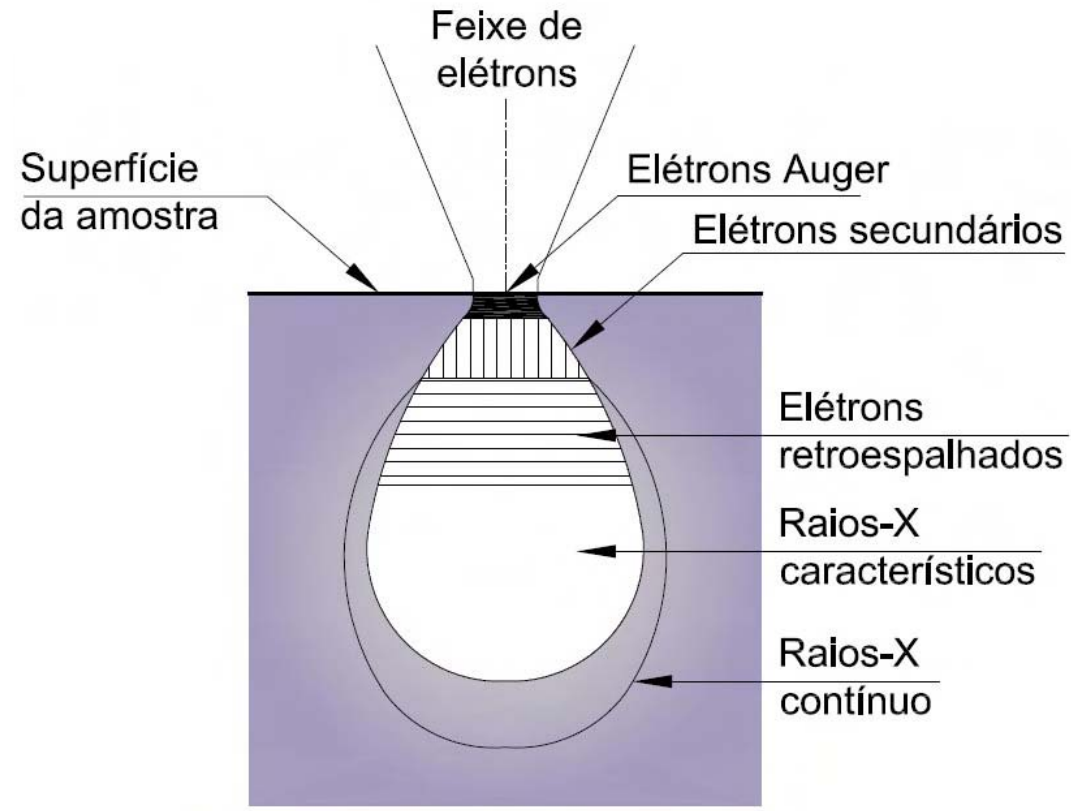

Figura 12 - Ilustração das interações dos elétrons com a amostra.

\subsubsection{Espectroscopia de impedância eletroquímica}

No início do século XIX, Georg Simon Ohm (1787-1854) demonstrou experimentalmente que quando a freqüência é zero, a corrente elétrica, $I$, que flui através de um condutor é diretamente proporcional à diferença de potencial, $E$, aplicada. 
Esta constante de proporcionalidade é a resistência, $R$, do material que é utilizado como meio condutor. De acordo com os experimentos de Ohm, tem-se que:

$$
E=R I
$$

Nos materiais, uma das características mais importantes é a facilidade com que eles transmitem a corrente elétrica. A corrente elétrica, ou taxa temporal de passagem de cargas, é constituída pelo movimento de partículas eletricamente carregadas (íons ou elétrons) em resposta a forças que atuam sobre elas a partir de um campo elétrico que é aplicado externamente [6].

Em um circuito de corrente alternada, a freqüência, $f$, é diferente de zero e o potencial elétrico, $\mathrm{E}$, varia com o tempo, $t$ [22]. Em resposta, a corrente elétrica apresentará um ângulo de fase, $\Phi$, em relação ao potencial elétrico. A Figura 13 exemplifica esquematicamente a variação do potencial elétrico e da corrente defasada de 90 graus, em função de um determinado tempo.

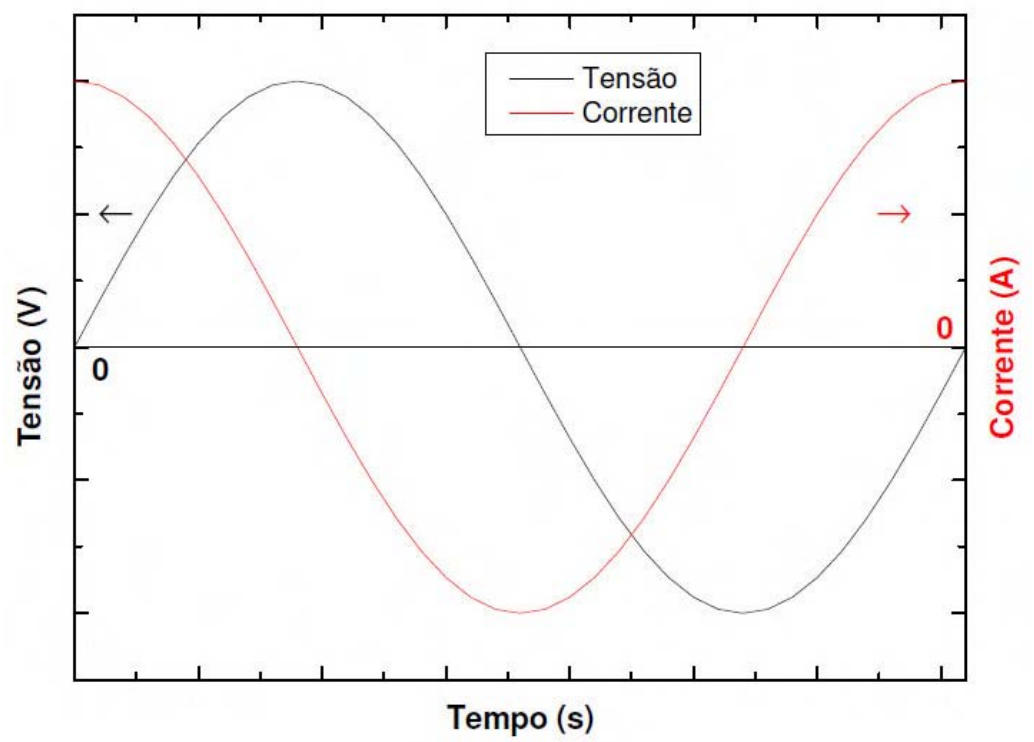

Figura 13 - Representação esquemática da variação da tensão e corrente no tempo. 
De acordo com a literatura [22], em um circuito de corrente alternada, o potencial elétrico, $E$, e a corrente elétrica, $I$, variam com o tempo de acordo com as seguintes expressões:

$$
\begin{gathered}
E(t)=E_{0} \cos \omega t \\
I(t)=I_{0} \cos (\omega t+\Phi) \\
\omega=2 \pi f
\end{gathered}
$$

A relação entre o potencial elétrico e a corrente elétrica é obtida por meio de uma expressão análoga a lei de Ohm:

$$
E(t)=Z I(t)
$$

Na equação (9), $E$ é amplitude de oscilação do potencial elétrico, I é a corrente elétrica e $Z$ é definido como impedância, que é equivalente à resistência do material, $R$, da equação (5), para circuitos de corrente alternada [37].

De acordo com Wolynec [38], o método de impedância eletroquímica apresenta diversas vantagens em relação às técnicas de corrente contínua, sendo as principais, as seguintes:

- Utilização de sinais de pequena intensidade que não degradam as propriedades da superfície em estudo;

- Possibilidade de estudar reações de corrosão e medir taxas de corrosão em meios de baixa condutividade; 
- A resistência de polarização e a capacitância da dupla camada podem ser determinadas em uma mesma medida.

Na Tabela 3 pode-se observar as principais simbologias e expressões de impedância para alguns circuitos elétricos simples.

Tabela 3 - Elementos de circuitos eletrônicos básicos. Adaptado de [38].

\begin{tabular}{|c|c|}
\hline $\begin{array}{c}\text { Elementos de } \\
\text { Circuito }\end{array}$ & $\begin{array}{c}\text { Equação de } \\
\text { Impedância }\end{array}$ \\
\hline \hline \multirow{4}{*}{$\mid$} & $Z=R$ \\
\hline|| & $Z=-j / 2 \pi f C$ \\
\hline
\end{tabular}

Pelas equações apresentadas na Tabela 3 pode-se notar que a impedância de um resistor não tem componente imaginário, $j$. Isto significa que a corrente não está defasada em relação à tensão, conforme apresentado na Figura 13. Neste caso, estando a corrente em fase com a tensão, a mudança de fase é de zero grau. Por outro lado, a impedância de um capacitor não contém componente real e o componente imaginário é função da capacitância e da freqüência. A mudança de fase é diferente de zero, isto é, a corrente está defasada em $\pi / 2$ em relação ao potencial [37].

A impedância, Z, é dada então pela seguinte equação:

$$
Z=Z^{\prime}+j Z^{\prime}
$$


A impedância é composta então por uma parte real, $Z$ ' e por uma parte imaginária $Z$ ” do número complexo Z. Um sistema eletroquímico simples pode ser representado pelo circuito esquematizado na Figura 14, no qual: $R e$ é a resistência não compensada existente entre o eletrodo de trabalho e o eletrodo de referência; $R p$ é a resistência de polarização da interface eletrodo/solução; Cdc: representa a capacitância da dupla camada da interface eletrodo/solução, também conhecida por capacitância total. A impedância de um capacitor não contém componente real e o componente imaginário é função da capacitância e da freqüência. Valores de freqüência muito baixos conduzem a altas impedâncias e valores de frequiência muito altos, conduzem a baixas impedâncias, conforme equações apresentadas na Tabela 3.

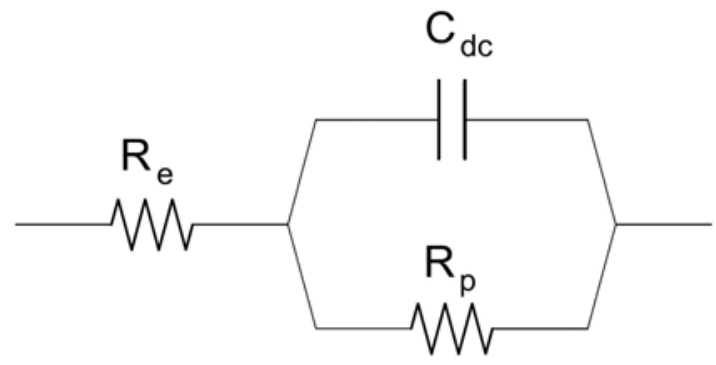

Figura 14 - Circuito eletrônico equivalente para um sistema eletroquímico simples de uma interface metal/solução eletrolítica em um sistema PEO. Adaptado de [36, 42].

Em um experimento de espectroscopia de impedância eletroquímica, a finalidade pode ser determinar os valores dos vários elementos de um circuito equivalente ou simplesmente confirmar que a um dado sistema eletroquímico corresponde um circuito equivalente particular, entretanto, a análise dos resultados podem ser feita também através dos diagramas de Bode, Nyquist, Linear ou Monologarítmica [37]. 
Pela análise dos diagramas de Bode $|\mathrm{Z}|$ e de Bode Fase é possível obter informações sobre reações de corrosão em poros e defeitos, e da interface entre a solução eletrolítica e o filme [39]. Os diagramas de Bode consistem na representação logarítmica da impedância e frequiência através de $\log |\mathrm{Z}|$ versus $\log \omega$.

Em baixas freqüências $\left(10^{-1} \mathrm{~Hz}\right)$ como também em altas frequiências $\left(10^{5} \mathrm{~Hz}\right)$ o valor da impedância, $|Z|$ independe da freqüência, $\omega$. Assim, os valores de Re e Rt (Re + Rp) podem ser determinados a partir dos patamares horizontais da Figura 15a. Para frequiências intermediárias, $10^{1}$ a $10^{3} \mathrm{~Hz},|\mathrm{Z}|$ é inversamente proporcional a $\omega[38]$.
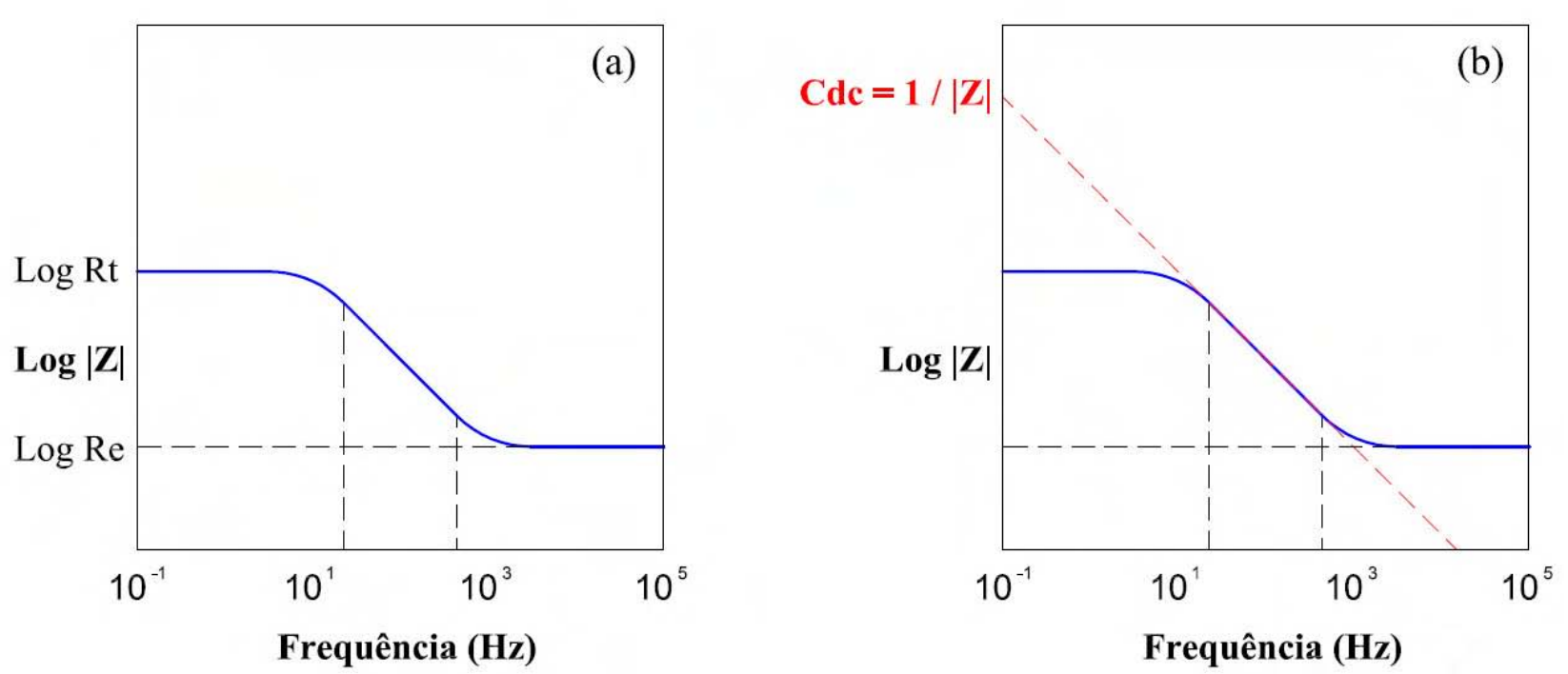

Figura 15 - Diagrama de Bode $\log |Z|$ x freqüência, $\log \omega$ utilizado para obter os valores de resistência total Rt (a) e de capacitância total Cdc. Adaptado de [39].

De acordo com Mansfeld [40], os resultados obtidos por impedância podem ser avaliados pela capacitância total $C d c$ que pode ser calculada pela extrapolação da curva de impedância em função da freqüência em $10^{1}$ a $10^{3} \mathrm{~Hz}$, interceptando o eixo da impedância em $10^{-1} \mathrm{~Hz}[38,39]$, conforme representado na Figura 15b. Como em altas e 
baixas freqüências a impedância independe da freqüência, a capacitância total pode ser expressa por:

$$
C d c=1 /|Z|
$$

O diagrama de Bode Fase também é uma alternativa para avaliação de revestimentos protetivos em metal e é dado pelo gráfico do ângulo de fase $-\Phi$ em função do $\log \omega$, conforme esquematizado na Figura 16.

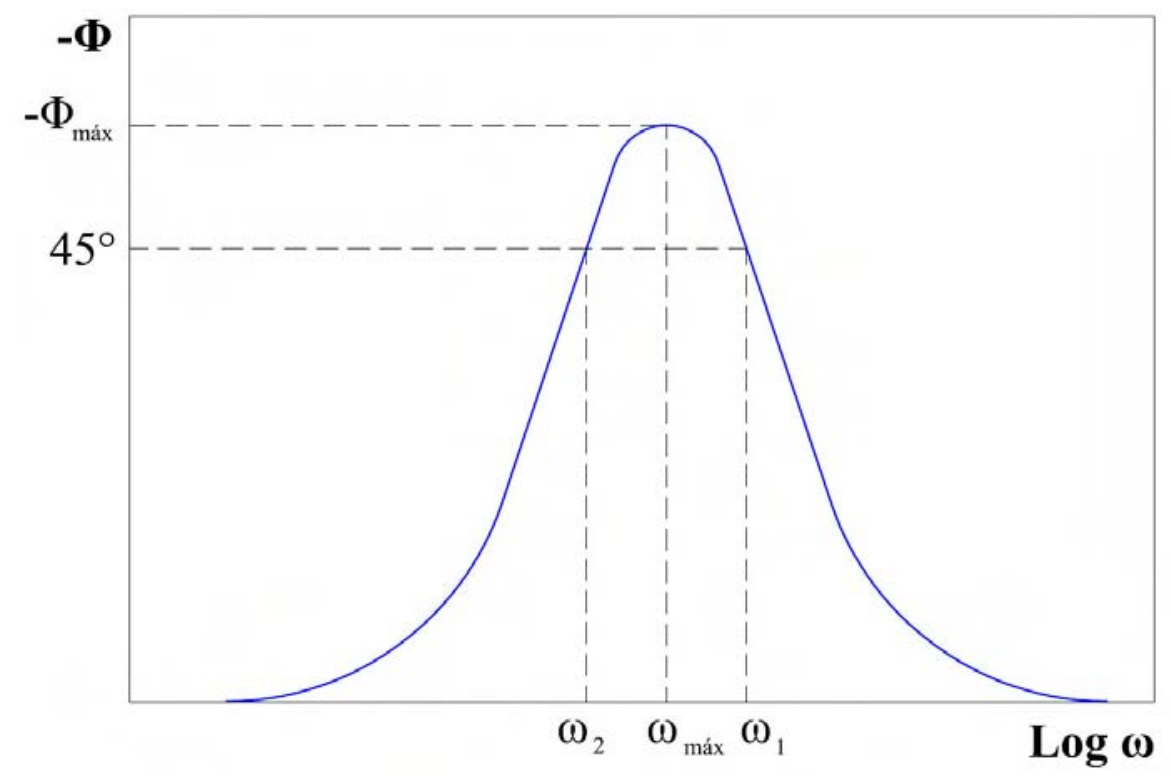

Figura 16 - Representação esquemática do diagrama de Bode Fase x Log $\omega$ utilizado em um sistema eletroquímico simples. Adaptado de [38].

\subsubsection{Polarização Potenciodinâmica}

Através de ensaios de polarização potenciodinâmica é possível determinar a taxa de corrosão e a propensão de materiais à corrosão em diferentes meios eletrolíticos. 
É um ensaio que se baseia em princípios eletroquímicos e a ocorrência de polarização leva a uma aproximação dos potenciais referentes às reações anódicas e catódicas, aumentando a resistência ôhmica do sistema, o que limita a velocidade do processo corrosivo [41].

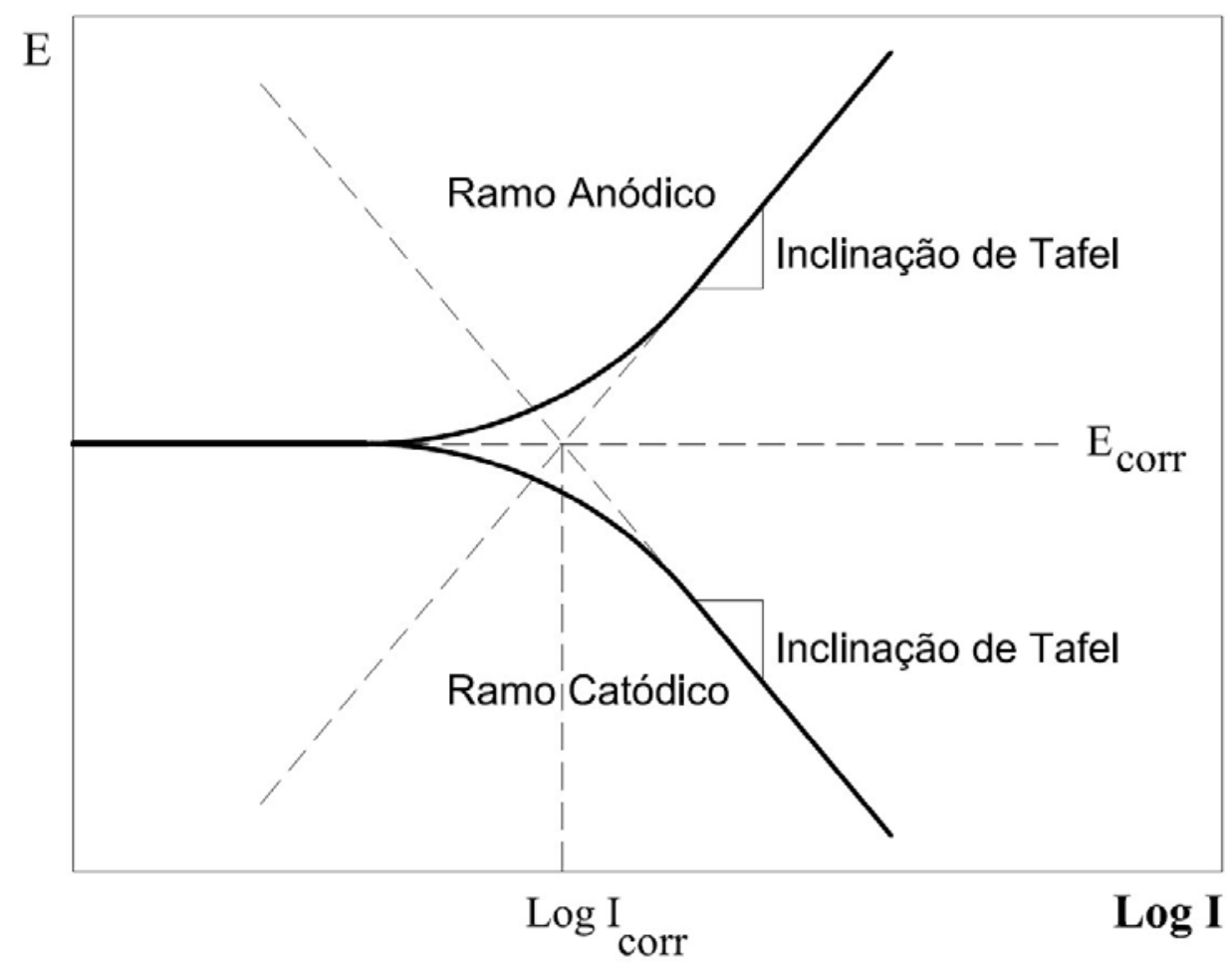

Figura 17 - Diagrama monologarítmico apresentando as curvas de polarização anódica e catódica e as retas de Tafel. Adaptado de [38].

Em ensaios de polarização potenciodinâmica, a corrente representa a taxa na qual as reações anódicas e catódicas irão ocorrer no eletrodo de trabalho (amostra). Desta forma é possível controlar as reações por polarizações nas regiões anódicas ou catódicas $[38,41]$. 
A Figura 17 apresenta a relação entre a corrente e a sobre-tensão de ativação demonstradas por Tafel [38]. Através da extrapolação das retas de Tafel é possível encontrar o potencial de corrosão $\mathrm{E}_{\text {corr }}$ e a corrente de corrosão $\mathrm{I}_{\text {corr }}$. Com o valor do potencial de corrosão, é possível verificar se o material apresenta tendência a não reagir com o meio. Com o valor da corrente de corrosão pode-se verificar a intensidade de permeação de espécies corrosivas no material.

\subsubsection{Espectroscopia de Infravermelho}

A espectroscopia de absorção no infravermelho é um tipo de espectroscopia de absorção que se utiliza da região do infravermelho do espectro eletromagnético. Como as demais técnicas espectroscópicas, ela pode ser usada para identificar um composto ou investigar a composição de uma amostra.

A espectroscopia no infravermelho se baseia no fato de que as ligações químicas das substâncias possuem freqüências de vibração específicas, as quais correspondem a níveis de energia da molécula, chamados nesse caso de níveis vibracionais. Quando ocorre a interação de um feixe de radiação infravermelha com a amostra, a energia deste feixe é absorvida causando movimentos vibracionais e rotacionais das moléculas que constituem o material. Tais freqüências dependem da forma da superfície de energia potencial da molécula, da geometria molecular, das massas dos átomos e eventualmente do acoplamento vibracional [33, 43].

Se a molécula receber luz com a mesma energia de uma dessas vibrações, então a luz será absorvida desde que sejam atendidas a determinadas condições. Para que uma vibração apareça no espectro infravermelho, a molécula precisa sofrer uma 
variação no seu momento dipolar durante essa vibração, ou seja, somente moléculas que não possuem simetria em sua distribuição de carga podem ser detectadas por esta técnica. Espécies homonucleares, tais como $\mathrm{O}_{2}, \mathrm{~N}_{2}$ e $\mathrm{Cl}_{2}$ não são evidenciadas por não apresentarem variações de momento de dipolo durante a oscilação [34].

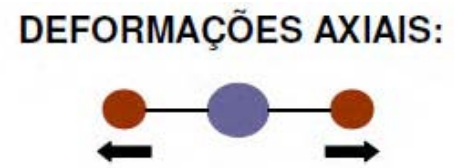

Simétrica

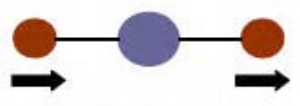

Assimétrica

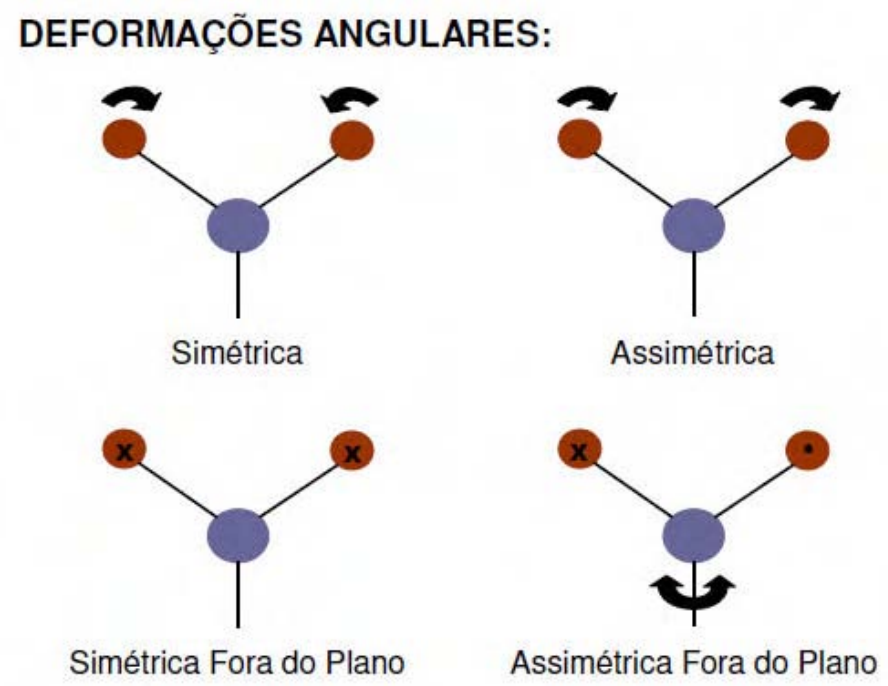

Figura 18 - Modos vibracionais simétricos e assimétricos de moléculas poliatômicas. Os símbolos $\times$ e • indicam movimentos para dentro e para fora do plano da página. Adaptado de [44].

Não obstante, as frequiências de ressonância podem ser em uma primeira aproximação relacionadas ao comprimento da ligação e às massas dos átomos em cada ponta dela, ou seja, cada grupo vibra com uma frequiência característica, que depende da massa dos átomos, da geometria das moléculas e da constante de força de ligação. Assim, cada composto ou material apresentará um espectro infravermelho distinto, 
como se fosse sua impressão digital. As ligações podem vibrar de seis modos, os quais se encontram esquematizados na Figura 18.

A região do infravermelho, de 200 a $12.500 \mathrm{~cm}^{-1}$ (50 a $\left.0,8 \mu \mathrm{m}\right)$, se situa no espectro eletromagnético entre as regiões das microondas e da luz visível. Normalmente, a faixa compreendida entre 400 a $4.000 \mathrm{~cm}^{-1}(25$ a $2,5 \mu \mathrm{m})$ abrange as freqüências de vibração da maioria das ligações químicas [44].

\subsubsection{Perfilometria}

A espessura de filmes depositados sobre a superfície de materiais pode ser medida através de um equipamento denominado Perfilômetro. Este equipamento contém uma ponta de diamante que se desloca sobre a superfície da amostra e mede a qualquer variação de altura na superfície. Entretanto, para se medir a espessura de filmes gerados sobre a superfície de materiais, é necessário que haja um degrau entre o filme e a superfície sem tratamento. Quando a agulha do equipamento encontra este degrau, há um deslocamento vertical, que gera sinais elétricos proporcionais à sua amplitude. Estes sinais elétricos são captados por um detector acoplado à ponta desta agulha e convertidos para o formato digital e processados em um computador, que fornece o valor da espessura do revestimento investigado. A Figura 19 representa esquematicamente uma medição de espessura realizada por perfilometria. 


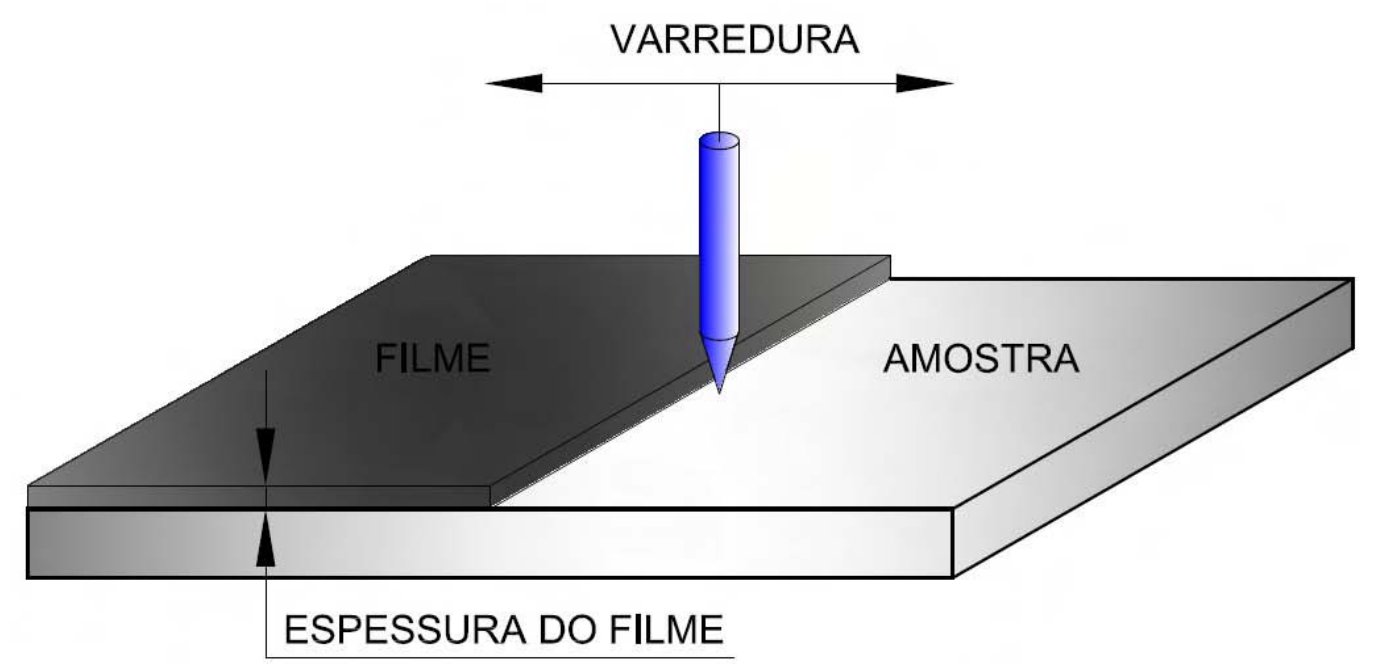

Figura 19 - Representação esquemática da medição da espessura de filme por perfilometria.

\subsubsection{Medição da Espessura do Revestimento por Correntes Parasitas}

Correntes de Foucault, ou correntes parasitas é o nome dado às correntes induzidas em massas metálicas como conseqüência da variação do fluxo magnético que as atravessam. O nome foi dado em homenagem a Jean Bernard Léon Foucault, que estudou esse efeito [45]. Estas correntes elétricas, em alguns idiomas são denominadas como correntes em rodamoinho ou turbilhonares (eddy currents, wirbelströme).

As correntes de Foucault, vantajosas em alguns casos, são nocivas em muitos outros, porque podem produzir resultados indesejáveis como acarretar grande dissipação de energia por efeito Joule, elevando a temperatura das peças metálicas, dentro das quais se originam.

Para evitar ou minimizar esta dissipação indesejável, os materiais sujeitos a campos magnéticos variáveis são frequentemente laminados ou construídos com placas muito pequenas isoladas umas das outras, como por exemplo, núcleos metálicos de transformadores. Uma forma de manifestação da corrente de Foucault é o efeito 
pelicular em condutores elétricos. Esta é uma forma na qual a corrente elétrica tende a fluir na periferia do condutor [46].

O método de ensaio por correntes parasitas baseia-se fundamentalmente na Lei de Indução de Faraday, onde o campo magnético, gerado por uma bobina quando alimentada por uma corrente elétrica alternada, induz, na peça a ser ensaiada, correntes elétricas, que são as correntes denominadas de parasitas. Estas correntes elétricas, por sua vez, afetam a impedância da bobina que as gerou e desta forma, qualquer variação no fluxo das correntes parasitas geradas na peça ensaiada implicará em variações na impedância da bobina.

Este método de ensaio é extremamente versátil e pode ser utilizado para diversas aplicações, entre elas para a medição de espessura de camada não condutora aplicada em material condutor ou camada condutora aplicada em material de condutividade diferente, conforme descrito nas normas ABNT NBR 12610, ASTM B244 e DIN EN ISO 2360.

Além de uma vasta área de aplicações, o ensaio por correntes parasitas ainda oferece uma série de vantagens tais como: alta sensibilidade, alta confiabilidade, rapidez de execução, facilidades para automação, não exige contato direto entre a sonda e a superfície inspecionada, limpeza, entre outros. Na área siderúrgica, os materiais podem ser diretamente ensaiados ainda quentes [47].

É um método não-destrutivo na medição da espessura de camada não condutora (camada anódica) sobre o alumínio e suas ligas (metal-base). 


\section{PROCEDIMENTOS EXPERIMENTAIS}

Todo o desenvolvimento do dispositivo para geração do plasma em meio eletrolítico foi realizado no Laboratório de Plasmas Tecnológicos, LaPTec, do Campus Experimental da Unesp em Sorocaba (www.sorocaba.unesp.br/gpm), assim como as investigações do ângulo de contato, as medições de espessura por perfilometria e as análises por infravermelho.

Os ensaios de espectroscopia e de polarização foram realizados no Laboratório de Engenharia de Corrosão da Unicamp. As medições de espessura por correntes parasitas foram realizadas na Companhia Brasileira de Alumínio, as análises de MEV no Laboratório Metalúrgico de Engenharia de Materiais da empresa Schaeffler Brasil Ltda-Divisão INA e os ensaios de névoa salina na empresa Rontan Eletro Metalúrgica Ltda.

\subsection{Sistema de Processamento a Plasma}

Foi desenvolvido um sistema em caráter de protótipo para o processamento de materiais via plasma eletrolítico baseado na técnica PEO. O sistema ilustrado na Figura 20 é composto de uma fonte de alimentação alternada com tensão de saída variável (1), um sistema para retificação de corrente (2), um medidor de tensão (3), um

medidor de corrente (4), um sistema mecânico para sustentação dos eletrodos (5) e a célula eletrolítica (6). 


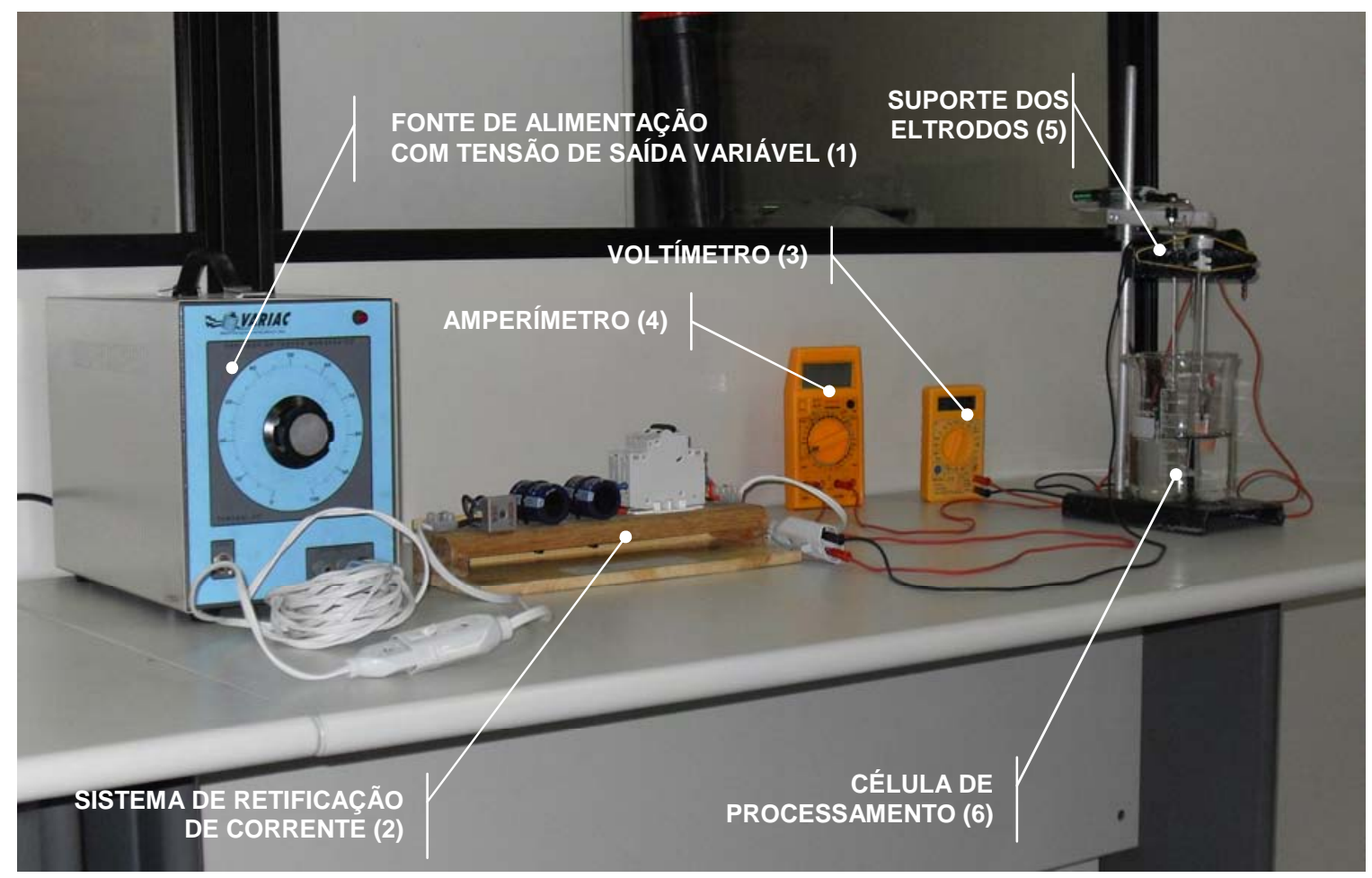

Figura 20 - Sistema de Processamento via Plasma Eletrolítico.

Para monitorar a temperatura de processamento, foi utilizado um termômetro (7) sustentado pelo suporte de eletrodos e com a ponta imersa na solução, conforme ilustra a Figura 21. As leituras foram feitas minuto a minuto para que a variação de temperatura pudesse ser acompanhada integralmente durante todo $o$ processamento.

Com a finalidade de garantir uma maior homogeneidade e distribuição iônica da solução, durante todo o processamento foi desenvolvido um mecanismo de agitação mecânica (8) composto de uma hélice de aço inoxidável mergulhada no interior da solução, conforme ilustra a Figura 21. 


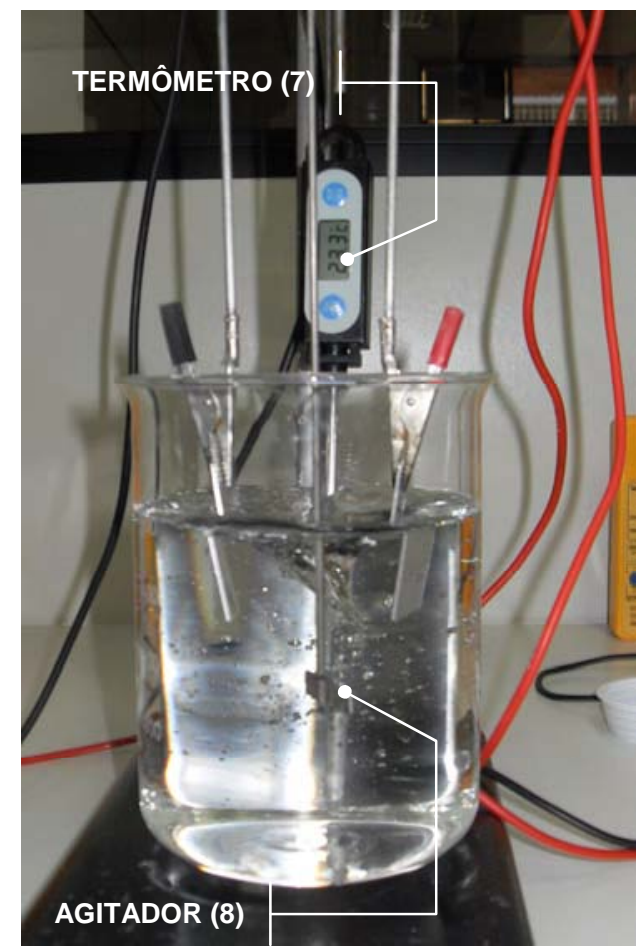

Figura 21 - Detalhe da medida de temperatura de processamento e do sistema de agitação da solução.

A célula de processamento, ou célula eletrolítica, é composta por um recipiente para conter a solução eletrolítica e um par de eletrodos (anodo e catodo) de aço inoxidável de diâmetro de 2,5 $\mathrm{mm}$ e distantes a 4,5 cm um do outro. Como recipiente, foi utilizado um béquer de $500 \mathrm{ml}$. No par de eletrodos é aplicada uma diferença de potencial apropriada, gerando o plasma a uma pressão de cerca de 760 Torr em um dos eletrodos. Os eletrodos possuem em suas extremidades terminais elétricos tanto para aplicação da tensão, quanto para fixação da amostra, funcionando também como porta amostras. O processamento do material é realizado através da técnica de Processamento via Plasma Eletrolítico, EPP (Electrolytic Plasma Processing). A célula de processamento está esquematizada na Figura 22. 


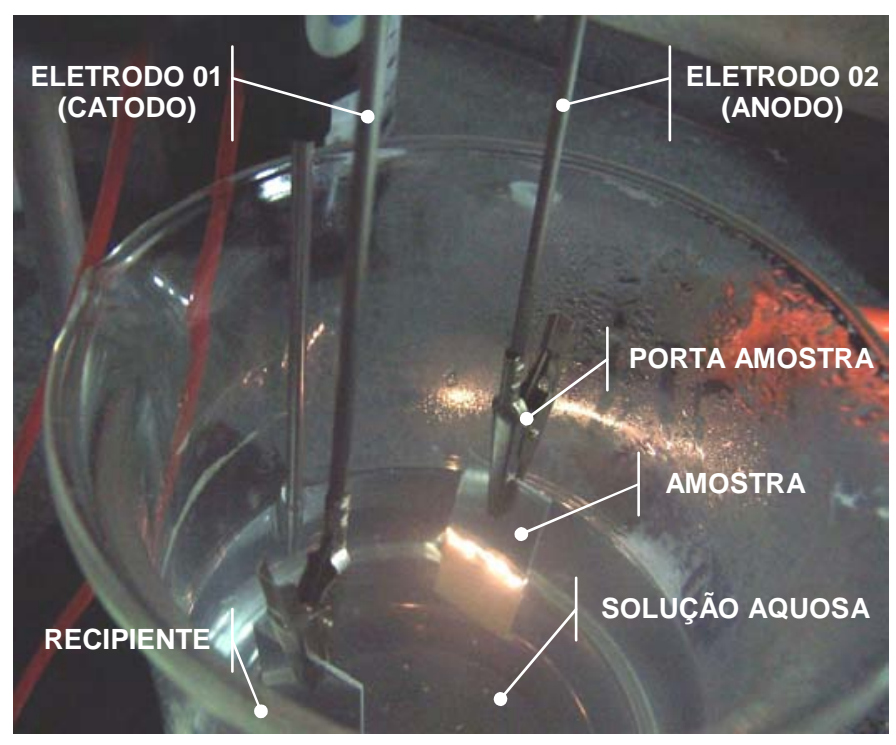

Figura 22 - Célula de Processamento via Plasma Eletrolítico.

Os principais elementos utilizados para a montagem do circuito elétrico do dispositivo de processamento de materiais via plasma eletrolítico está ilustrado na Figura 23

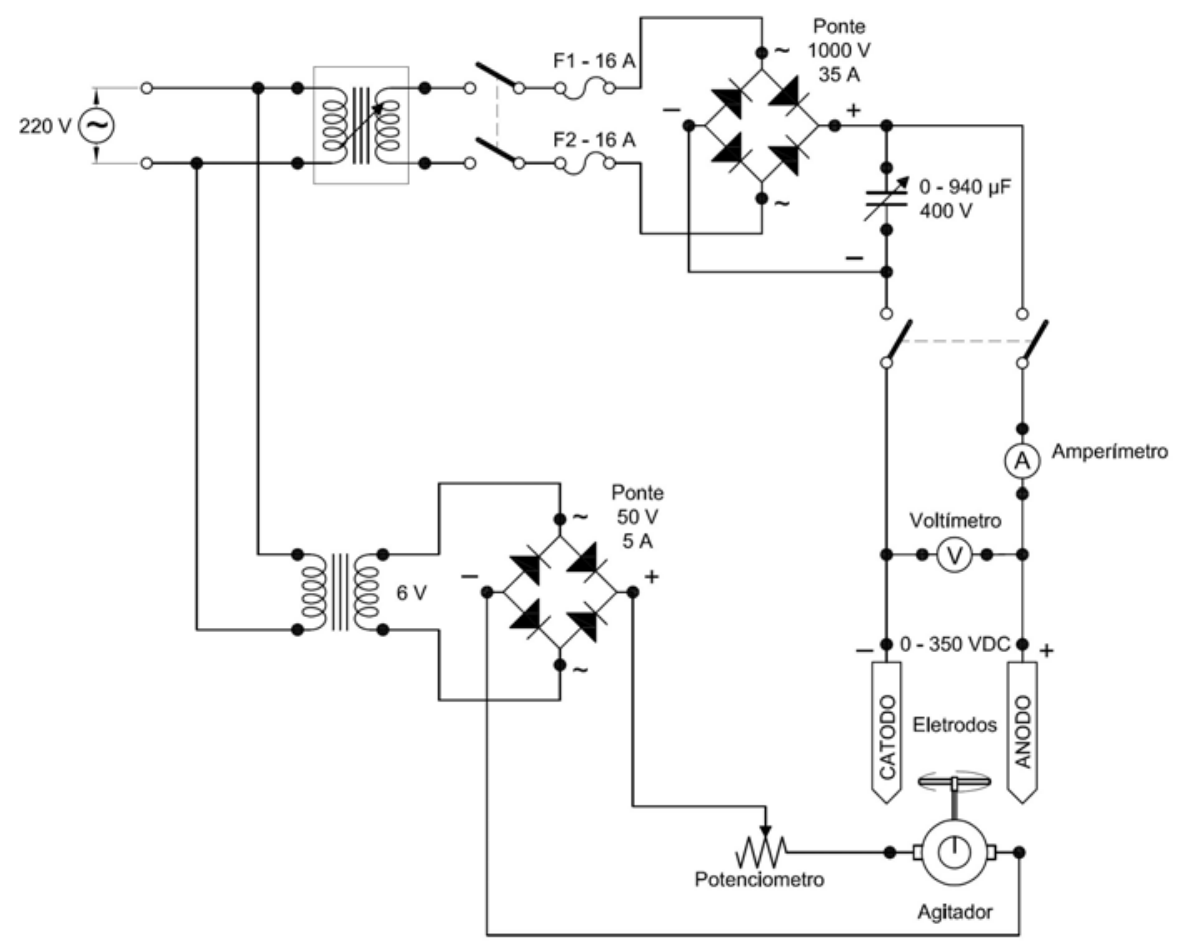

Figura 23 - Circuito do Sistema de Processamento via Plasma Eletrolítico. 


\subsection{Preparação das amostras}

Os substratos utilizados foram produzidos a partir de placas de alumínio com espessura de 1,6mm na liga 2024-T3, cortados com dimensões de 2,0 x 4,0 cm. Antes do processamento a plasma, os substratos foram submetidos à limpeza para remoção de impurezas e para garantir a ausência de resíduos superficiais que possam contaminar a solução eletrolítica. As amostras foram lavadas em uma cuba ultrassônica (ULTRASONIC CLEAR CBU-100) com detergente especial para limpeza de alumínio, durante 900 s. Foram enxaguadas em água corrente e lavadas novamente em água destilada e álcool isopropílico. Após o processo de lavagem as amostras foram secas uma a uma utilizando um soprador térmico (HL 1500 Steinel).

Para a determinação da espessura dos filmes gerados nos substratos, foram utilizadas amostras polidas com acabamento espelhado. O processo de polimento foi realizado atritando lixas 220, 400, 600, 800 e 1200 e braço polidor contra superfície do substrato. O valor rugosidade superficial padrão, determinada por perfilometria, foi adotado através dos resultados da medição de 10 valores de rugosidade da face polida da amostra no sentido transversal e 10 valores no sentido longitudinal em 10 amostras diferentes. A média dos valores de rugosidade, Ra, encontrada no sentido transversal foi de $500 \AA$ e no sentido longitudinal de $400 \AA$. Adotou-se como valor padrão de rugosidade o valor médio dos dois resultados que foi de $450 \AA$.

\subsection{Preparação da solução}

A solução eletrolítica utilizada para a realização deste trabalho foi o silicato de sódio $\left(\mathrm{Na}_{2} \mathrm{SiO}_{3}\right)$ a uma concentração de $20 \mathrm{~g} / \mathrm{L}$. O preparo da solução eletrolítica foi 
realizado através da mistura de 34,76g de metassilicato de sódio penta-hidratado em 1 litro de água destilada. Com isto, obteve-se uma solução eletrolítica de silicato de sódio com a concentração de $20 \mathrm{~g} / \mathrm{L}$. A mistura foi mantida em uma cuba ultrassônica (ULTRASONIC CLEAR CBU-100) durante $900 \mathrm{~s}$ para garantir a melhor homogeneidade da solução.

Para cada ensaio foi utilizado cerca de $300 \mathrm{ml}$ de solução. Para garantir que as condições de igualdade de tratamento fossem mantidas, a solução eletrolítica era sempre trocada a cada amostragem.

\subsection{Tratamento Superficial}

O tratamento é iniciado aplicando-se uma diferença de potencial entre os eletrodos durante um determinado tempo. Após o desenvolvimento do protótipo e verificada a eficácia do equipamento na geração do plasma em meio eletrolítico, iniciou-se o tratamento de uma primeira uma série amostral composta por 7 (sete) amostras na liga 2024 de alumínio. Estes substratos foram submetidos ao PEO com tensões de 50, 100, 150, 200, 250, 275 e $300 \mathrm{~V}$, por um período de $1800 \mathrm{~s}$.

Após estarem limpas, as amostras eram colocadas nos eletrodos, os quais dispõem em suas extremidades de dispositivos de fixação que funcionam como porta amostras e possibilitam o tratamento superficial dos substratos. A amostra de interesse é fixada no anodo, onde ocorre a descarga de plasma e, consequentemente, a criação do filme de óxido na superfície da amostra. A amostra colocada no catodo é um elemento de sacrifício, utilizado para garantir as condições de igualdade dimensional em ambos os eletrodos. 
Durante a realização dos ensaios desta série, verificou-se que para este equipamento e nas condições de tensão estabelecidas, tempos de tratamento com durações superiores a 900 s conduziam a uma diminuição abrupta da densidade de corrente, conforme pode ser observado na Figura 24.

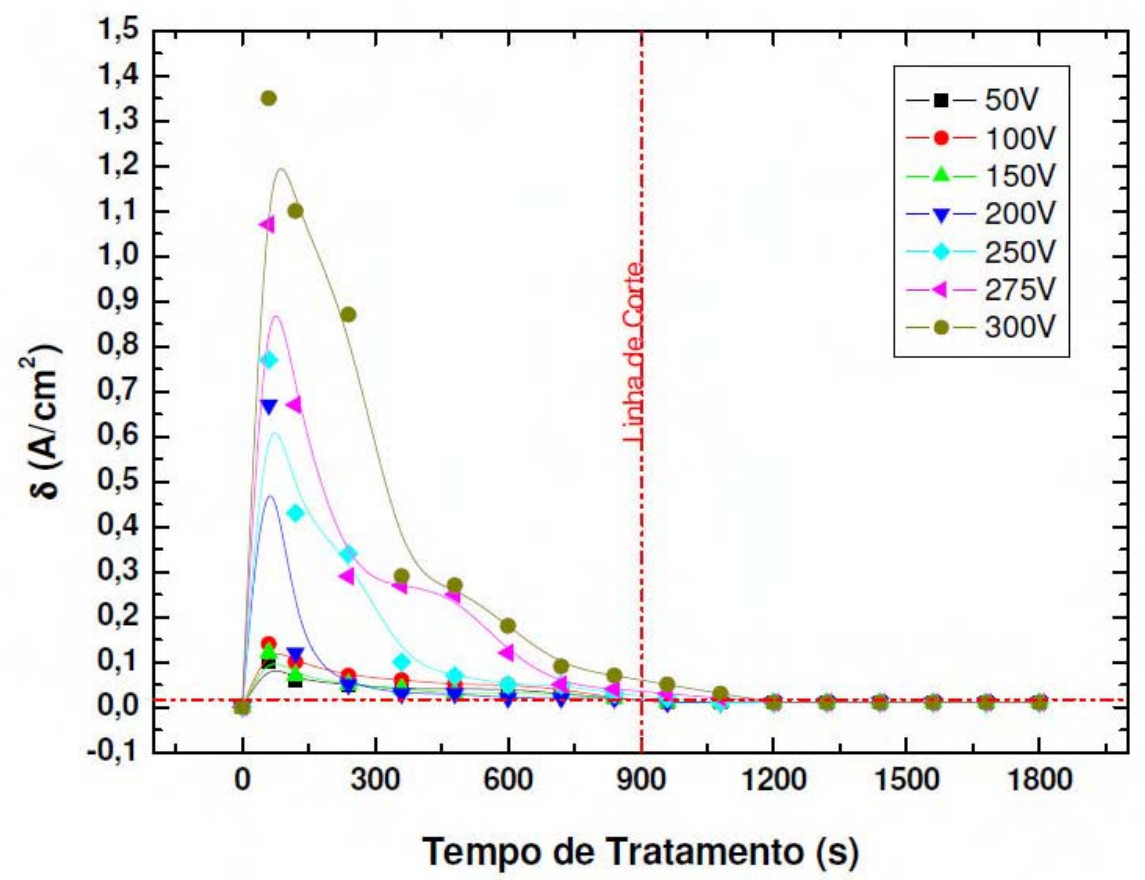

Figura 24 - Variação da densidade de corrente $(\delta)$ em função do tempo de tratamento em amostras expostas ao PEO por 1800s.

De acordo com os valores apresentados na Figura 24, nota-se que para tempos de tratamento superiores a $900 \mathrm{~s}$, a densidade de corrente chega a valores muito próximos a $0,01 \mathrm{~A} / \mathrm{cm}^{2}$, que normalmente é o mínimo para que as condições de tratamento em plasma de eletrólise sejam alcançadas [7]. Arbitrariamente, decidiu-se então adotar uma "linha de corte" em 900 s. Desta forma, todos os ensaios subseqüentes foram realizados com um tempo de tratamento de $900 \mathrm{~s}$. 
Foram realizadas outras 5 séries amostrais com 7 ensaios em cada série com tensões contínuas de 50, 100, 150, 200, 250, 275 e 300 V.

\subsection{Técnicas de Caracterização dos Filmes Produzidos}

As amostras foram retiradas da célula de processamento, lavadas com água destilada e secas com o soprador térmico HL 1500 Steinel. Em seqüência, foram submetidas a processos de caracterização para identificação de suas propriedades. Neste trabalho, análises de superfície foram realizadas nas amostras com a finalidade de verificar o comportamento e as características encontradas nos filmes depositados, nas diversas faixas de tensão as quais as amostras foram submetidas.

\subsection{1. Ângulo de Contato e Energia de Superfície}

Os valores das medições de ângulo de contato e energia de superfície apresentados neste trabalho foram obtidos através do uso do Goniômetro Ramé-Hart 100-00, apresentado na Figura 25. Este equipamento é composto de uma plataforma móvel com parafusos de nivelamento onde a amostra é colocada, uma micro-seringa capaz de produzir gotas com volumes da ordem de $0,2 \mu \mathrm{l}$, um sistema de iluminação com fibra ótica, uma câmera $\mathrm{CCD}$ e um microcomputador que processa a imagem da gota captada pela câmera, através de um programa específico (RHI 2001 Imaging). Para a investigação da molhabilidade dos filmes, é medido o valor do ângulo de contato para água deionizada. Para a determinação da energia de superfície através do método da média geométrica os líquidos usados são: água deionizada e diiodometano. 


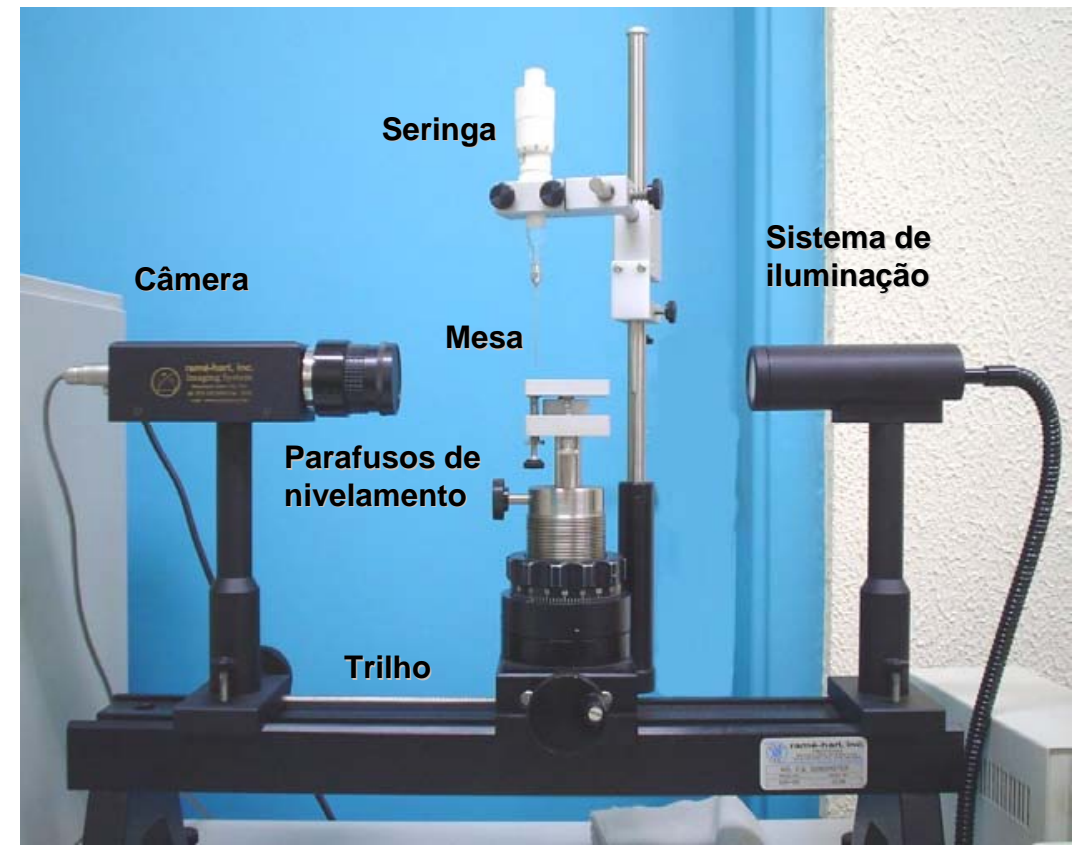

Figura 25 - Foto do Goniômetro usado nas medidas de ângulo de contato e energia de superfície.

Os valores do ângulo de contato e da energia de superfície apresentados neste trabalho correspondem à média aritmética dos valores obtidos em 30 medidas realizadas nos filmes depositados sobre amostras de alumínio, bem como 30 medidas realizadas nas amostras antes do tratamento para uso como referência.

\subsubsection{Testes de Corrosão}

Para verificação do comportamento do filme produzido, as amostras foram submetidas aos ensaios de névoa salina, potencial de circuito aberto (EOCP), impedância eletroquímica (EIS) e a polarização potenciodinâmica. 


\subsubsection{Névoa Salina}

A Câmara de Névoa Salina é padronizada por norma nacional (ABNT NBR 8094) e internacional (ASTM B117 e DIN 50021). O aparato experimental que compõe o sistema de teste de névoa salina é:

- Câmara de ensaio, com capacidade mínima de $0,4 \mathrm{~m}^{3}$;

- Reservatório para acondicionamento da solução de $\mathrm{NaCl}$;

- Reservatório de água destilada;

- Fonte de ar comprimido;

- Bicos pulverizadores;

- Suporte de corpos de prova;

- Dispositivo para aquecimento da câmara;

- Meios para o controle das condições de operação durante o período do ensaio.

A Figura 26 apresenta uma foto do equipamento utilizado para ensaiar os substratos.

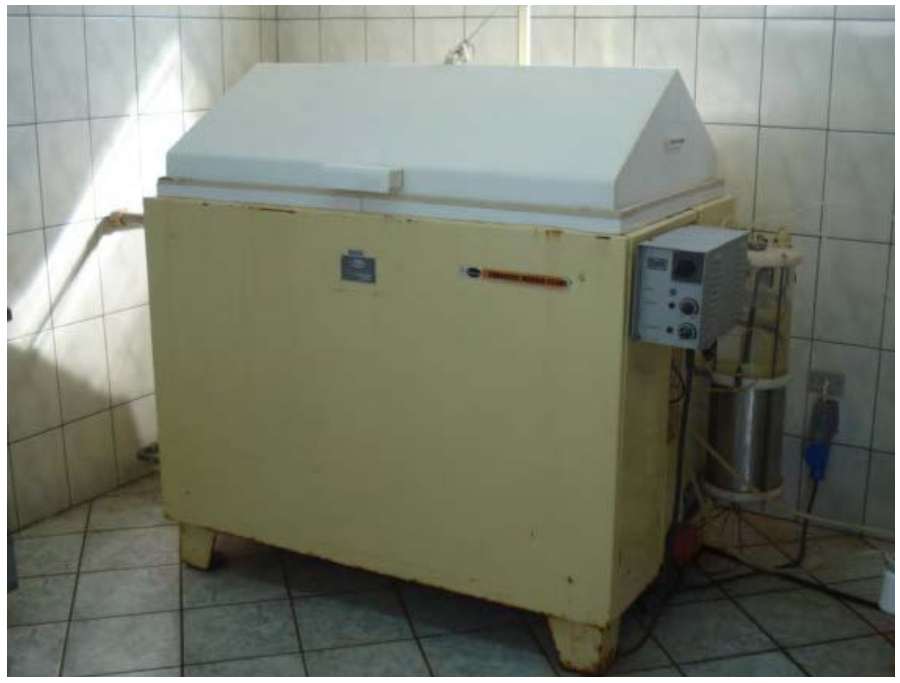

Figura 26 - Foto da câmara de névoa salina utilizada nos ensaios de corrosão. 
A névoa salina é obtida pela passagem de ar comprimido através da solução salina que também pode conter ácido acético e cloreto de cobre para intensificar o seu efeito corrosivo. A distribuição da solução salina no interior da câmara é feita através de bicos pulverizadores Todas as partes da aparelhagem que entram em contato com a névoa ou com a solução são fabricadas com um material resistente à ação corrosiva da solução, e não interferem nos resultados dos ensaios durante o processo de corrosão.

Através de suportes padrão existentes no interior da câmara, Figura 27, as amostras são dispostas de forma que sua inclinação esteja entre 15 e $30^{\circ}$ com a vertical, paralelamente ao fluxo da névoa. O suporte também não deve possibilitar o contato entre as amostras, nem com outras peças metálicas.

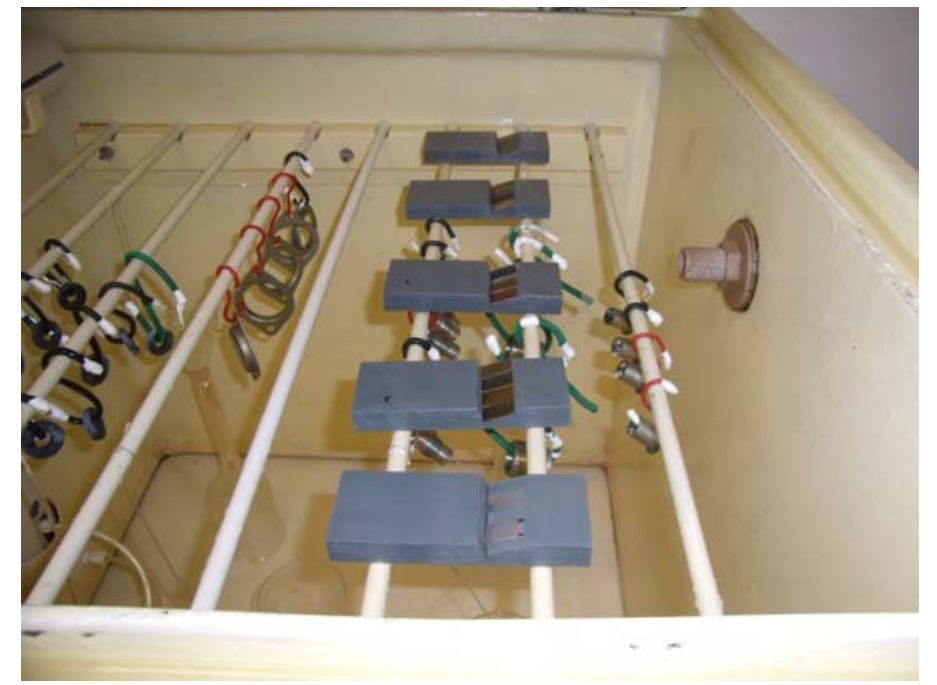

Figura 27 - Detalhe dos suportes porta-amostra no interior do equipamento.

A solução aquosa utilizada para o ensaio foi de $5 \%$ de cloreto de sódio $(\mathrm{NaCl})$ e foi preparada pela dissolução de $50 \mathrm{~g}$ de $\mathrm{NaCl}$ em um volume de água destilada que permita a obtenção de 1 litro de solução, à temperatura ambiente. 
A solução de ensaio tem que ser pulverizada somente uma vez, não podendo ser reaproveitada. $\mathrm{O}$ pH da solução de cloreto de sódio deve ser ajustado se a solução coletada após a pulverização a $35{ }^{\circ} \mathrm{C}$ não apresentar um pH entre 6,5 e 7,2, determinado a $(25 \pm 2){ }^{\circ} \mathrm{C}$. Para o ajuste do $\mathrm{pH}$, emprega-se solução diluída de ácido clorídrico ou hidróxido de sódio. Os ensaios foram realizados em uma câmara Corrotest-CA 680, Druckman (Figura 26) segundo o estabelecido na norma ASTM B117-07a na empresa Rontan Eletro Metalúrgica Ltda.

O ar comprimido utilizado para a formação da névoa salina manteve uma variação de pressão entre 0,8 a $1,1 \mathrm{kgf} / \mathrm{cm}^{2}$. A zona de exposição da câmara de apresentou uma variação máxima de temperatura entre 34 a $37^{\circ} \mathrm{C}$.

Para comprovação da distribuição uniforme da névoa na parte utilizável da câmara de ensaio, um recipiente de coleta é disposto de forma que gotas da solução de ensaio, provenientes dos corpos de prova ou de outras partes da câmara não seja por ele coletada. Os bicos pulverizadores foram posicionados de forma que nenhum dos fluxos de névoa atinja diretamente os corpos de prova.

A quantidade de solução a pulverizar na câmara de ensaio foi ajustada de modo que para uma área de coleta de aproximadamente $80 \mathrm{~cm}^{2}$ sejam recolhidos em cada coletor 1,0 a 2,0 mL de solução por hora, em um período de no mínimo $16 \mathrm{~h}$.

O ensaio de nevoa salina para a liga de alumínio 2024 mostra-se bastante agressivo devido aos íons de cloreto presentes na solução. A corrosão acontece devido à difusão destes íons pelas descontinuidades das camadas de óxido, alcançando os contornos de grão. Os contornos de grão são caminhos preferenciais para os íons de cloreto e permitem que estes permeiem até os precipitados de $\mathrm{CuAl}_{2}$.

Para verificação das alterações superficiais conferidas às amostras, as ligas tratadas foram submetidas à névoa salina juntamente com uma amostra sem tratamento 
para servir de referência. A cada hora de ensaio, foi realizada a inspeção visual das amostras, procurando-se verificar o aparecimento de qualquer sinal nas amostras, como manchas ou pites, por exemplo, que indicassem o início de corrosão. Inicialmente, as amostras permaneceram na câmara por um período de 220 horas. Amostras que não apresentaram sinal de corrosão foram mantidas na câmara de névoa salina e monitoradas a cada hora.

\subsubsection{Espectroscopia de impedância eletroquímica}

Os ensaios de espectroscopia de impedância eletroquímica foram realizados em uma célula com três eletrodos: o eletrodo de referência, de calomelano saturado, o contra eletrodo (placa de platina) e o eletrodo de trabalho de platina, com área de 0,78 $\mathrm{cm}^{2}$, onde é colocada a amostra, conforme ilustra a Figura 28. O sinal aplicado, com amplitude de $10 \mathrm{mV}$, foi variado nas freqüências de $10^{-2}$ a $10^{5} \mathrm{~Hz}$. A concentração da solução utilizada foi de $3,5 \%$ de $\mathrm{NaCl}$. As medidas foram realizadas em potencial de circuito aberto, utilizando-se um potenciostato PAR modelo 273A conectado a um Lock-in PAR modelo 5210, com programa para aquisição dos dados Electrochemistry Power Suite da PAR. Antes de iniciar os testes as amostras permaneceram imersas na solução por uma hora, para atingir um estado de equilíbrio. Os ensaios foram realizados no Laboratório de Engenharia de Corrosão - ENGECORR do Departamento de Engenharia de Materiais da Faculdade de Engenharia Mecânica da UNICAMP. 


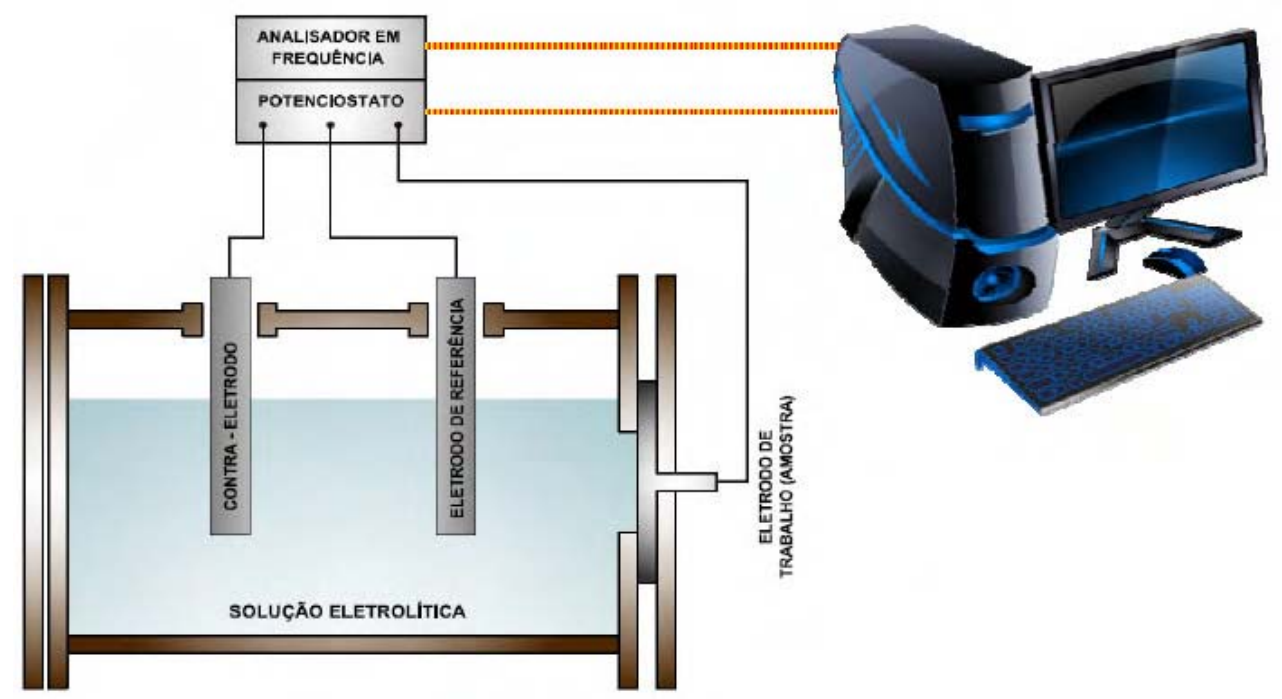

Figura 28 - Ilustração do aparato experimental utilizado nos ensaios de impedância eletroquímica.

\subsubsection{Polarização potenciodinâmica}

Inicialmente, antes de realizar o ensaio de polarização, determinou-se o potencial de circuito aberto (EOCP), ou seja, o potencial entre o eletrodo de trabalho (amostra) e eletrodo de referência (de calomelano). As curvas foram feitas a partir das polarizações partindo de um potencial de inicial de $-0,25 \mathrm{~V}$ x EOCP até um potencial final de $1,0 \mathrm{~V}$ x EOCP com uma velocidade de varredura de $0,5 \mathrm{mV} / \mathrm{s}$. A solução utilizada foi a mesma das análises de espectroscopia de impedância eletroquímica, que entrou em contato com $0,78 \mathrm{~cm}^{2}$ da amostra. O equipamento utilizado para a polarização foi o potenciostato PAR modelo 273A. A Figura 29 ilustra o equipamento utilizado na analise das amostras. 


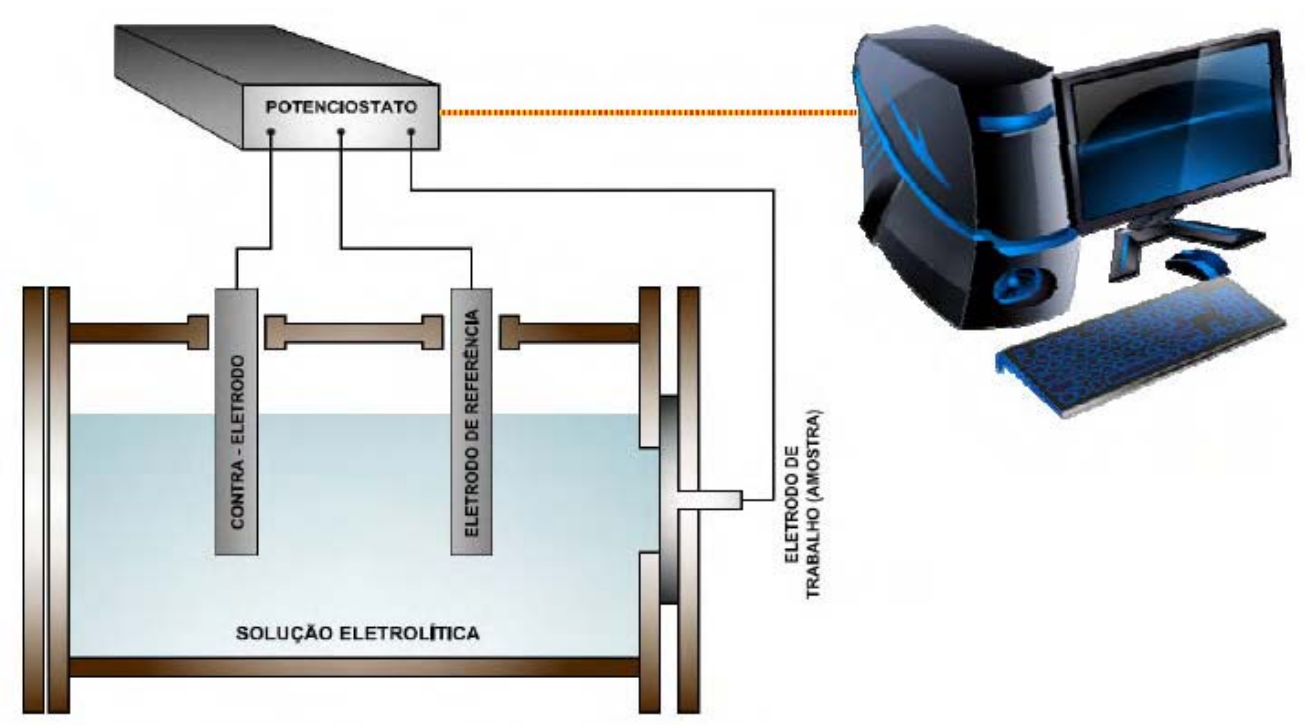

Figura 29 - Ilustração do aparato experimental utilizado nos ensaios de polarização potenciodinâmica.

Os ensaios foram realizados no Laboratório de Engenharia de Corrosão ENGECORR do Departamento de Engenharia de Materiais da Faculdade de Engenharia Mecânica da UNICAMP.

\subsubsection{Identificação da estrutura química}

A identificação dos elementos químicos nos filmes depositados por PEO em diferentes tensões nominais foi realizada por Espectroscopia de Absorção na Região do Infravermelho no modo de transmitância em um espectrômetro Jasco FTIR-410 no Laboratório de Plasmas Tecnológicos, LaPTec, da UNESP de Sorocaba. Para esta análise, foram utilizadas amostras de alumínio com superfície polida tratadas no PEO. Cada amostra foi submetido a 128 varreduras, com resolução de $4 \mathrm{~cm}^{-1}$. A Figura 30 
mostra o espectrômetro de infravermelho por transformada de Fourier utilizado nas medições presentes neste trabalho.

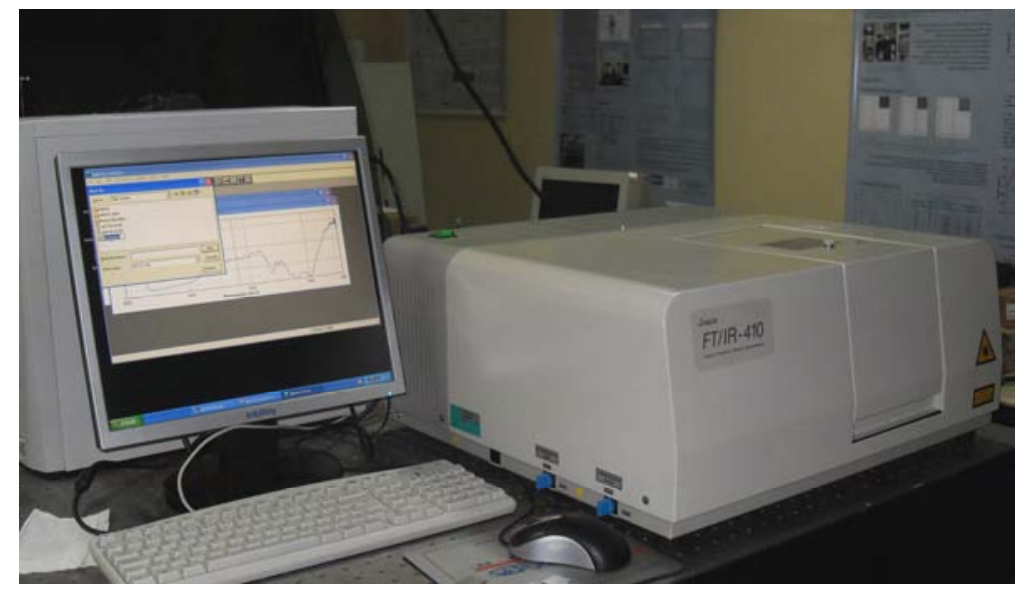

Figura 30 - Espectrômetro de Absorção no Infravermelho por Transformada de Fourier Jasco FTIR-410.

\subsubsection{Microscopia Eletrônica de Varredura}

Para a obtenção das micrografias foi utilizado detector de elétrons retroespalhados e energia do feixe de elétrons igual a $20.000 \mathrm{kV}$. Para tal, foi utilizado o microscópio eletrônico de varredura: Quanta Inspect S - FEI Company do Laboratório Metalúrgico - Engenharia de Materiais da empresa Schaeffler Brasil Ltda-Divisão INA.

\subsubsection{Espessura}

Para medição das espessuras dos filmes produzidos, foram utilizados os métodos da perfilometria, através da formação de um degrau entre a superfície e o filme e o método de correntes parasitas. 


\subsubsection{Perfilometria}

Para formar o degrau para medição da espessura entre os filmes depositados e a superfície do material, aplicou-se uma máscara com fita de Kapton (5413, 3M) em parte da superfície da amostra. Após o tratamento, a fita adesiva foi removida e, com isso, formou-se um degrau entre a região protegida e a região exposta ao plasma.

As medidas de espessura foram realizadas com o perfilômetro Veeco, Dektak 150, Figura 31, no Laboratório de Plasmas Tecnológicos, LaPTec, da UNESP de Sorocaba. Este equipamento possui a capacidade de medir espessuras de até $100 \AA$.

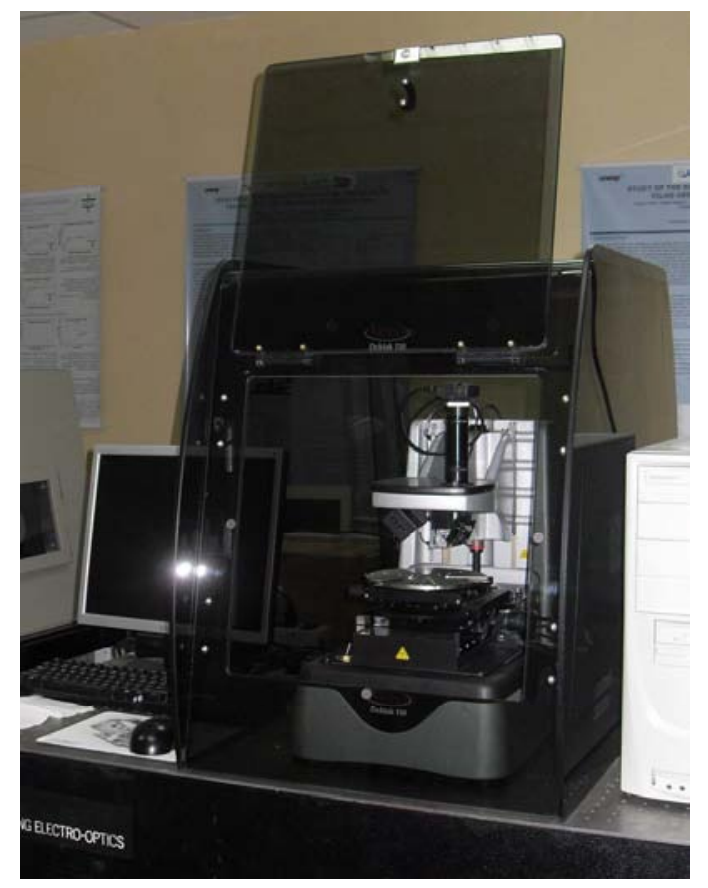

Figura 31 - Perfilômetro Veeco, Dektak 150. 
Para cada amostra foram realizadas dez medições de espessura em diferentes regiões do degrau, sendo o resultado apresentado a média aritmética destes valores acompanhado de seus respectivos desvios padrão.

\subsubsection{2.- Medição por Correntes Parasitas}

$\mathrm{Na}$ aplicação desta técnica foi utilizado um aparelho capaz de medir a espessura de camadas não condutoras, através da produção de correntes parasitas no metal-base. A Figura 32 ilustra o aparelho Isoscope utilizado para medição de espessura de camada anódica em ligas de alumínio. A sonda do instrumento de medição gera um campo eletromagnético de alta freqüência, produzindo correntes parasitas no metalbase, cuja amplitude e fase são funções da espessura da camada não condutora presente entre o metal-base e a sonda.

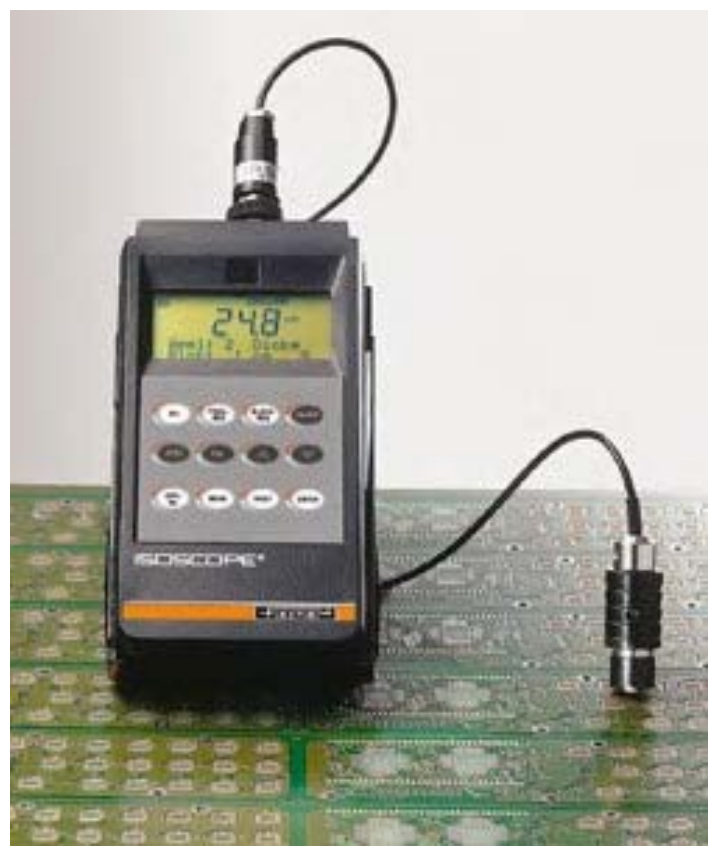

Figura 32 - Medidor de camadas não-ferrosas. ISOSCOPE (marca Fischer). 
As medições foram realizadas no departamento de engenharia da anodização da Companhia Brasileira de Alumínio, segmento metais do grupo Votorantim.

\section{RESULTADOS E DISCUSSÕES}

\subsection{Ensaios}

Conforme estudado por Yerokhin e outros pesquisadores [7] e também observado durante os tratamentos realizados neste trabalho, em baixas tensões a corrente aumenta linearmente conforme as Leis de Faraday. O processo tem então características de uma eletrólise convencional. A partir de certo valor de tensão, a corrente passa a sofrer oscilações no decorrer do tempo [7].

Nos tratamentos realizados neste trabalho, a centelha de ignição é observada através do aparecimento de uma luminescência na amostra disposta no anodo, mergulhada na solução. De acordo com Yerokhim [7], os valores nos quais normalmente esta condição é observada estão entre 40 a $80 \mathrm{~V}$. Neste trabalho, o aparecimento da luminescência foi observado em valores de tensão em torno de $75 \mathrm{~V}$. A Figura 33 apresenta fotos de amostras sendo expostas ao plasma com tensão aplicada de 75 Volts. As fotos foram obtidas em condições de pouca luminosidade para que fosse possível identificar o aparecimento da luminescência. 

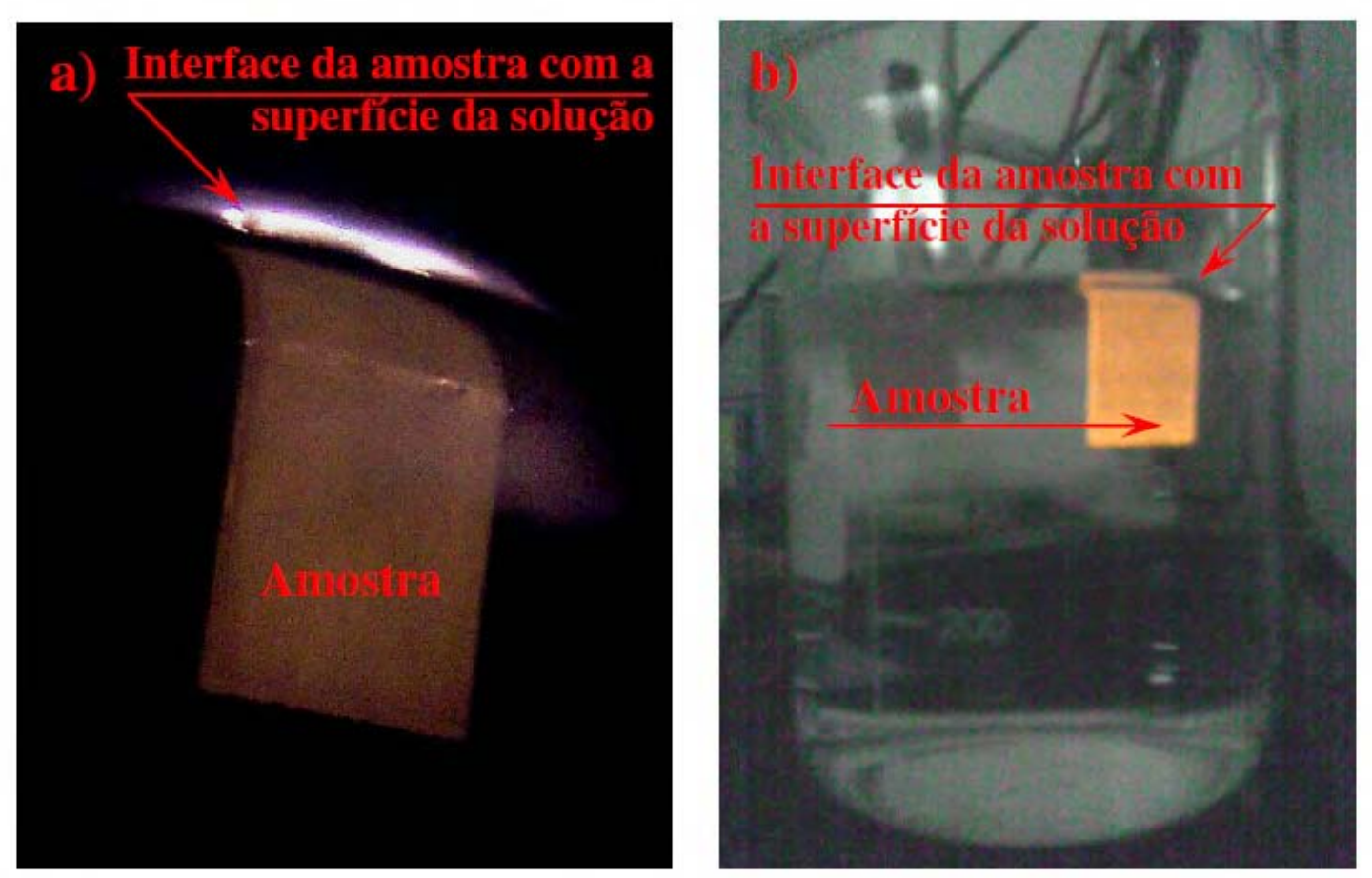

Figura 33 - Foto de uma amostra exposta ao PEO com 75 V.

Para se verificar a variação da corrente elétrica em função do aumento da tensão, foram realizados dois experimentos nos quais a tensão aplicada aumentava gradativamente com o tempo. Os valores desta variação para ambos os ensaios foram capturados através de uma câmera digital Sansung L100. No primeiro ensaio, realizado em um tempo total de 30 segundos, a tensão teve seus valores aumentados variando de 0 a cerca de 200 V. Já no segundo ensaio, com um tempo total de 80 segundos, a tensão foi variada de 0 a $300 \mathrm{~V}$, que é praticamente o limite do equipamento disponível no laboratório. Os valores das variações da corrente elétrica nos eletrodos, na medida em que se aumentava o potencial elétrico, foram compilados para apresentação em forma gráfica com intervalos variando a cada segundo. As Figuras 33 e 34 apresentam os resultados destas variações. 


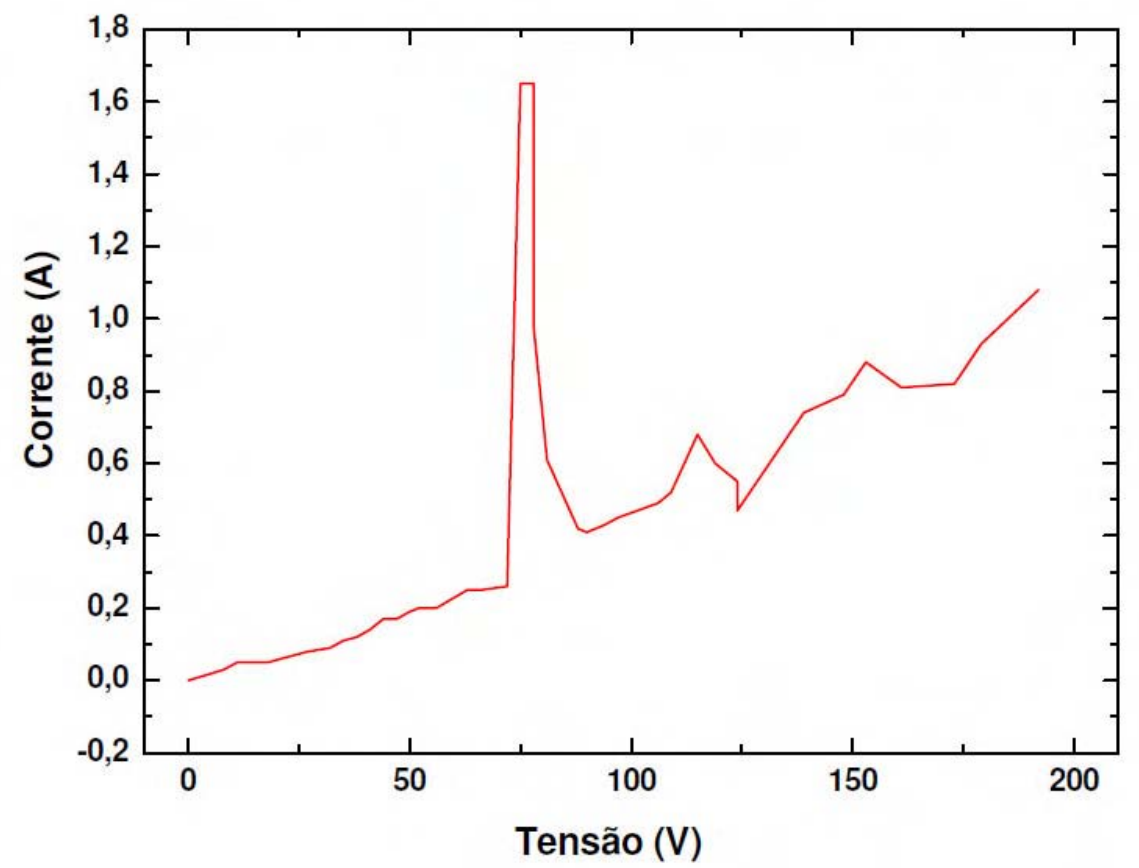

Figura 34 - Variação da corrente elétrica em função da tensão aplicada na célula. De 0 a $200 \mathrm{~V}$ em 30s.

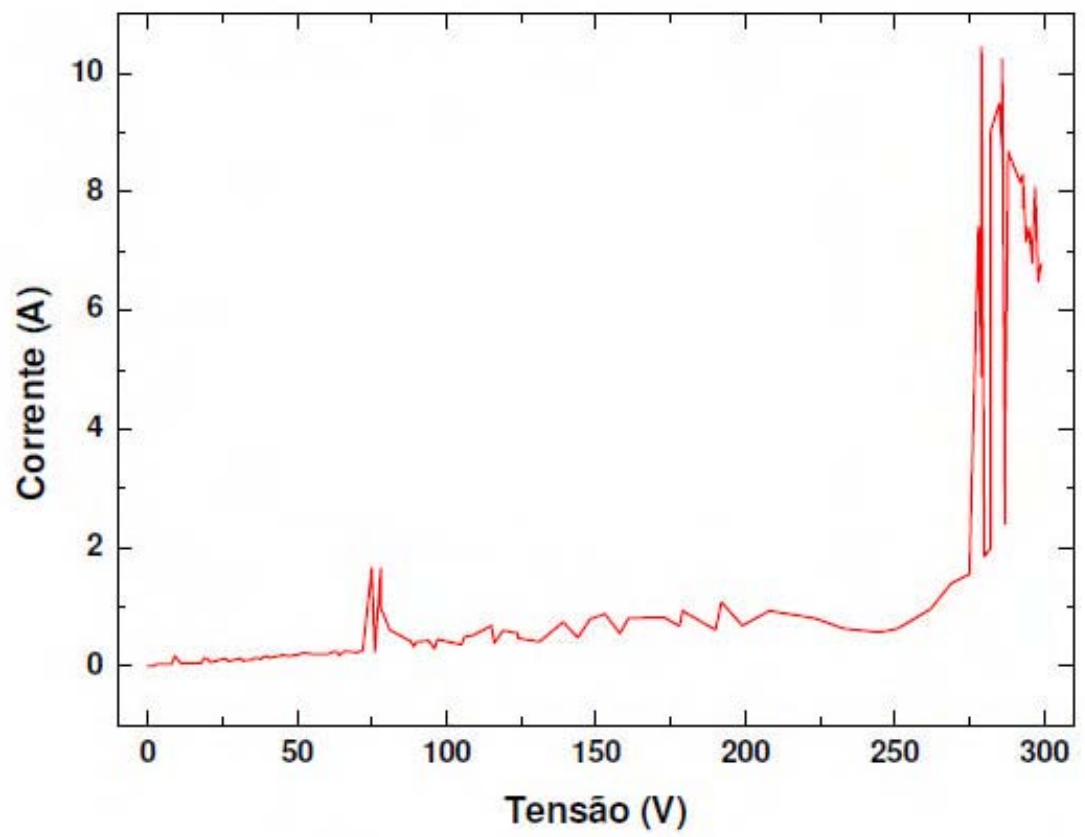

Figura 35 - Variação da corrente elétrica em função da tensão aplicada na célula. De 0 a $300 \mathrm{~V}$ em 80 s. 
Para investigar o efeito das alterações superficiais provocadas nas amostras de alumínio expostas ao PEO, foram executadas 5 séries amostrais compostas de 7 amostras cada série. As amostras foram tratadas pela imersão em uma solução eletrolítica de silicato de sódio $\left(\mathrm{Na}_{2} \mathrm{SiO}_{3}\right)$ a uma concentração de $20 \mathrm{~g} / \mathrm{L}$ e exposição ao processo de eletrólise. Em cada série, as amostras foram tratadas em diferentes faixas de tensão para que fosse possível identificar a que faixa o processo deixa de se comportar como eletrólise convencional e passa a ter as características de processamento a plasma, mais particularmente do PEO.

As faixas de tensão aplicadas foram de 50, 100, 150, 200, 250, 275 e $300 \mathrm{~V}$ durante um tempo de $900 \mathrm{~s}$ e densidade média de corrente conforme apresentado na Tabela 4. O valor nominal da tensão foi atingido pelo aumento gradual da tensão em um tempo máximo de $30 \mathrm{~s} \mathrm{e}$, a partir de então, a amostra ficou exposta ao tratamento.

Tabela 4 - Densidades médias de corrente $\left(\mathrm{A} / \mathrm{cm}^{2}\right)$ para as diversas tensões aplicadas.

\begin{tabular}{|c|c|c|c|c|c|c|c|}
\hline \multirow{2}{*}{$\begin{array}{c}\text { Série } \\
\text { Amostral }\end{array}$} & \multicolumn{7}{|c|}{ Tensão Nominal de Ensaio (V) } \\
\cline { 2 - 8 } & $\mathbf{5 0}$ & $\mathbf{1 0 0}$ & $\mathbf{1 5 0}$ & $\mathbf{2 0 0}$ & $\mathbf{2 5 0}$ & $\mathbf{2 7 5}$ & $\mathbf{3 0 0}$ \\
\hline $\mathbf{1}$ & 0,044 & 0,091 & 0,062 & 0,188 & 0,201 & 0,391 & 0,436 \\
\hline $\mathbf{2}$ & 0,022 & 0,027 & 0,069 & 0,086 & 0,242 & 0,287 & 0,464 \\
\hline $\mathbf{3}$ & 0,072 & 0,059 & 0,120 & 0,201 & 0,336 & 0,298 & 0,554 \\
\hline $\mathbf{4}$ & 0,051 & 0,074 & 0,088 & 0,158 & 0,291 & 0,367 & 0,524 \\
\hline $\mathbf{5}$ & 0,062 & 0,103 & 0,160 & 0,149 & 0,244 & 0,361 & 0,443 \\
\hline Média: & $\mathbf{0 , 0 5 0}$ & $\mathbf{0 , 0 7 1}$ & $\mathbf{0 , 1 0 0}$ & $\mathbf{0 , 1 5 6}$ & $\mathbf{0 , 2 6 3}$ & $\mathbf{0 , 3 4 1}$ & $\mathbf{0 , 4 8 4}$ \\
\hline
\end{tabular}

A variação da densidade de corrente nas amostras expostas ao PEO durante o tratamento de pode ser vista na Figura 36. 


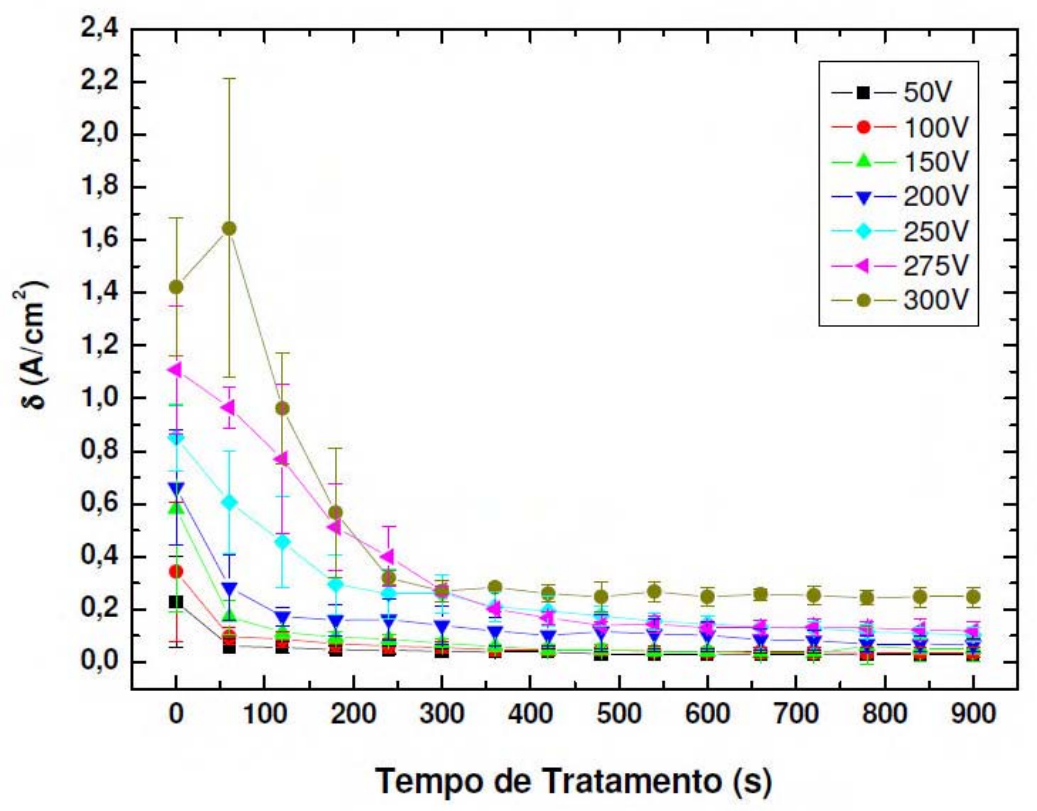

Figura 36 - Variação da densidade de corrente $(\delta)$ em função do tempo de tratamento em amostras expostas ao PEO por 900s.

A variação do potencial aplicado durante o tempo de tratamento pode ser vista na Figura 37.

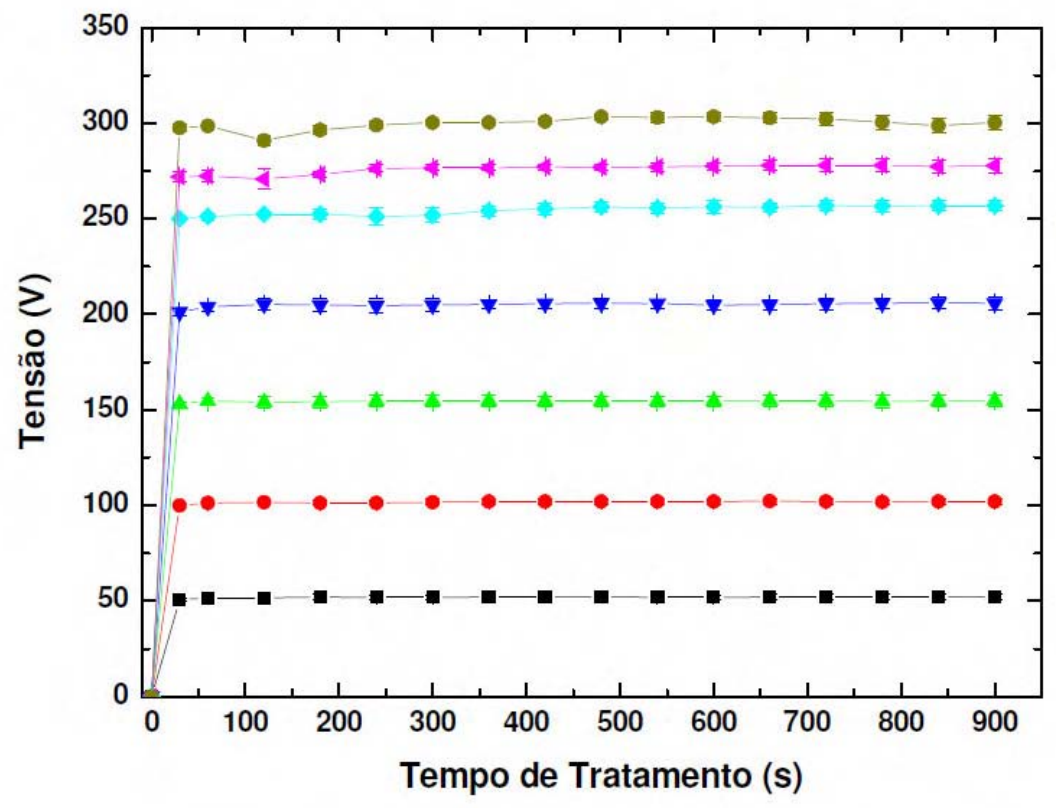

Figura 37 - Variação da tensão (V) em função do tempo de tratamento em amostras expostas ao PEO por 900s. 
O processamento realizado na eletrólise convencional, a baixas voltagens é acompanhado por um grande número de processos no eletrodo, em particular a liberação de gases e a oxidação do metal na superfície anódica [7]. Entretanto, uma característica que pode ser facilmente observada na transição do processamento realizado na eletrólise convencional para o processamento a plasma é o aparecimento da luminescência característica na superfície da amostra, conforme descrito por diversos pesquisadores $[7,8,9,11,18,19,20,22]$.

A partir de um determinado valor de tensão, neste estudo a cerca de $190 \mathrm{~V}$, foram observadas centelhas no processo que são como luzes brancas e uniformes que envolvem todo o eletrodo (amostra). Sequencialmente, estas luzes iam mudando sua cor para uma série de centelhas amarelas separadas e que se moviam rapidamente por toda a superfície da amostra. Estas luzes observadas em tratamentos PEO são denominadas por Sundararajan [48] e outros pesquisadores como micro-arcos, mais particularmente micro-arcos de oxidação (MAO), ou oxidação de micro-plasma. Os micro-arcos observados durante os tratamentos realizados neste trabalho podem ser vistos na Figura 38.

No sistema de processamento PEO, a corrente elétrica que flui através da solução eletrolítica é afetada pelas características elétricas da solução. Isto pode ser exemplificado através do circuito equivalente apresentado na Figura 14, onde $R e$ representa a resistência equivalente entre eletrodos e $R p$ e $C d c$ representam, respectivamente, a resistência e a capacitância do filme de óxido [43]. A voltagem é escolhida para manter a centelha de descarga no substrato. 
A variação da temperatura da solução eletrolítica observada durante o tratamento dos substratos em função do tempo de tratamento para as tensões investigadas pode ser observada na Figura 39.
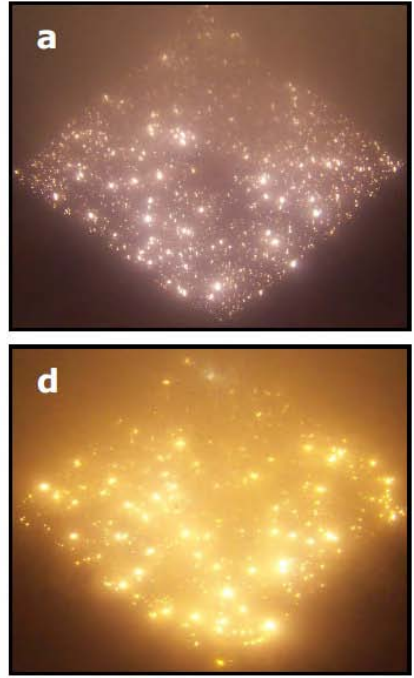
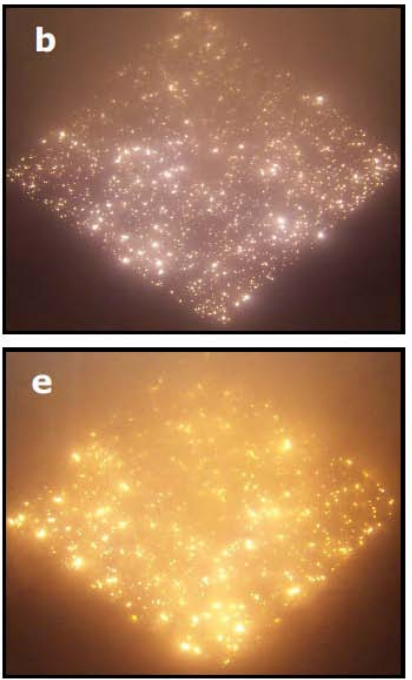
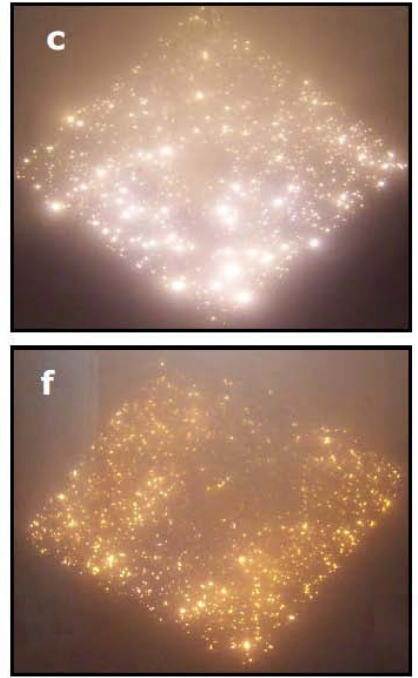

Figura 38 - Micro-arcos observados nas amostras durante o tratamento a plasma com tensões de a) $200 \mathrm{~V}$, b) $225 \mathrm{~V}$, c) $250 \mathrm{~V}$, d) $270 \mathrm{~V}$, e) $280 \mathrm{~V}$ e f) $300 \mathrm{~V}$.

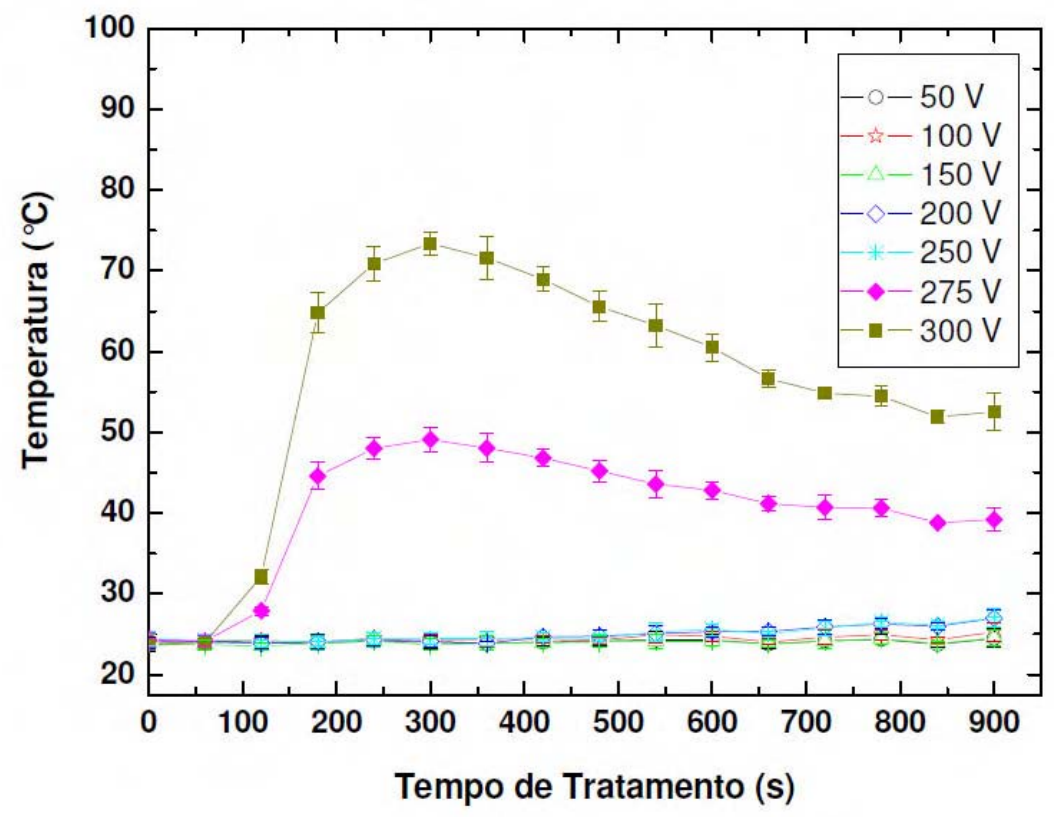

Figura 39 - Variação da temperatura em função do tempo de tratamento. 
Observa-se que a variação da temperatura para tensões de tratamento de até 250 V não ultrapassa $30{ }^{\circ} \mathrm{C}$. Para tensões superiores ocorre um aumento significativo na temperatura, chegando a valores em torno de $75{ }^{\circ} \mathrm{C}$ para a tensão de $300 \mathrm{~V}$. Muito embora a temperatura de tratamento tenha aumentado para tensões maiores que $200 \mathrm{~V}$, de acordo com Nie [48, 49], o Plasma Eletrolítico de Oxidação (PEO) é uma técnica de que pode ser usada para fabricar filmes de óxido em substratos de alumínio admitindo temperaturas de tratamento de até $100{ }^{\circ} \mathrm{C}$. Desta forma consideramos que a variação de temperatura observada em todos os tratamentos realizados estava adequada ao processo.

A oxidação de micro-arcos é uma inovação da técnica tradicional de oxidação anódica (anodização). Com este método, podem ser formadas camadas cerâmicas compactas na superfície de ligas de alumínio [51]. A Figura 40, obtida através de microscopia eletrônica, ilustra um filme anódico formado em um substrato de alumínio através do processo de oxidação de micro-arcos.

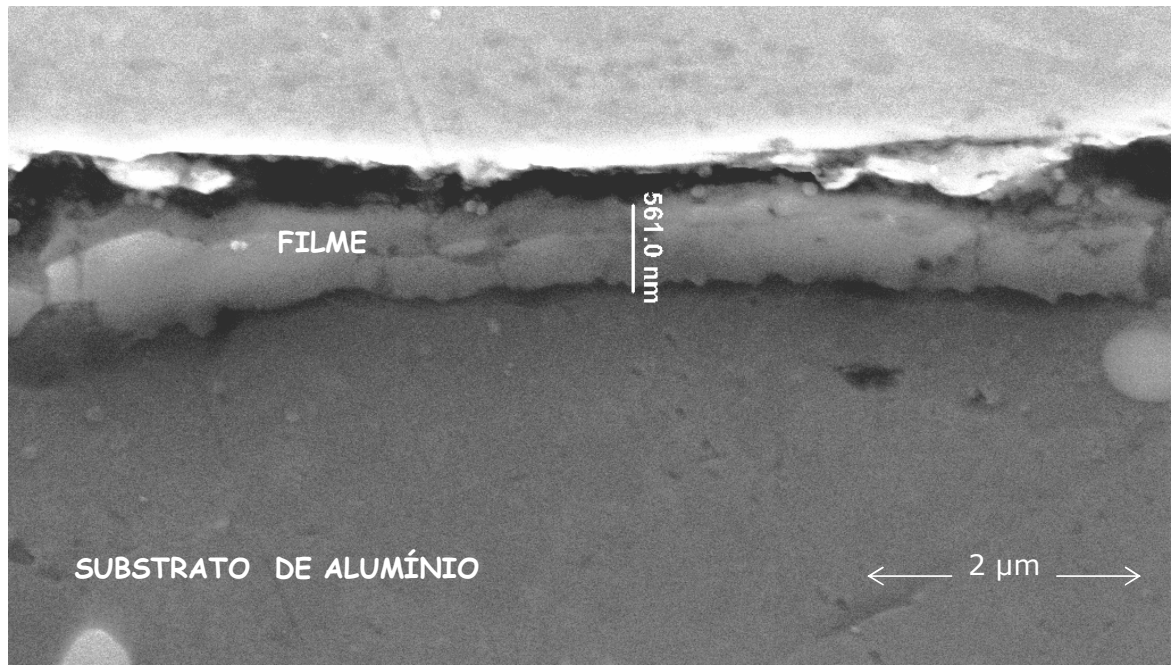

Figura 40 - Filme formado em um substrato de alumínio através do processo PEO. 


\subsection{Caracterização da camada superficial}

\subsection{1. Ângulo de contato e Energia de Superfície}

$\mathrm{Na}$ caracterização preliminar do filme produzido sobre o substrato de alumínio, adotou-se uma série amostral composta das amostras A1 a A7. Através da análise destas amostras, investigou-se se houve alteração no valor do ângulo de contato do material após a exposição ao PEO. Através de medições realizadas nas amostras antes do tratamento e posteriormente tratadas a plasma, foram verificadas as principais alterações ocorridas. Os resultados do ângulo de contato obtidos nas amostras sem tratamento, bem como nas amostras tratadas em diferentes tensões são apresentados na Figura 41.

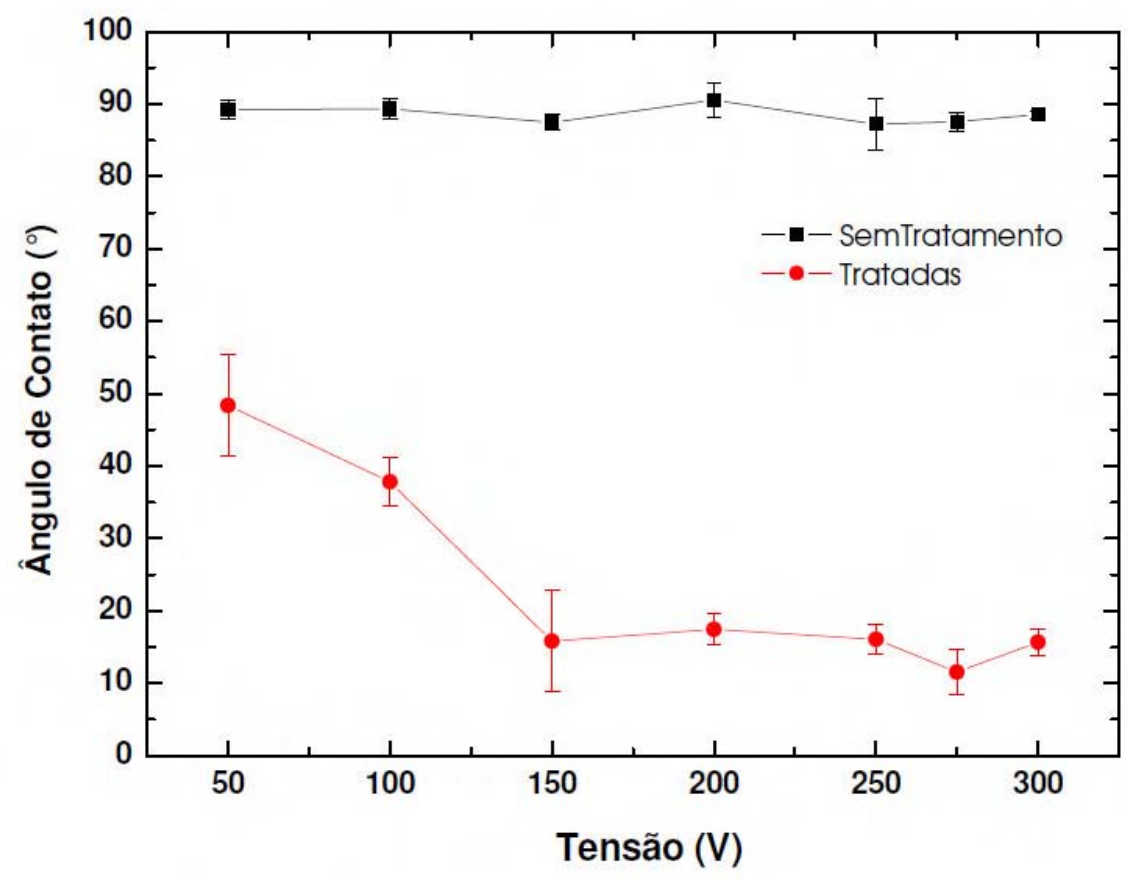

Figura 41 - Variação do ângulo de contato de amostras sem tratamento e tratadas 
Cada medição foi realizada através da aplicação de três gotas de água sobre a superfície. É importante que a água utilizada esteja livre de íons adicionais e assim, nessas medidas utilizou-se água deionizada. Para cada gota, e ajustando-se o programa, foram realizadas 10 medições de ângulo de contado, totalizando 30 medições amostrais. Através do cálculo da média dessas 30 leituras, cada amostra nos dá um ponto no gráfico.

Como pode ser notado na Figura 41, o ângulo de contato diminui à medida que a tensão de tratamento aplicada aumenta, entretanto, mesmo para o menor valor de tensão utilizado, $50 \mathrm{~V}$, houve uma diminuição do ângulo de contato em torno de $54 \%$, em relação à mesma amostra, antes do tratamento.

A molhabilidade de uma superfície está relacionada ao balanço das forças eletrostáticas entre moléculas do líquido e da superfície. Quando grupos polares como, por exemplo, $\mathrm{C}-\mathrm{O}, \mathrm{C}=\mathrm{O},(\mathrm{C}=\mathrm{O})-\mathrm{O}$, estão presentes na superfície e o líquido usado também é polar, como a água, prevalece a atração eletrostática.

As variações ocorridas no ângulo de contato com o passar do tempo (envelhecimento), foram investigadas em cada amostra em diversos momentos diferentes. Adotou-se, um tempo médio de 25 dias de intervalo para a realização de cada medição. $\mathrm{O}$ que pode ser verificado através da Figura 42 é que à medida que o filme envelhece ocorre um aumento no ângulo de contato. Este aumento é mais significativo em amostras tratadas com tensões até $100 \mathrm{~V}$, onde praticamente o substrato volta a apresentar as características superficiais naturais, observadas antes do tratamento. Para tensões maiores, embora também ocorra um sensível aumento no valor do ângulo de contato, o substrato mantém valores menores que $40^{\circ}$, levando a conclusão que o filme depositado é seguramente hidrofílico. 


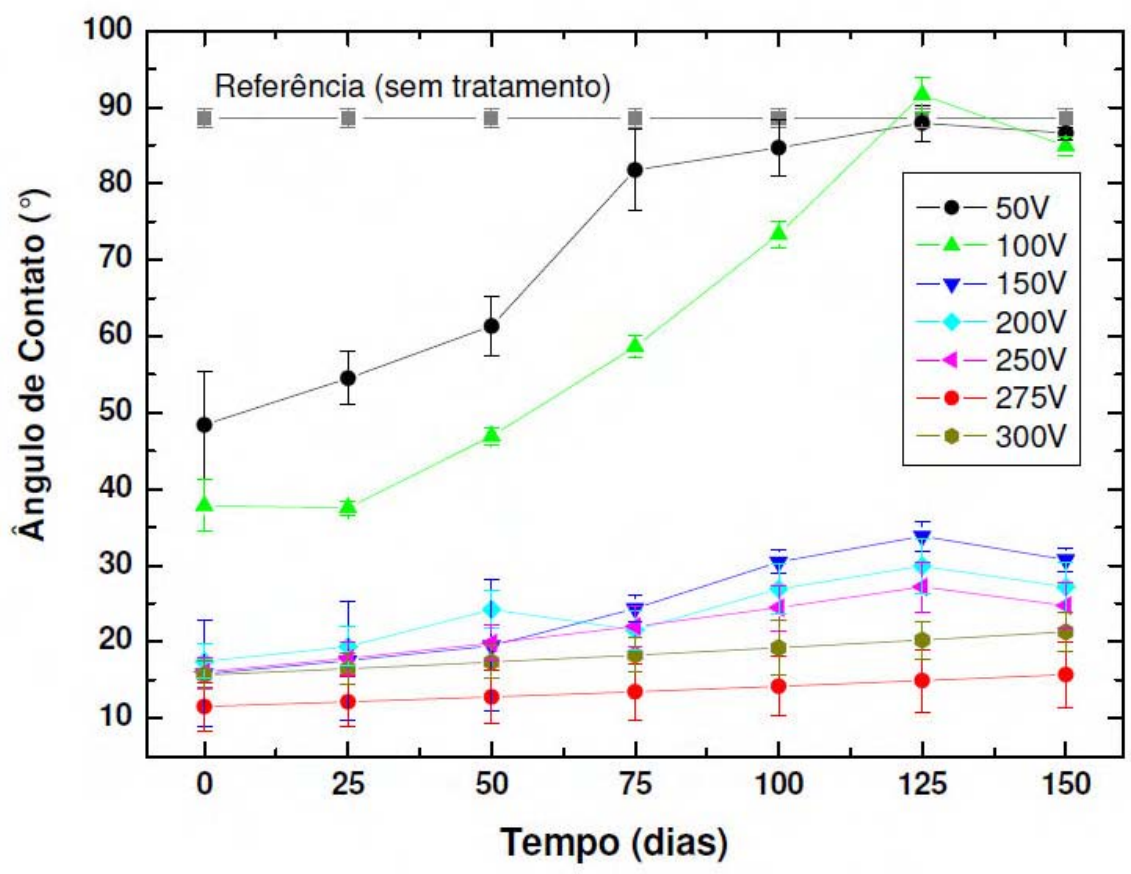

Figura 42 - Variação do ângulo de contato em função do tempo de envelhecimento, em dias.

A Figura 43 apresenta a variação das componentes de energia polar, EP e dispersiva, ED e da energia de superfície, calculada a partir da média geométrica destas componentes, em função da tensão de tratamento das amostras submetidas ao plasma. $\mathrm{O}$ maior valor de $\operatorname{ED}(33,39$ Dyn $\mathrm{cm})$ foi obtido para amostras tratadas a $200 \mathrm{~V}$, sugerindo que a molhabilidade para líquidos apolares é maior neste caso. O menor e o maior valor (1,61 e 6,51 Dyn cm) da componente EP foram obtidos para filmes depositados com tensões nominais de 200 e $300 \mathrm{~V}$, respectivamente. 


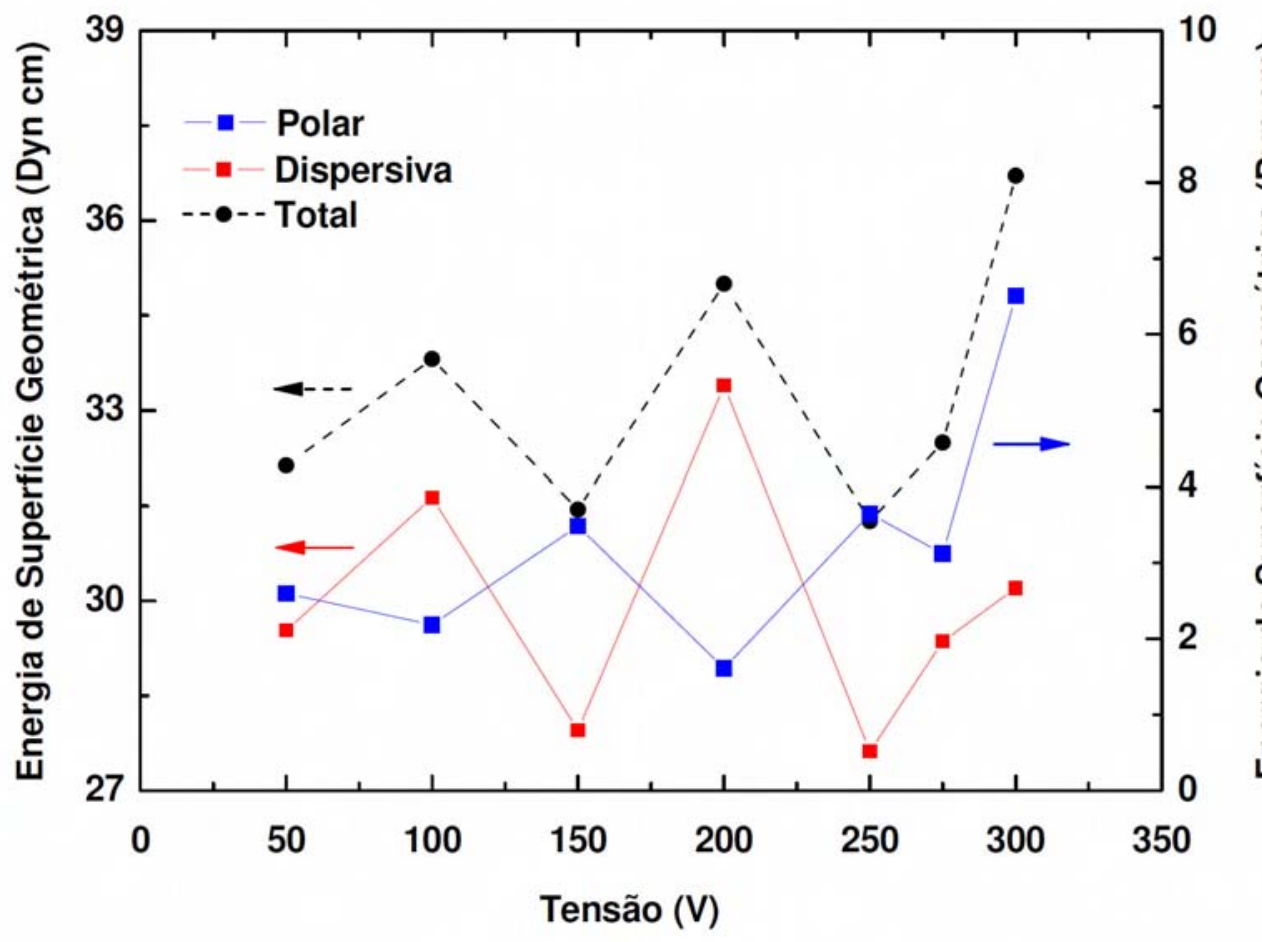

Figura 43 - Energia de superfície e suas componentes para filmes depositados sobre substratos de alumínio em função da tensão de tratamento aplicada.

\subsubsection{Rugosidade Superficial do Filme}

A variação da rugosidade superficial que o filme conferiu às amostras, investigada por perfilometria, foi avaliada através de 10 medições no sentido longitudinal e 10 medições no sentido vertical de cada amostra tratada para cada faixa de tensão aplicada. Os valores apresentados na Figura 44 referem-se aos resultados, em mícron, das médias aritméticas e seus respectivos desvios padrão obtidos em cada amostra. 


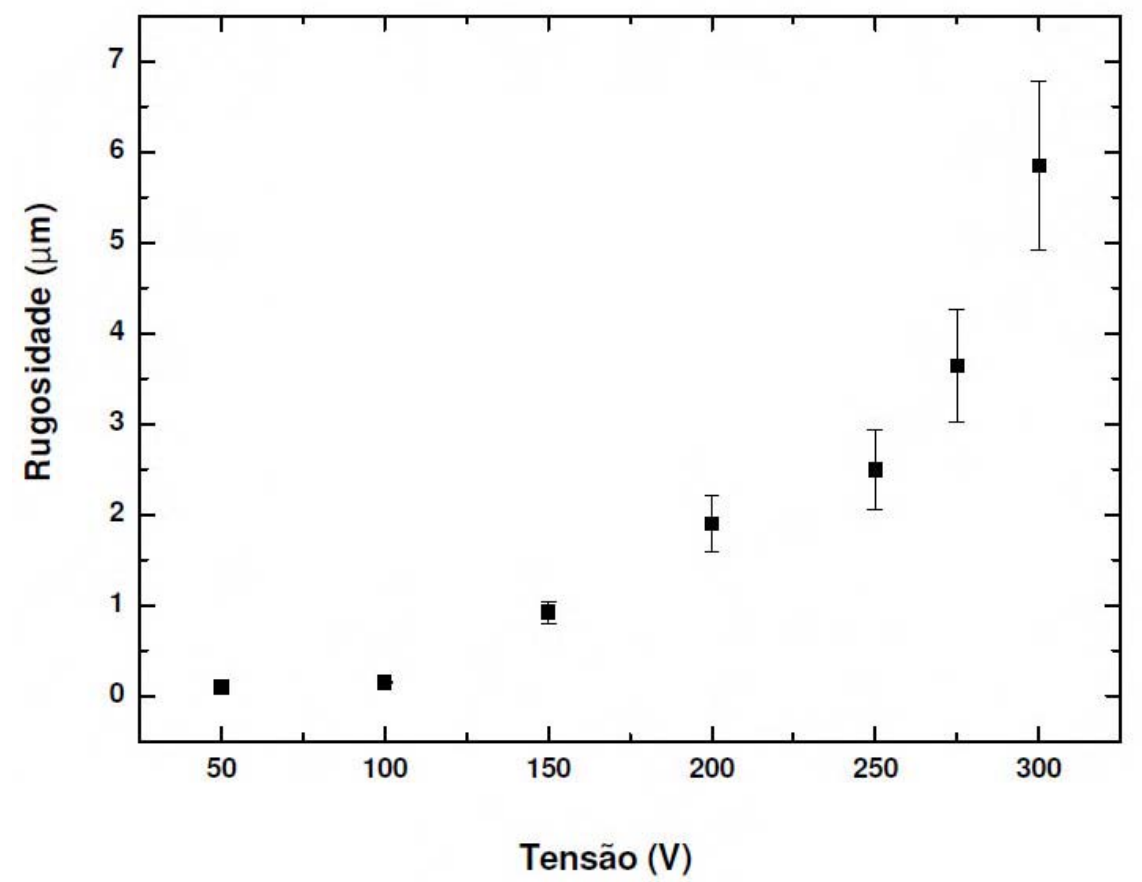

Figura 44 - Variação da rugosidade superficial das amostras tratadas em diferentes faixas de tensão.

Os valores apresentados na Figura 44 sugerem que a rugosidade superficial do filme formado no substrato de alumínio aumenta continuamente com a diferença de potencial utilizada no tratamento.

\subsubsection{Espessura}

Com o perfilômetro, foram realizadas 10 medições do degrau formado entre filme e o substrato, em cada amostra ensaiada nas diferentes tensões de tratamento.

O comprimento de varredura adotado foi de $300 \mu \mathrm{m}$ e os valores encontrados nas medições estão apresentados na Tabela 5.

A medição das espessuras dos filmes produzidos nos substratos de alumínio também foi determinada pelo método das correntes parasitas. As espessuras foram medidas com o uso do equipamento medidor de camadas não-ferrosas. Isoscope MP2 na 
Companhia Brasileira de Alumínio. Assim como na perfilometria, em cada amostra foram executadas 10 medições e os valores encontrados são apresentados na Tabela 6.

Tabela 5 - Espessuras dos filmes formados nas amostras tratadas em diferentes voltagens, medidas por perfilometria, sendo: Amostra 1: $50 \mathrm{~V}$, Amostra 2: $100 \mathrm{~V}$, Amostra 3: $150 \mathrm{~V}$, Amostra 4: $200 \mathrm{~V}$, Amostra 5: 250 V, Amostra 6: $275 \mathrm{~V}$ e Amostra 7: $300 \mathrm{~V}$.

\begin{tabular}{|c|c|c|c|c|c|c|c|}
\hline \multirow{2}{*}{ Medição } & \multicolumn{7}{|c|}{ Espessura do Filme $(\boldsymbol{\mu m})$} \\
\cline { 2 - 8 } & $\mathbf{5 0} \mathbf{~ V}$ & $\mathbf{1 0 0} \mathbf{~}$ & $\mathbf{1 5 0} \mathbf{V}$ & $\mathbf{2 0 0} \mathbf{V}$ & $\mathbf{2 5 0} \mathbf{V}$ & $\mathbf{2 7 5} \mathbf{~ V}$ & $\mathbf{3 0 0} \mathbf{~}$ \\
\hline $\mathbf{1}$ & 0,035 & 0,506 & 0,616 & 3,650 & 8,300 & 8,121 & 7,943 \\
\hline $\mathbf{2}$ & 0,044 & 0,387 & 0,760 & 4,018 & 6,762 & 7,077 & 7,392 \\
\hline $\mathbf{3}$ & 0,055 & 0,574 & 0,570 & 4,050 & 5,934 & 6,452 & 6,970 \\
\hline $\mathbf{4}$ & 0,040 & 0,576 & 0,480 & 2,555 & 5,754 & 5,841 & 5,928 \\
\hline $\mathbf{5}$ & 0,067 & 0,624 & 0,882 & 3,159 & 5,670 & 5,992 & 6,314 \\
\hline $\mathbf{6}$ & 0,058 & 0,585 & 0,756 & 2,835 & 7,144 & 6,990 & 6,837 \\
\hline $\mathbf{7}$ & 0,039 & 0,779 & 0,880 & 2,842 & 6,900 & 7,130 & 7,360 \\
\hline $\mathbf{8}$ & 0,074 & 0,559 & 0,779 & 2,613 & 6,160 & 6,524 & 6,888 \\
\hline $\mathbf{9}$ & 0,058 & 0,333 & 0,663 & 3,036 & 6,512 & 6,597 & 6,683 \\
\hline $\mathbf{1 0}$ & 0,048 & 0,280 & 0,663 & 3,431 & 6,480 & 6,705 & 6,930 \\
\hline Média: & $\mathbf{0 , 0 5 2}$ & $\mathbf{0 , 5 2 0}$ & $\mathbf{0 , 7 0 5}$ & $\mathbf{3 , 2 1 9}$ & $\mathbf{6 , 5 6 2}$ & $\mathbf{6 , 7 4 3}$ & $\mathbf{6 , 9 2 4}$ \\
\hline
\end{tabular}

Tabela 6 - Espessuras dos filmes formados nas amostras tratadas em diferentes voltagens, medidas pelo método de correntes parasitas, sendo: Amostra 1: $50 \mathrm{~V}$, Amostra 2: $100 \mathrm{~V}$, Amostra 3: 150 V, Amostra 4: $200 \mathrm{~V}$, Amostra 5: $250 \mathrm{~V}$, Amostra 6: $275 \mathrm{~V}$ e Amostra 7: $300 \mathrm{~V}$.

\begin{tabular}{|c|c|c|c|c|c|c|c|}
\hline \multirow{2}{*}{ Medição } & \multicolumn{7}{|c|}{ Espessura do Filme $(\boldsymbol{\mu m})$} \\
\cline { 2 - 8 } & $\mathbf{5 0} \mathbf{~ V}$ & $\mathbf{1 0 0} \mathbf{~ V}$ & $\mathbf{1 5 0} \mathbf{V}$ & $\mathbf{2 0 0} \mathbf{V}$ & $\mathbf{2 5 0} \mathbf{~ V}$ & $\mathbf{2 7 5} \mathbf{~ V}$ & $\mathbf{3 0 0} \mathbf{~}$ \\
\hline $\mathbf{1}$ & 0,0 & 1,1 & 1,4 & 7,3 & 16,6 & 30,7 & 16,9 \\
\hline $\mathbf{2}$ & 0,1 & 0,9 & 1,9 & 8,2 & 14,7 & 25,2 & 16,8 \\
\hline $\mathbf{3}$ & 0,1 & 1,4 & 1,5 & 9,0 & 13,8 & 22,6 & 17,0 \\
\hline $\mathbf{4}$ & 0,0 & 1,6 & 1,2 & 7,3 & 13,7 & 24,0 & 15,2 \\
\hline $\mathbf{5}$ & 0,1 & 1,3 & 2,1 & 8,1 & 12,6 & 20,6 & 15,4 \\
\hline $\mathbf{6}$ & 0,1 & 1,5 & 1,8 & 6,3 & 15,2 & 27,5 & 15,9 \\
\hline $\mathbf{7}$ & 0,0 & 1,9 & 2,0 & 5,8 & 13,8 & 23,4 & 16,0 \\
\hline $\mathbf{8}$ & 0,1 & 1,3 & 1,9 & 6,7 & 14,0 & 23,4 & 16,8 \\
\hline $\mathbf{9}$ & 0,1 & 0,9 & 1,7 & 6,9 & 14,8 & 26,2 & 16,3 \\
\hline $\mathbf{1 0}$ & 0,1 & 0,8 & 1,7 & 7,3 & 14,4 & 24,6 & 16,5 \\
\hline Média: & $\mathbf{0 , 0 7}$ & $\mathbf{1 , 2 7}$ & $\mathbf{1 , 7 2}$ & $\mathbf{7 , 2 9}$ & $\mathbf{1 4 , 3 6}$ & $\mathbf{2 4 , 8 2}$ & $\mathbf{1 6 , 2 8}$ \\
\hline
\end{tabular}


Os valores médios encontrados nos dois métodos, bem como seus desviospadrão são apresentados na Figura 45.

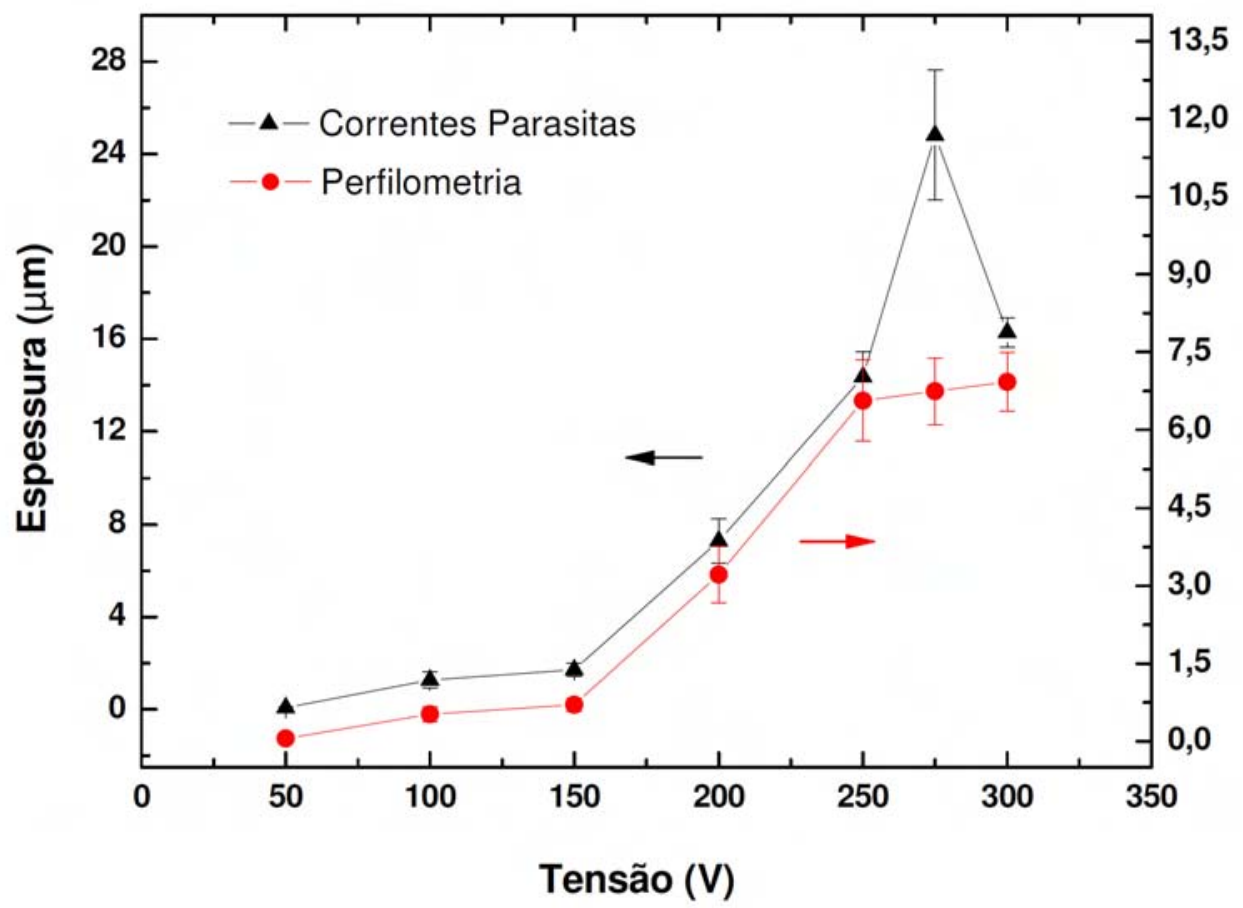

Figura 45 - Variação da espessura dos filmes em função da tensão de tratamento utilizada.

De acordo com os valores apresentados na Figura 45, pode-se dizer que existe uma tendência de aumento da espessura do revestimento com a tensão de tratamento. A partir de $150 \mathrm{~V}$ há um crescimento considerável na espessura do revestimento. De acordo com Yerokhin [7] o aparecimento de micro arcos, observado em torno de $200 \mathrm{~V}$ torna o tratamento mais energético intensificando o processo de formação do revestimento. De acordo com os valores encontrados em ambos os métodos de medição utilizados, conclui-se ainda que os valores apresentados na perfilometria são menores que os apresentados no método das correntes parasitas.

A adoção de um segundo método de verificação da espessura do filme formado no substrato foi proposital, pois se notava que durante o tratamento das 
amostras, devido ao aquecimento da solução eletrolítica nas proximidades do eletrodo e formação dos arcos, a fita de Kapton se desprendia em parte das suas extremidades, conforme esquematizado na Figura $46 \mathrm{~b}$ e não formava um degrau perpendicular à superfície, Figura 46a, conforme esperado.
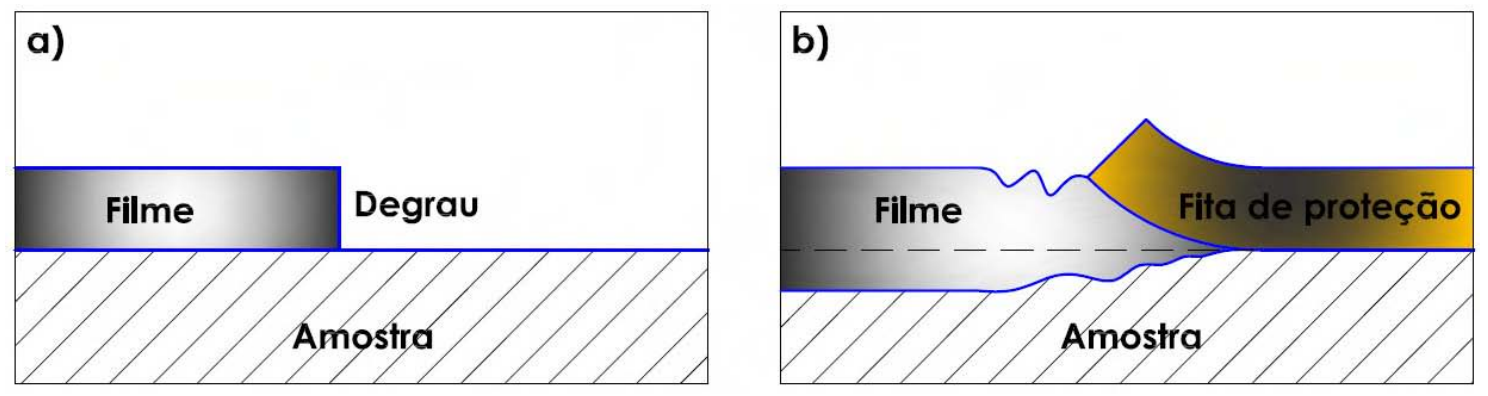

Figura 46 - Formação do degrau para medição de espessura de filmes. a) Degrau perpendicular à superfície da amostra, b) Desprendimento da fita de proteção e má formação do degrau.

Outro fator que levou a adoção de um segundo método para a verificação da espessura do filme formado no substrato foi o fato de que, assim como na oxidação de polarização anódica em eletrólise convencional, onde se tem a formação de filmes com duas camadas sendo uma camada barreira e uma porosa $[36,51]$, no tratamento PEO, o filme formado também apresenta duas regiões distintas, sendo uma região interna mais densa, ou região de barreira e uma camada externa porosa [21, 52].

A observação dos resultados de espessuras obtidos em ambos os métodos e o fato do filme possuir duas camadas indicam que, dentre os métodos adotados, o que melhor caracteriza a espessura dos filmes produzidos é o método das correntes parasitas. A Figura 47, adaptada de [51], ilustra de forma esquemática o crescimento de um filme de alumina em um substrato de alumínio. As partes $a$ e $b$ se referem às camadas parciais que crescem externamente e internamente na superfície do substrato, 
respectivamente. A linha tracejada representa a posição original da superfície da amostra antes do tratamento e a dimensão $h$, a espessura total da camada cerâmica formada no substrato de alumínio.

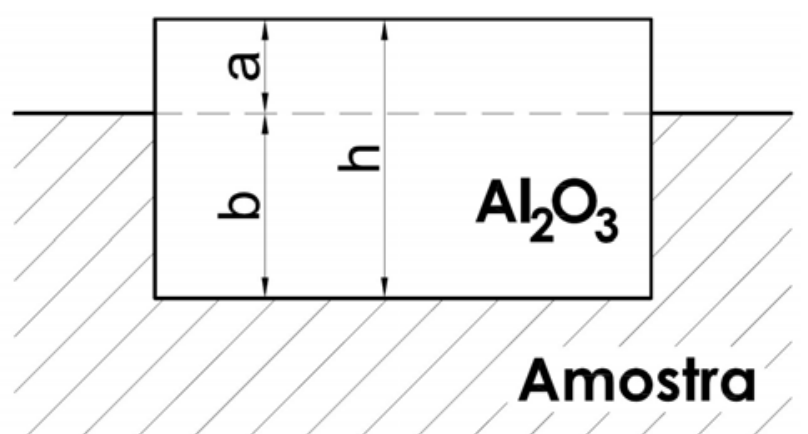

Figura 47 - Representação esquemática do crescimento de um filme em uma amostra tratada em processo de oxidação de micro-arcos. As dimensões $a$ e $b$ representam o crescimento parcial do revestimento para o exterior e interior da amostra, respectivamente e $h$, a dimensão total do filme Adaptado de [50].

\subsubsection{Corrosão}

O ensaio de névoa salina foi realizado de acordo com a norma ASTM B11707a, e foi utilizado para avaliar o desempenho das amostras mediante um ambiente extremamente agressivo de forma acelerada. Todas as amostras são de alumínio, liga 2024.

$\mathrm{O}$ aspecto superficial da amostra sem tratamento (como recebida) e das amostras revestidas pelos filmes depositados a plasma em diferentes tensões de tratamento, antes da exposição à câmara de névoa salina e após a exposição foram acompanhados visualmente e as imagens foram registradas através de fotografias. As imagens apresentadas se referem às amostras com dimensões de $2 \times 2 \mathrm{~cm}$. 
A Figura 48 ilustra o aspecto da amostra sem tratamento antes da exposição à névoa salina e após 6 horas de exposição. Nota-se que a amostra já começa a apresentar pequenos sinais de degradação, entretanto a amostra foi mantida dentro da câmara de névoa salina.
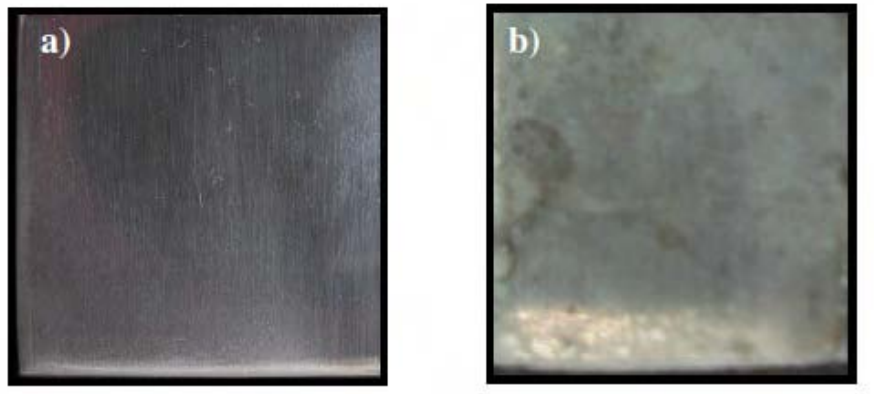

Figura 48 - Imagem da amostra não tratada. a) antes da exposição à névoa salina e b) após 6 h de exposição à névoa salina.

Após 30 h de exposição à nevoa salina, a amostra tratada a plasma com tensão de $50 \mathrm{~V}$ também apresentou pontos de corrosão. A Figura 49 ilustra o aspecto da amostra antes do ensaio e após 30 h de exposição à névoa salina. A amostra também foi mantida dentro da câmara de névoa salina.

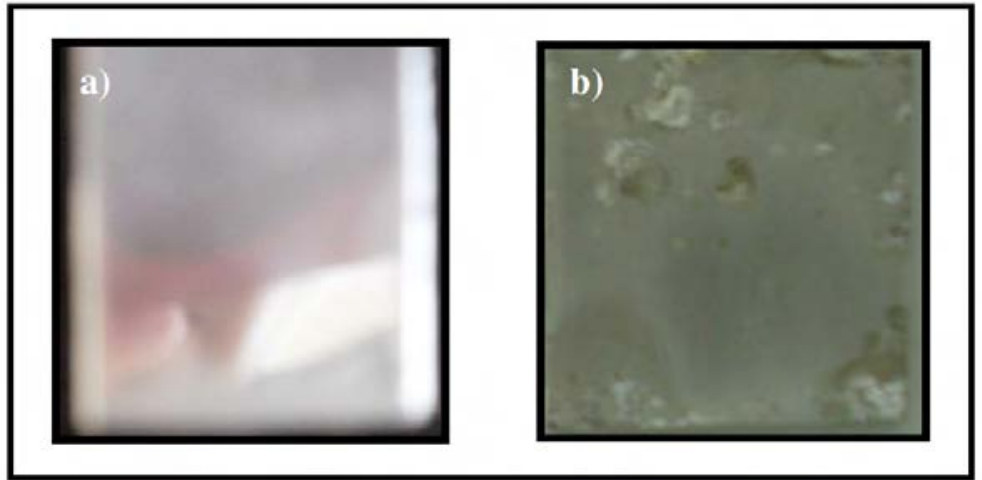

Figura 49 - Imagem da amostra 1 tratada com tensão de 50 V. a) antes da exposição à névoa salina e b) após 30 h de exposição à névoa salina. 
$\mathrm{Na}$ amostra tratada a plasma com tensão de $100 \mathrm{~V}$, notou-se pontos de corrosão após 150 h de exposição à névoa salina. O aspecto da amostra antes e após o tratamento pode ser visto na Figura 50.

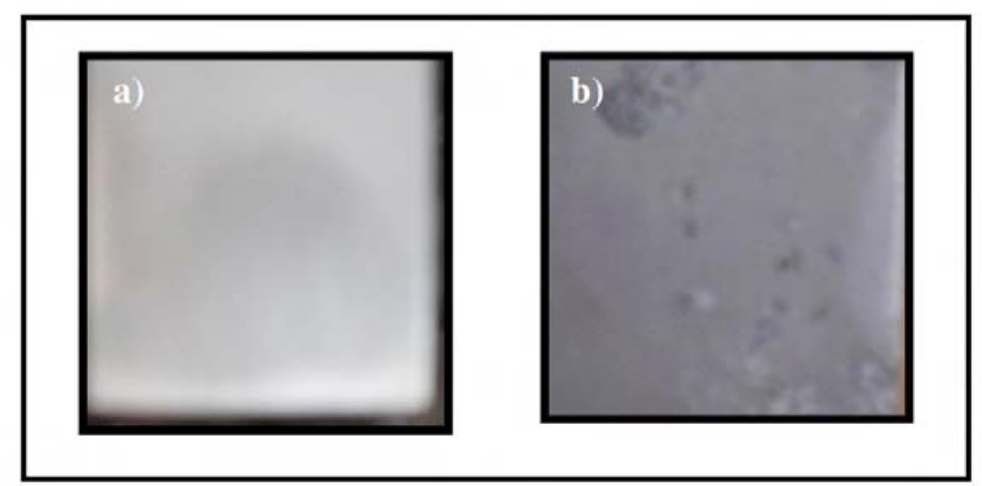

Figura 50 - Imagem da amostra 2 tratada a plasma com tensão de 100 V. a) antes da exposição à névoa salina e b) após 150 h de exposição à névoa salina.

Após 220 horas de exposição à névoa salina, as amostras tratadas a plasma com 50 e $100 \mathrm{~V}$ foram retiradas da câmara de névoa salina, pois já apresentavam pontos expressivos de corrosão. O Aspecto destas amostras após 220 h de tratamento pode ser visto na Figura 51.
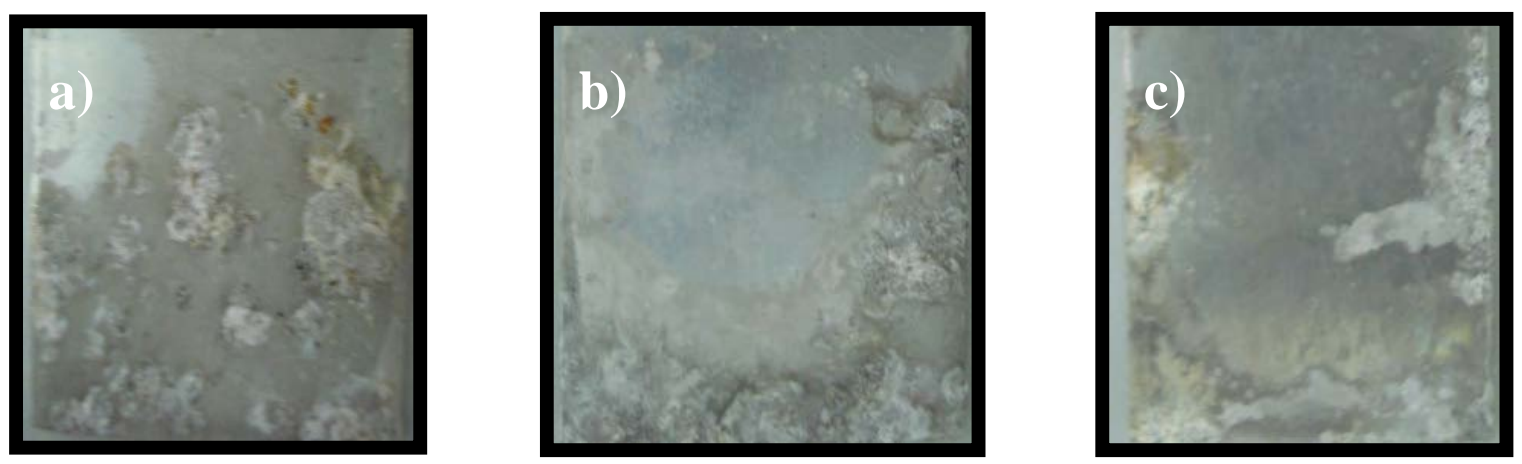

Figura 51 - Imagem das amostras após 220 h de exposição à névoa salina. a) amostra não tratada a plasma. b) amostra 1 tratada a plasma com tensão de 50 V. e c) amostra 2 tratada a plasma com tensão de $100 \mathrm{~V}$. 
A amostra sem tratamento foi mantida na câmara de névoa salina para fins de comparação.

As amostras tratadas a plasma com tensões de 150 e $200 \mathrm{~V}$ apresentaram pequenos sinais de degradação superficial a partir de 220 horas de exposição à névoa salina, entretanto estas amostras foram mantidas na câmara. $\mathrm{O}$ aspecto das amostras antes da exposição e após as 220 horas de ensaio pode ser visto nas Figuras 51 e 52.

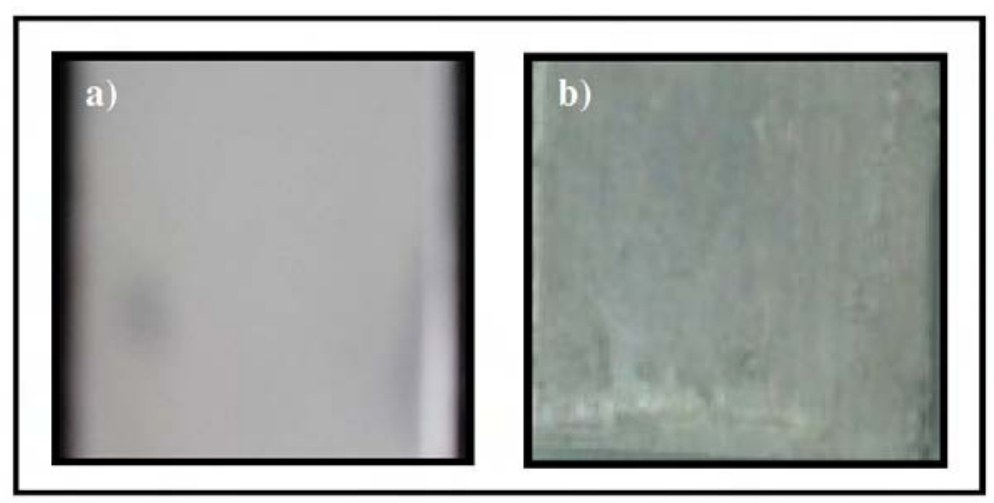

Figura 52 - Imagem da amostra 3 tratada a plasma com tensão de 150 V. a) antes da exposição à névoa salina e b) após 220 h de exposição à névoa salina.

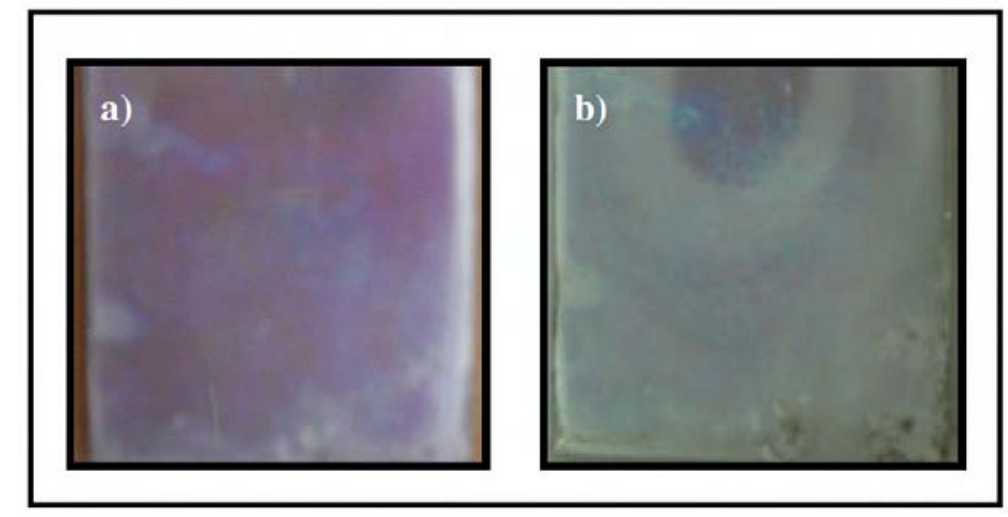

Figura 53 - Imagem da amostra 4 tratada a plasma com tensão de 200 V. a) antes da exposição à névoa salina e b) após 220 h de exposição à névoa salina. 
Após 330 horas de exposição à névoa salina, a amostra 3, tratada a $150 \mathrm{~V}$ e a amostra 4, tratada a $200 \mathrm{~V}$, também foram retiradas da câmara, pois também apresentavam pontos expressivos de degradação superficial. As demais amostras foram mantidas expostas à névoa salina, pois ainda não apresentaram sinais de degradação. A Figura 54 ilustra o aspecto das amostras 3 e 4 tratadas a plasma com 150 e 200 V, respectivamente.
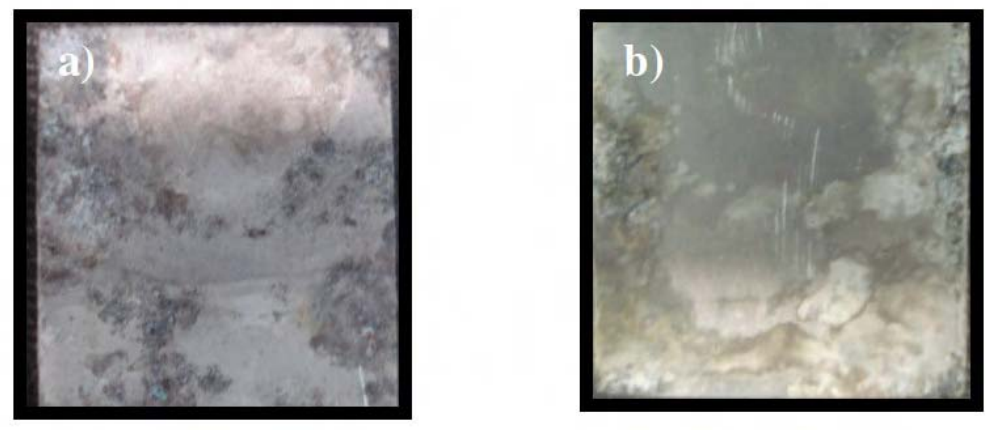

Figura 54 - Imagem das amostras após 330 h de exposição à névoa salina. a) amostra 3 tratada a plasma com tensão de $150 \mathrm{~V}$. e b) amostra 4 tratada a plasma com tensão de $200 \mathrm{~V}$.

As amostras 5, 6 e 7, tratadas a plasma com tensões nominais de 250, 275 e $300 \mathrm{~V}$ permaneceram expostas à névoa salina por mais $540 \mathrm{~h}$. A partir de então, foram observados pequenos sinais degradação superficial. Estas amostras totalizaram 870 horas de exposição a nevoa salina. Segundo Ortiz [54] e outros pesquisadores, filmes de óxido de alumínio apresentam excelentes características físicas e químicas, entre as quais se destaca a alta resistência à corrosão. O aspecto superficial das amostras 5, 6 e 7, tratadas a plasma com tensões de 250, 275 e $300 \mathrm{~V}$, respectivamente, após serem removidas da câmara de nevoa salina pode ser visto na Figura 55. 

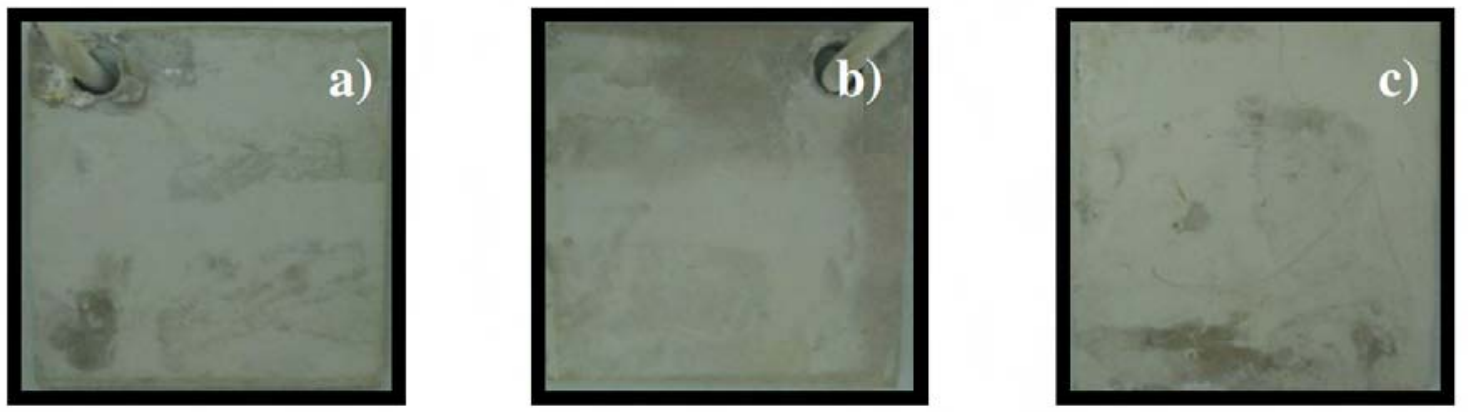

Figura 55 - Imagem das amostras após 870 h de exposição à névoa salina. a) amostra 5 tratada a plasma com tensão de 250 V. b) amostra 6 tratada a plasma com tensão de 275 V. e c) amostra 7 tratada a plasma com tensão de $300 \mathrm{~V}$.

Após 870 h de exposição à névoa salina, a amostra que apresentou um melhor aspecto superficial foi a tratada a plasma com tensão nominal de $275 \mathrm{~V}$. A Figura 56 ilustra o aspecto da amostra tratada, bem como da amostra sem tratamento.
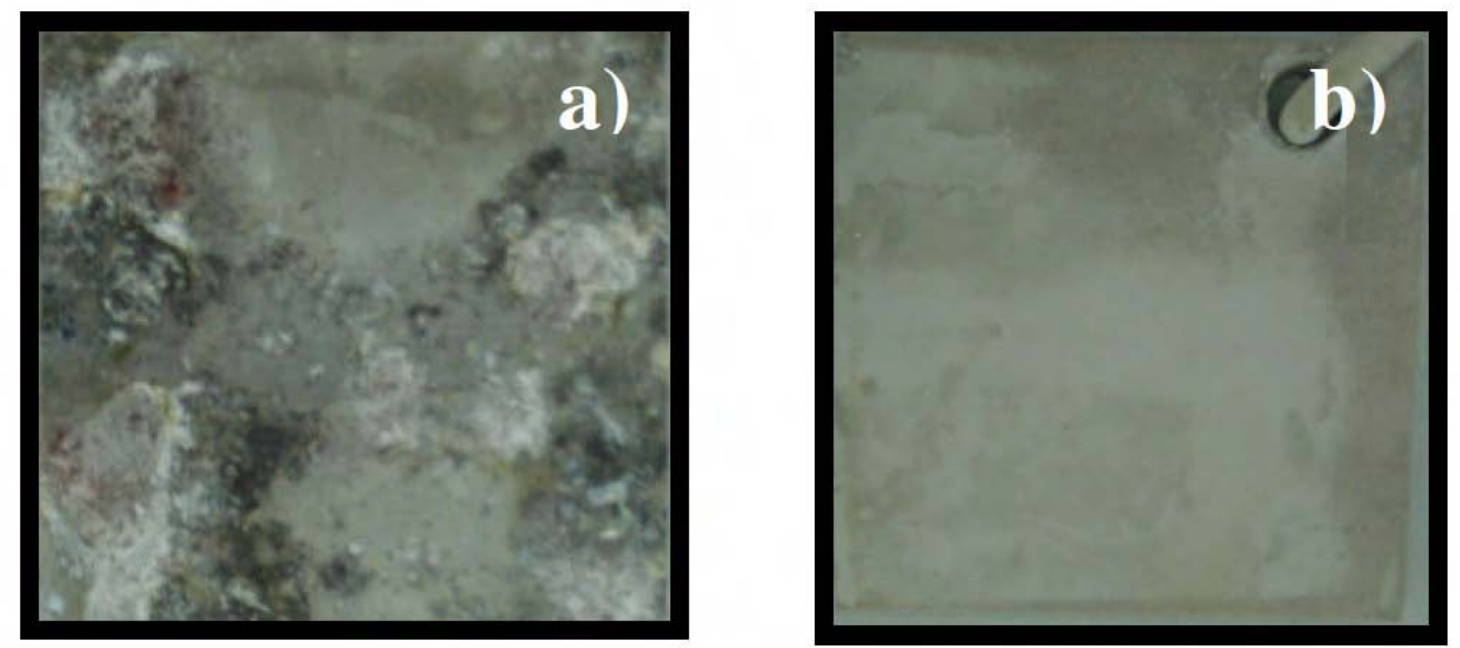

Figura 56 - Imagem das amostras após 870 h de exposição à névoa salina. a) amostra sem tratamento. b) amostra 6 tratada a plasma com tensão de $275 \mathrm{~V}$. 
Outro estudo realizado para investigar a resistência das amostras a ambientes corrosivos foi o de Espectroscopia de Impedância Eletroquímica e de polarização. A Figura 57 apresenta os diagramas de Bode $|Z|$ e Bode Fase para a liga AA 2024 conforme recebida.

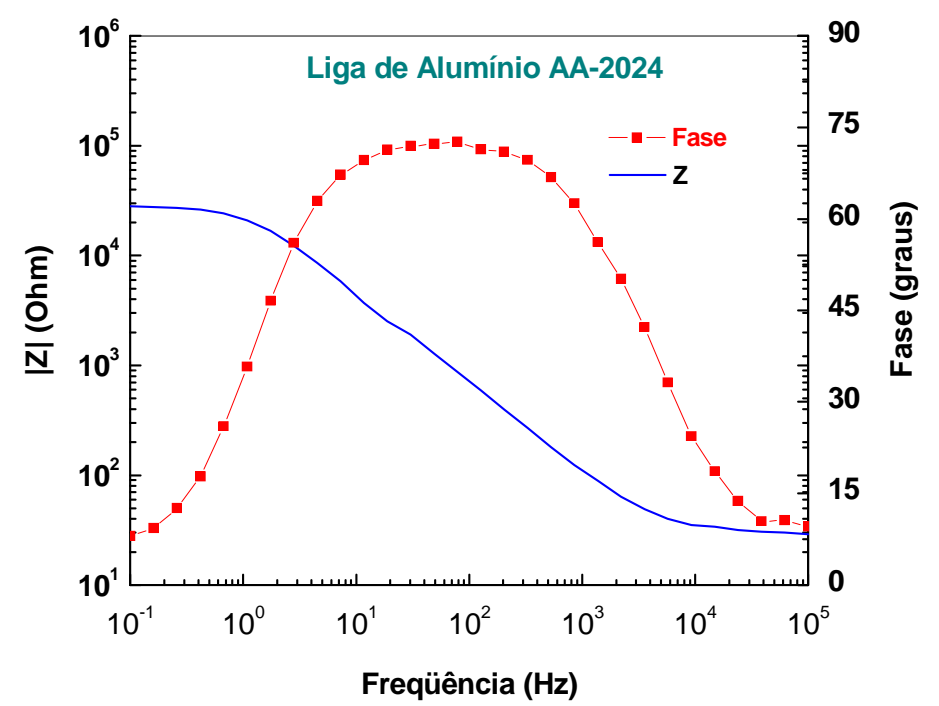

Figura 57 - Diagrama de Bode $|Z|$ e Bode Fase para a liga AA 2024 conforme recebida.

A Figura 58 apresenta os diagramas de Bode $|\mathrm{Z}|$ e Bode Fase tanto da liga sem tratamento, quanto das amostras expostas ao PEO em diferentes voltagens de tratamento.

Através dos diagramas de Bode Fase, nota-se que na liga não tratada o ângulo de fase $(\theta)$ cresce com o aumento da freqüência do sinal aplicado, mas volta a cair para frequiências maiores que $1,2 \times 10^{2} \mathrm{~Hz}$, formando uma concavidade. Quando as amostras são tratadas a plasma, há mudança significativa neste comportamento: todas as amostras passam a apresentar mais de uma concavidade na curva de fase. Em frequiências altas, a concavidade indica que estão ocorrendo reações entre o eletrólito e o filme. Para freqüências menores, a concavidade indica que o eletrólito já começa a 
estabelecer reações com a liga. Isto não significa, entretanto, que as reações com o filme já cessaram.
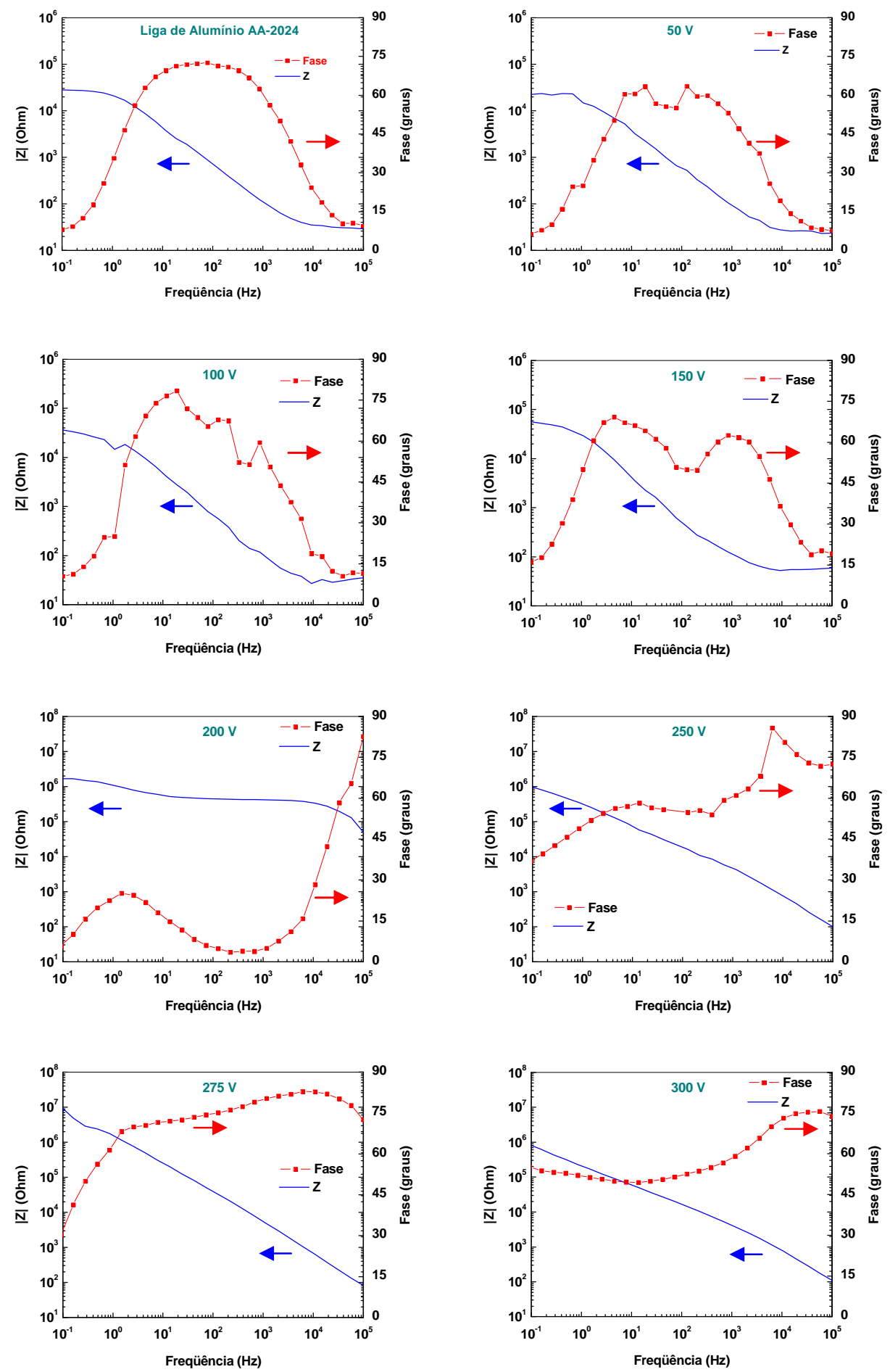

Figura 58 - Diagrama de Bode $|Z|$ e Bode Fase para a liga AA 2024 conforme recebida e das amostras expostas ao PEO em diferentes voltagens de tratamento. 
Com exceção da amostra tratada a $50 \mathrm{~V}$, todos os demais filmes apresentaram um aumento no valor da Fase para a frequiência de $10^{5} \mathrm{~Hz}$, quando comparado com o da liga de alumínio 2024 sem a deposição de filme. Para tensões entre 50 a $150 \mathrm{~V}$ este aumento não é tão expressivo, entretanto para tensões $\geq 200 \mathrm{~V}$ nota-se um aumento mais significativo. Esse aumento indica que os filmes atribuíram um maior caráter capacitivo às amostras em relação à liga sem deposição. Os filmes com o comportamento mais capacitivo foram os depositados com tensões de tratamento entre 200 a $300 \mathrm{~V}$, os quais apresentaram os maiores valores de fase. A pequena interferência do filme no ângulo de fase das amostras tratadas entre 50 a $150 \mathrm{~V}$, pode ser atribuída às pequenas espessuras dos filmes formados no substrato, observadas experimentalmente.

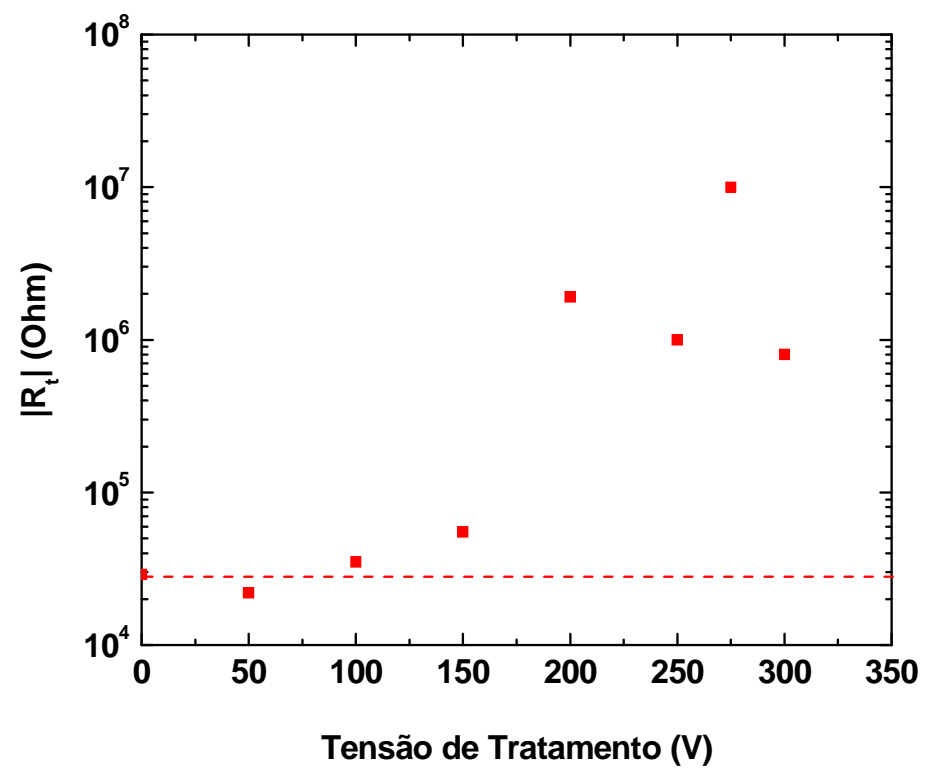

Figura 59 - Comportamento dos valores de resistência total em função da tensão de tratamento empregada no processamento PEO. A linha tracejada corresponde à liga 2024 sem tratamento.

Os valores de impedância determinados em baixas freqüências $\left(10^{-1} \mathrm{~Hz}\right)$ são utilizados para caracterizar as propriedades de barreira contra a corrosão do material através resistência total, Rt (soma da resistência do filme, da resistência à polarização e 
da resistência do eletrólito). De acordo com a curva do módulo de impedância, a Rt da liga de alumínio não tratada é de $2,9 \times 10^{4} \Omega$.

A Figura 59 ilustra o comportamento da resistência total das amostras em função da tensão de tratamento utilizada no processo.

De uma forma geral, os filmes apresentam uma tendência crescente no valor de Rt, com o aumento da tensão de tratamento. Os filmes depositados com tensões entre 50 e $150 \mathrm{~V}$ apresentam Rt muito próximo ao da liga. Já os filmes depositados com tensões iguais ou superiores a $200 \mathrm{~V}$, apresentaram valores de Rt bem superiores aos da liga sem tratamento, comportando-se como uma camada de proteção para o substrato. $\mathrm{O}$ filme depositado com $300 \mathrm{~V}$, entretanto, apresentou um decréscimo no valor de Rt. Este decréscimo muito provavelmente deve-se à presença de trincas e fissuras observadas nas imagens de microscopia da amostra.

As Resistências totais para os filmes tratados com 200, 250, 275 e $300 \mathrm{~V}$ apresentaram, respectivamente, um aumento de aproximadamente 65, 34, 345 e 27 vezes a Rt da liga não tratada.

Utilizando-se o modelo proposto por Mansfeld [42], também é possível determinar a capacitância de dupla camada, ou capacitância total dos filmes produzidos. Através do diagrama de Bode $|\mathrm{Z}|$, a capacitância total pode ser determinada pela extrapolação da curva de $|\mathrm{Z}|$ em médias freqüências $\left(10^{1}\right.$ a $\left.10^{3} \mathrm{~Hz}\right)$ até baixas freqüências, conforme ilustrado na Figura 15. É importante lembrar que a capacitância de dupla camada, $C d c$ é dada pelo inverso da Resistência total, pois $|Z|$ é independente da frequiência, $\omega$, para valores baixos $\left(10^{-1} \mathrm{~Hz}\right)$ como também para valores altos $\left(10^{5} \mathrm{~Hz}\right)$. A Figura 60 apresenta os valores da capacitância total, em função da tensão de tratamento empregada. 


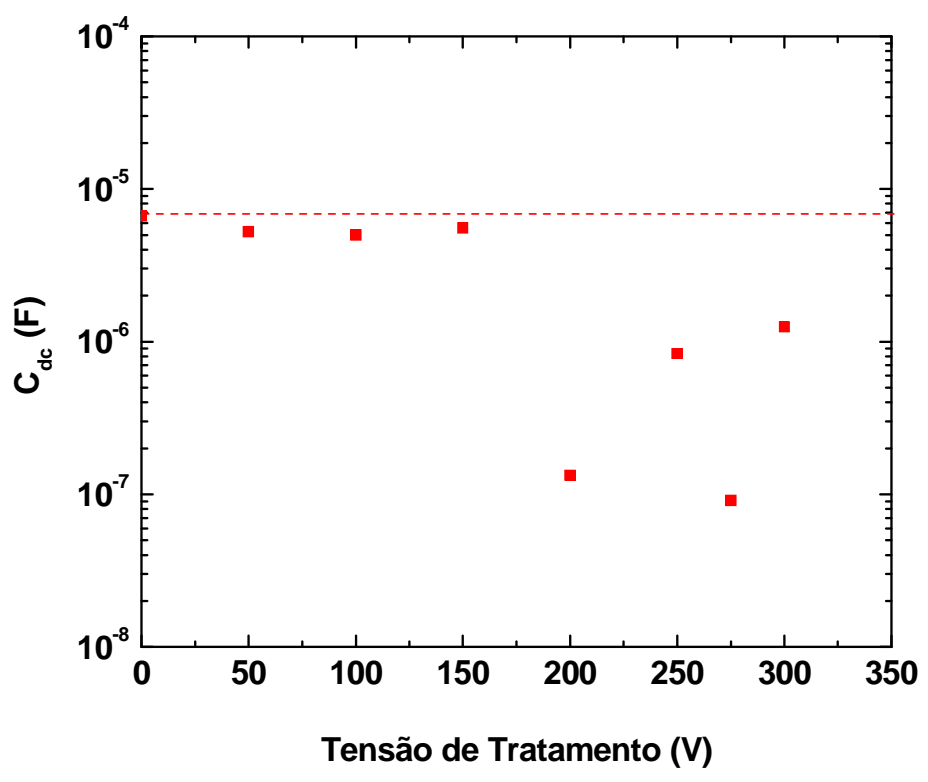

Figura 60 - Capacitância total em função da tensão de tratamento empregada no processamento PEO. A linha tracejada corresponde à liga 2024 sem tratamento.

De acordo com a Figura 60, é possível observar que o comportamento da capacitância total apresenta tendência contrária à observada para Rt. Os filmes depositados com tensões entre 50 a $150 \mathrm{~V}$ apresentam valores de $C_{d c}$ muito próximos aos valores da liga sem tratamento. Os depositados com tensões iguais ou superiores a $200 \mathrm{~V}$, entretanto, apresentaram valores de $C_{d c}$ bem inferiores aos da amostra padrão. Sendo a melhor barreira protetiva contra corrosão a que apresentar o menor valor de capacitância [55], o filme que obteve melhor resultado foi o depositado com tensão nominal de tratamento de $275 \mathrm{~V}$. O comportamento da capacitância dos filmes acompanha a tendência apresentada pelos ângulos de fase, confirmando também o melhor desempenho do filme tratado a $275 \mathrm{~V}$ de tensão nominal.

Tanto a espessura quanto a estrutura dos filmes formados afetam o comportamento da $C_{d c}$. Defeitos como poros poderão afetar os valores de $C_{d c}$ e de Rt. 

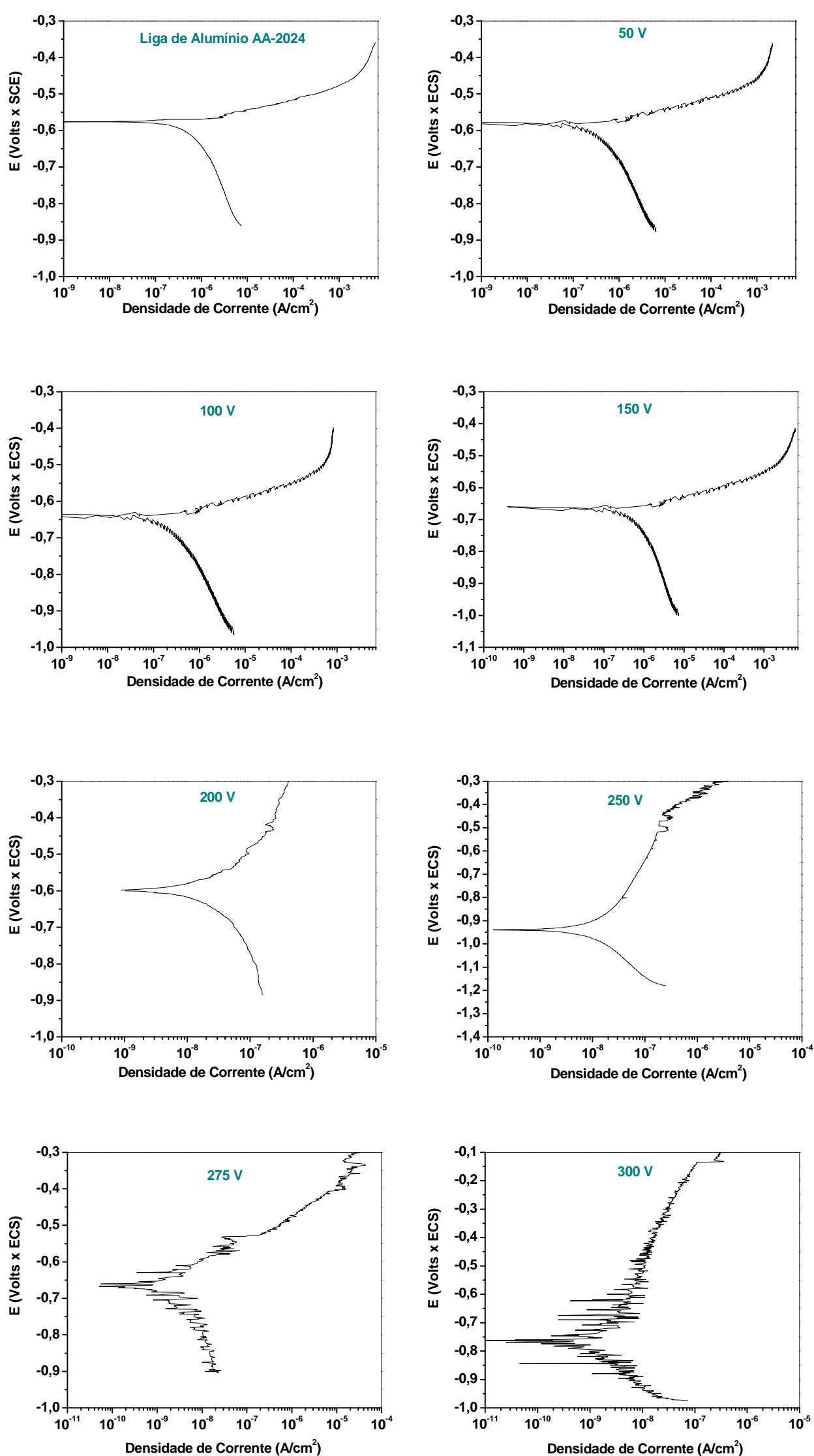

Figura 61 - Curvas de polarização para a liga AA 2024 conforme recebida e das amostras expostas ao PEO em diferentes voltagens de tratamento. 
A Figura 61 apresenta as curvas de polarização das amostras investigadas neste trabalho. A região catódica apresenta comportamento normalmente observado neste tipo de teste, entretanto a região anódica apresenta descontinuidades que podem estar relacionadas com a passivação e repassivação da liga de alumínio 2024. Desta forma, somente a região catódica foi utilizada para a extrapolação de Tafel [36, 54].

Os resultados obtidos para o potencial de corrosão $\left(\mathrm{E}_{\mathrm{corr}}\right)$, embora sofram variações, não conduzem a resultados conclusivos, pois a faixa de variação, além de não ser expressiva denota que os filmes apresentam um potencial mais ativo em relação ao da liga. Estes resultados podem significar que existe alguma irregularidade no revestimento. Os valores obtidos estão apresentados na Figura 62.

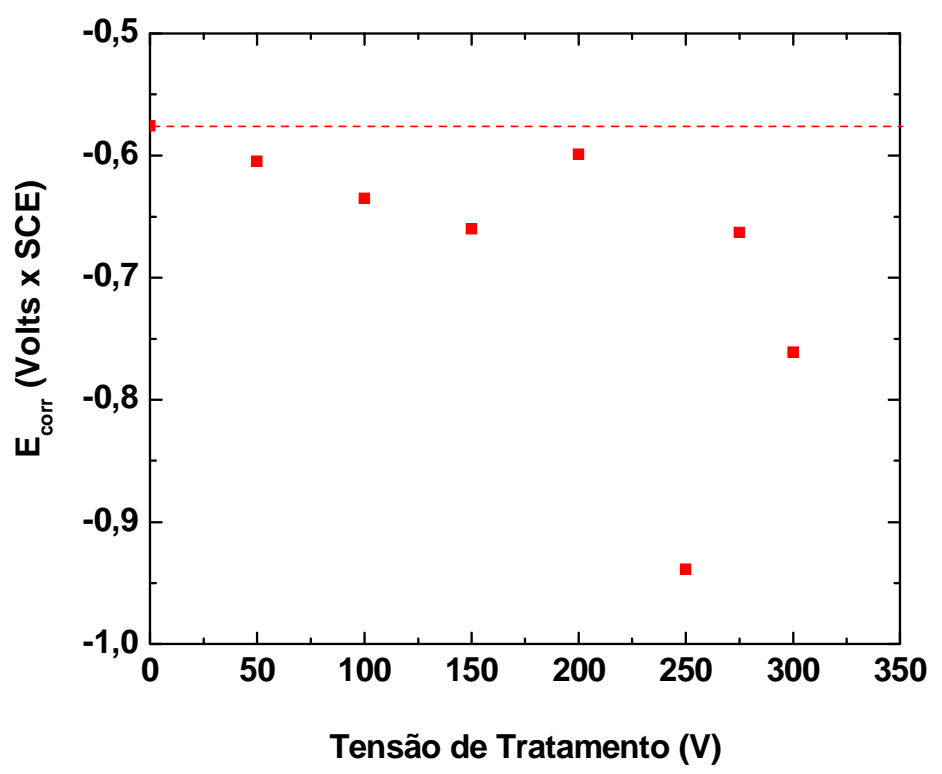

Figura 62 - Potencial de corrosão (Ecorr) em função da tensão de tratamento empregada no processamento PEO. A linha tracejada corresponde à liga 2024 sem tratamento.

Os valores obtidos pela extrapolação das retas de Tafel para a densidade de corrente de corrosão $\left(i_{\text {corr }}\right.$ ) são apresentados na Figura 63. O valor de $i_{\text {corr }}$ está associado à passagem de espécies responsáveis pela corrosão através da camada de proteção. 
Desta forma, quanto menor a $i_{\text {corr }}$, maior será o caráter protetivo do filme. Através da observação dos valores apresentados, pode-se dizer que a amostra, a amostra mais resistente à corrosão foi a que recebeu o filme depositado com tensão de $275 \mathrm{~V}$.

A partir dos resultados obtidos nos testes de polarização pode-se assumir que o mecanismo de proteção dos filmes depositados nas condições aqui empregadas é baseado na barreira à permeação de espécies corrosivas e não na passivação da superfície metálica, uma vez os filmes são mais ativos que a própria liga.

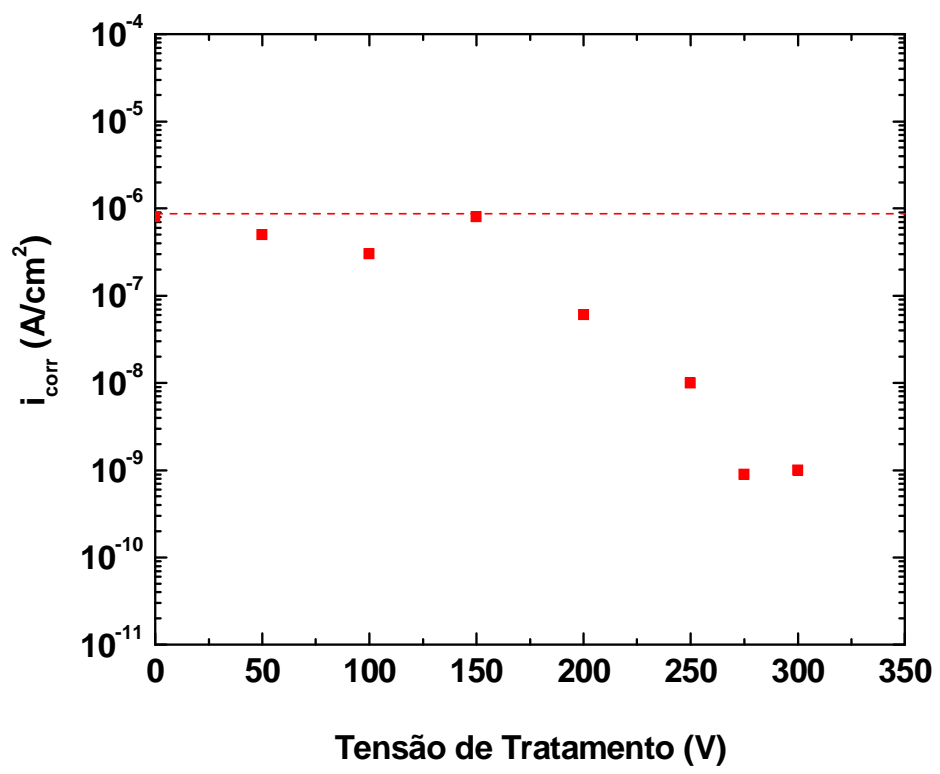

Figura 63 - Densidade da corrente de corrosão (Icorr) em função da tensão de tratamento empregada no processamento PEO. A linha tracejada corresponde à liga 2024 sem tratamento.

É interessante mencionar que os resultados de polarização obtidos nas amostras tratadas com 275 e $300 \mathrm{~V}$ possuem muita interferência na região do potencial de corrosão. 


\subsubsection{Microscopia Eletrônica de Varredura e Análise de Energia Dispersiva}

A microscopia eletrônica de varredura foi utilizada para avaliar o aspecto morfológico dos filmes formados na superfície do alumínio e a espectroscopia de energia dispersiva foi empregada para analisar a composição de algumas áreas dos

filmes. Os resultados estão presentes nas Figuras 64 a 70. É importante salientar que as imagens obtidas são representativas de toda região amostral.

Neste trabalho, a composição semi-quantitativa da liga foi caracterizada através dos espectros de energia dispersiva obtidos através do equipamento INCAxsight - Oxford Instruments do Laboratório Metalúrgico - Engenharia de Materiais da empresa Schaeffler Brasil Ltda-Divisão INA.

A espectroscopia de energia dispersiva de raios-X (EDS) é uma técnica de microanálise semi-quantitativa acoplada ao microscópio eletrônico. Consiste em raios-X característicos emitidos quando uma amostra é bombardeada por um feixe de elétrons. A emissão de raios-X ocorre quando um elétron das camadas mais externas ocupa a vacância deixada por um elétron de uma camada próxima ao núcleo. Durante esse fenômeno, o fóton que é liberado na forma de raios-X possui energia definida, com valores específicos de comprimento de onda e característico ao elemento do qual foi emitido. A grande vantagem do EDS é permitir a análise de amostras de tamanhos muito reduzidos ( $\geq 5 \mu \mathrm{m}$ ), limitada apenas pelo diâmetro do feixe de elétrons. 

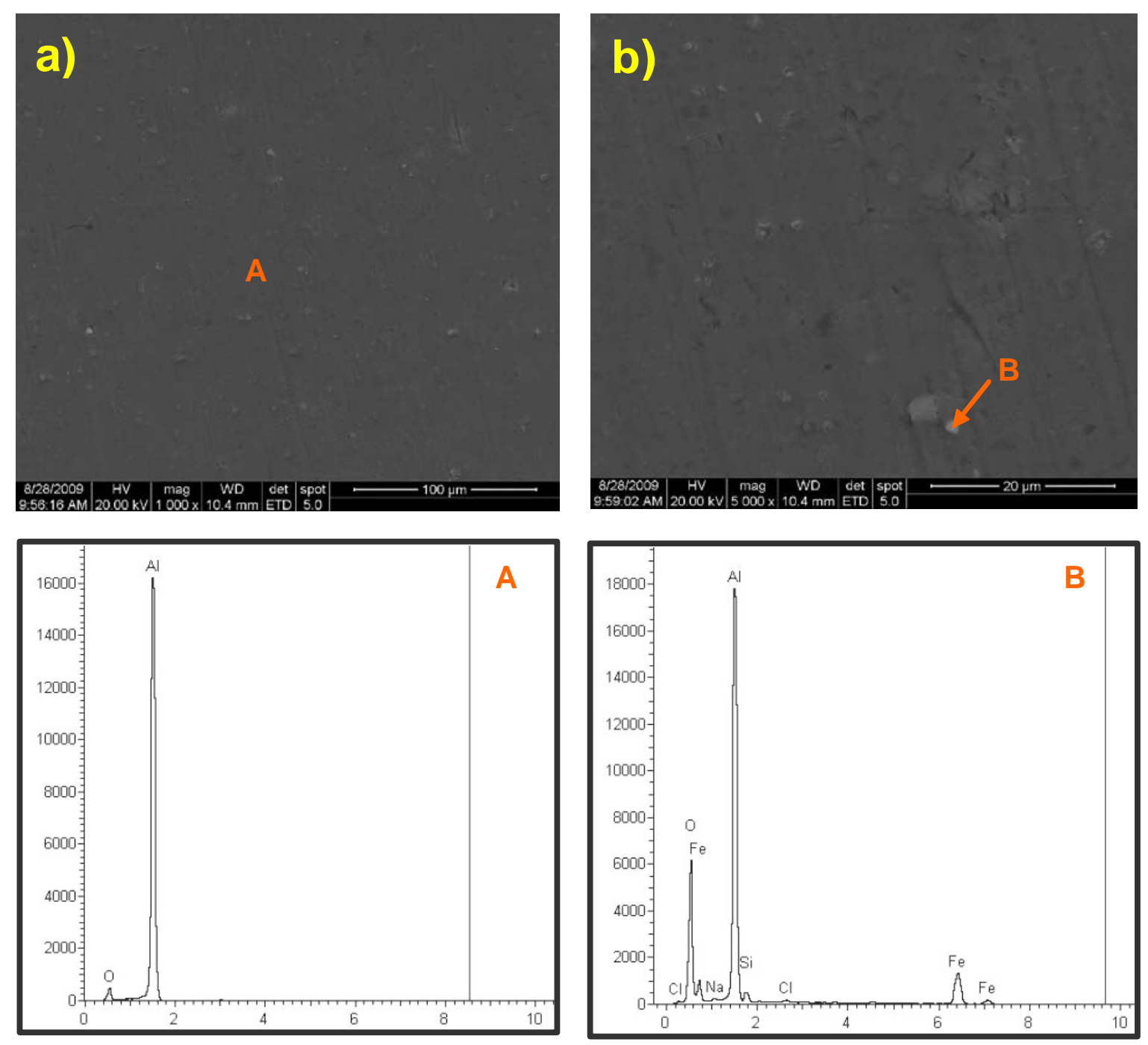

Figura 64 - Microscopia eletrônica de varredura com a) ampliação de 1000x e b) ampliação de 5000x e espectro de energia dispersiva das regiões A e B de uma amostra tratada a plasma com tensão nominal de $50 \mathrm{~V}$. 

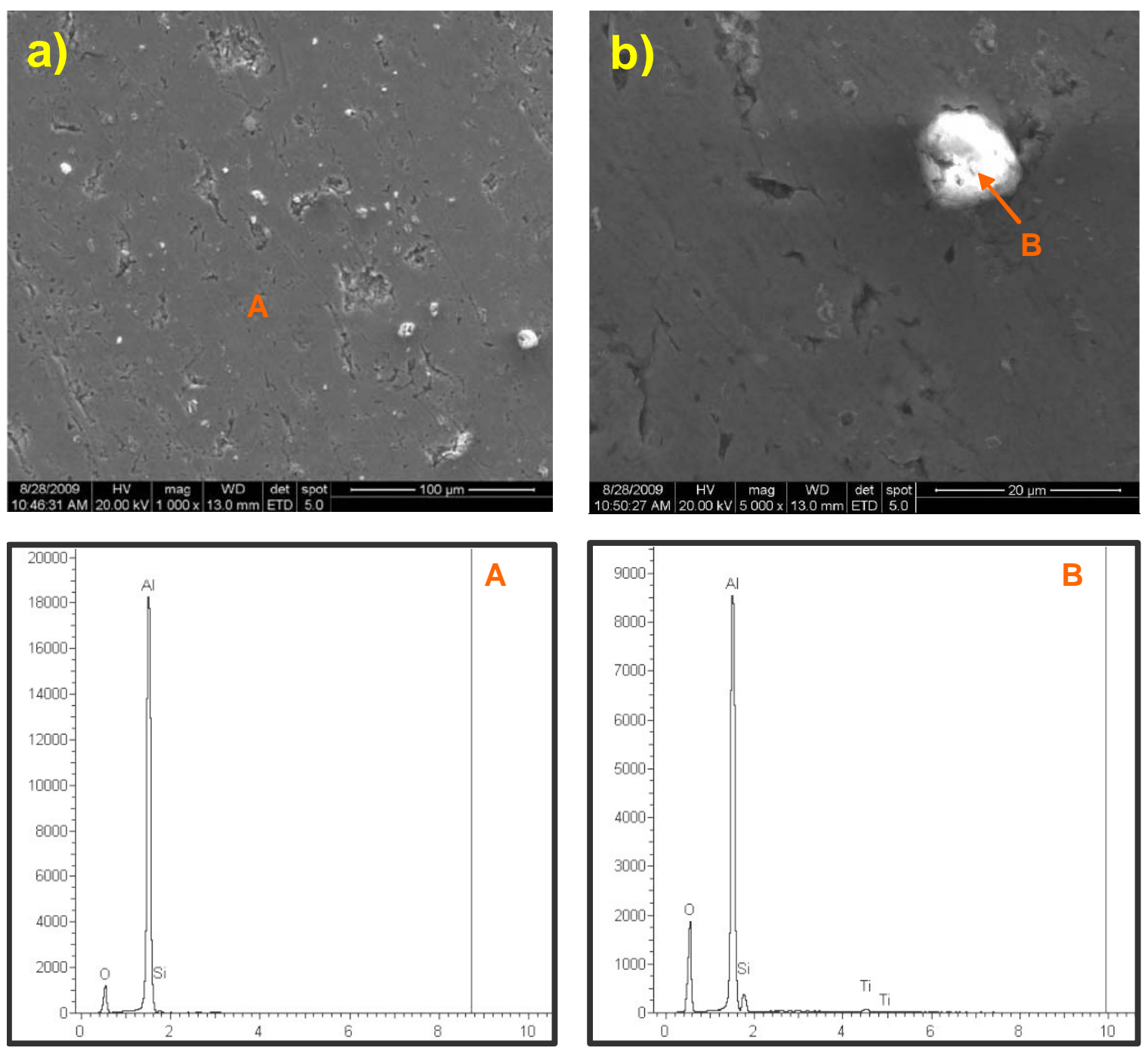

Figura 65 - Microscopia eletrônica de varredura com: a) ampliação de 1000x e b) ampliação de 5000x e espectro de energia dispersiva das regiões A e B de uma amostra tratada a plasma com tensão nominal de $100 \mathrm{~V}$. 

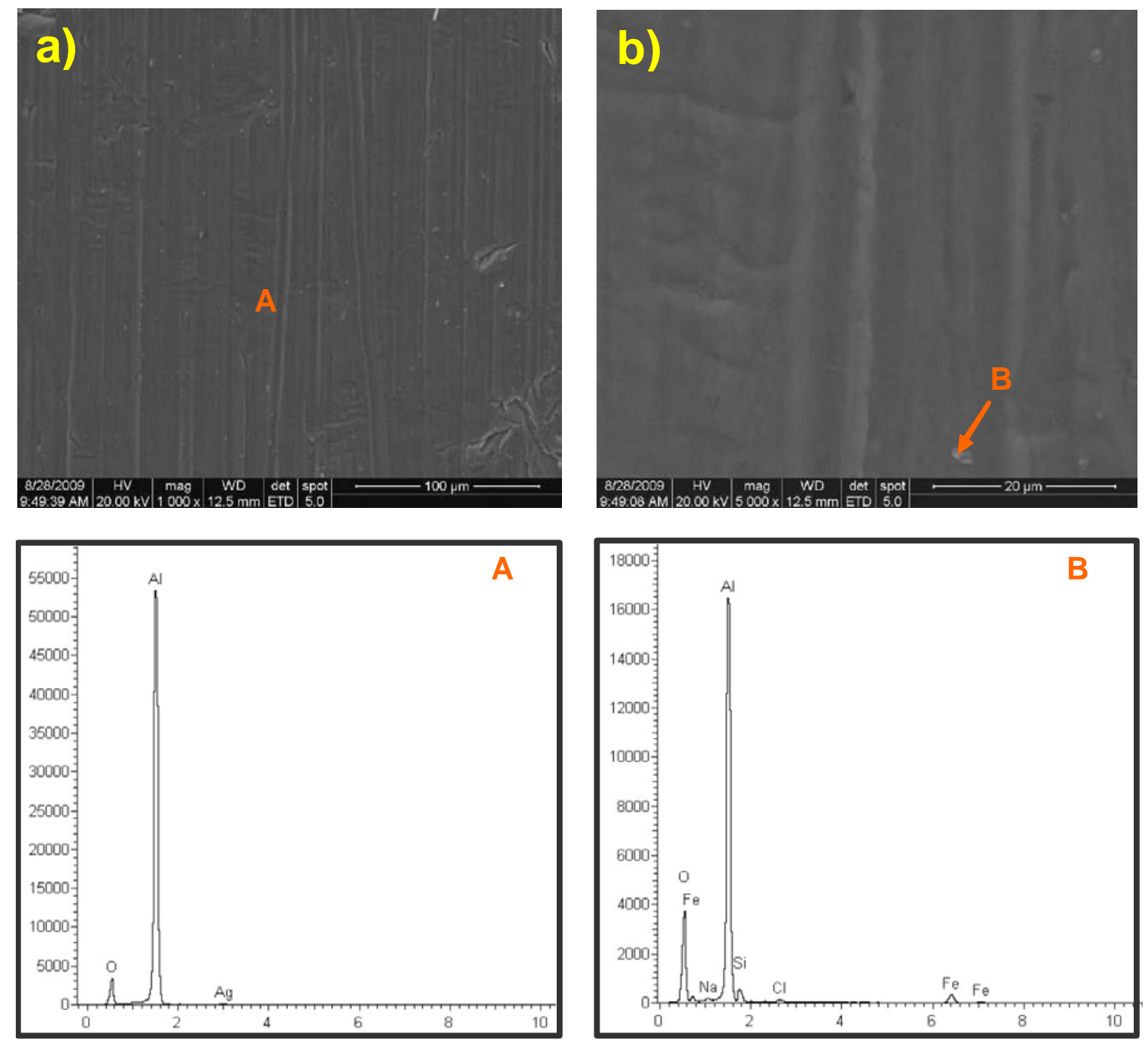

Figura 66 - Microscopia eletrônica de varredura com: a) ampliação de 1000x e b) ampliação de 5000x e espectro de energia dispersiva das regiões A e B de uma amostra tratada a plasma com tensão nominal de $150 \mathrm{~V}$. 

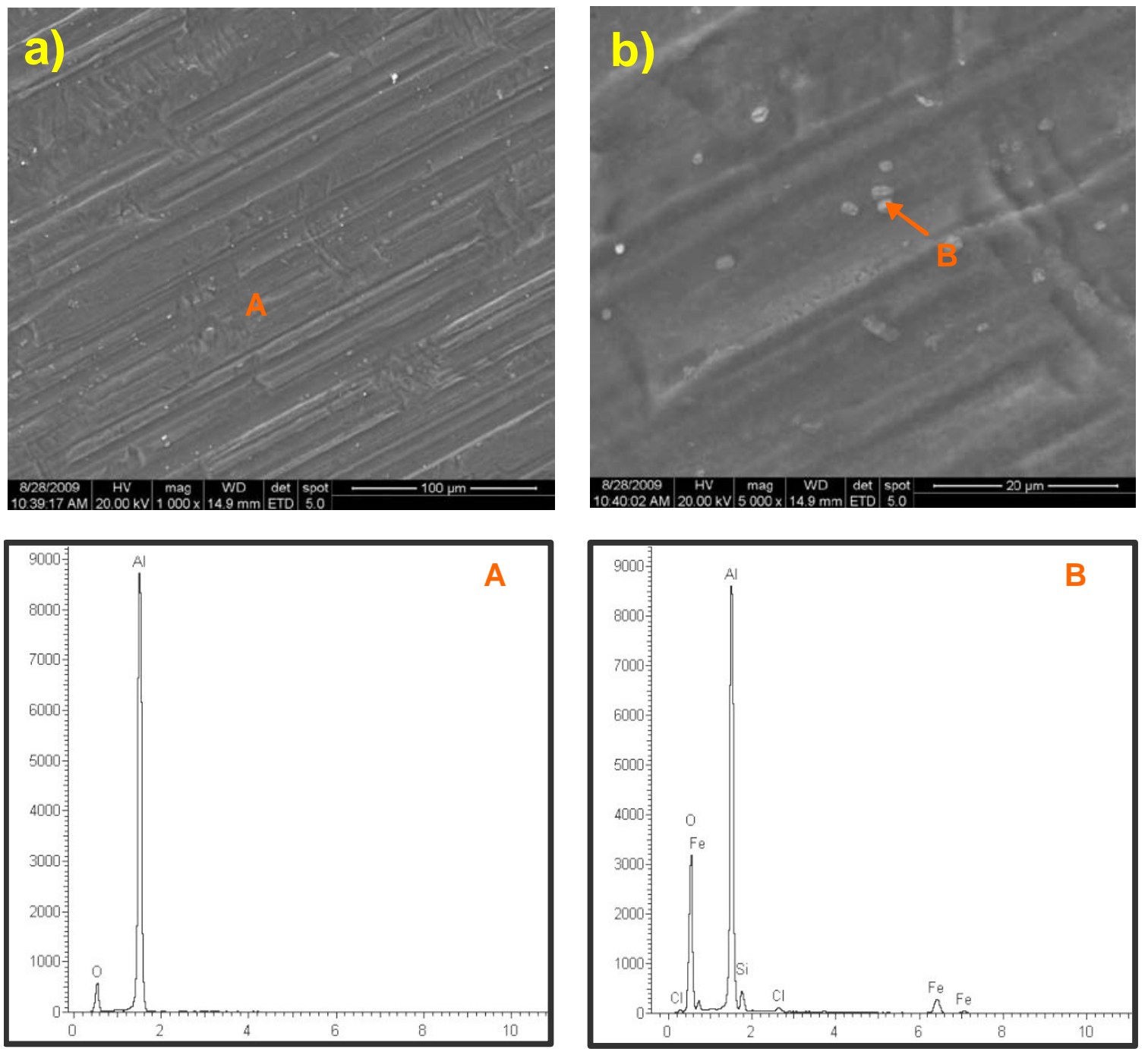

Figura 67 - Microscopia eletrônica de varredura com: a) ampliação de 1000x e b) ampliação de 5000x e espectro de energia dispersiva das regiões A e B de uma amostra tratada a plasma com tensão nominal de $200 \mathrm{~V}$. 

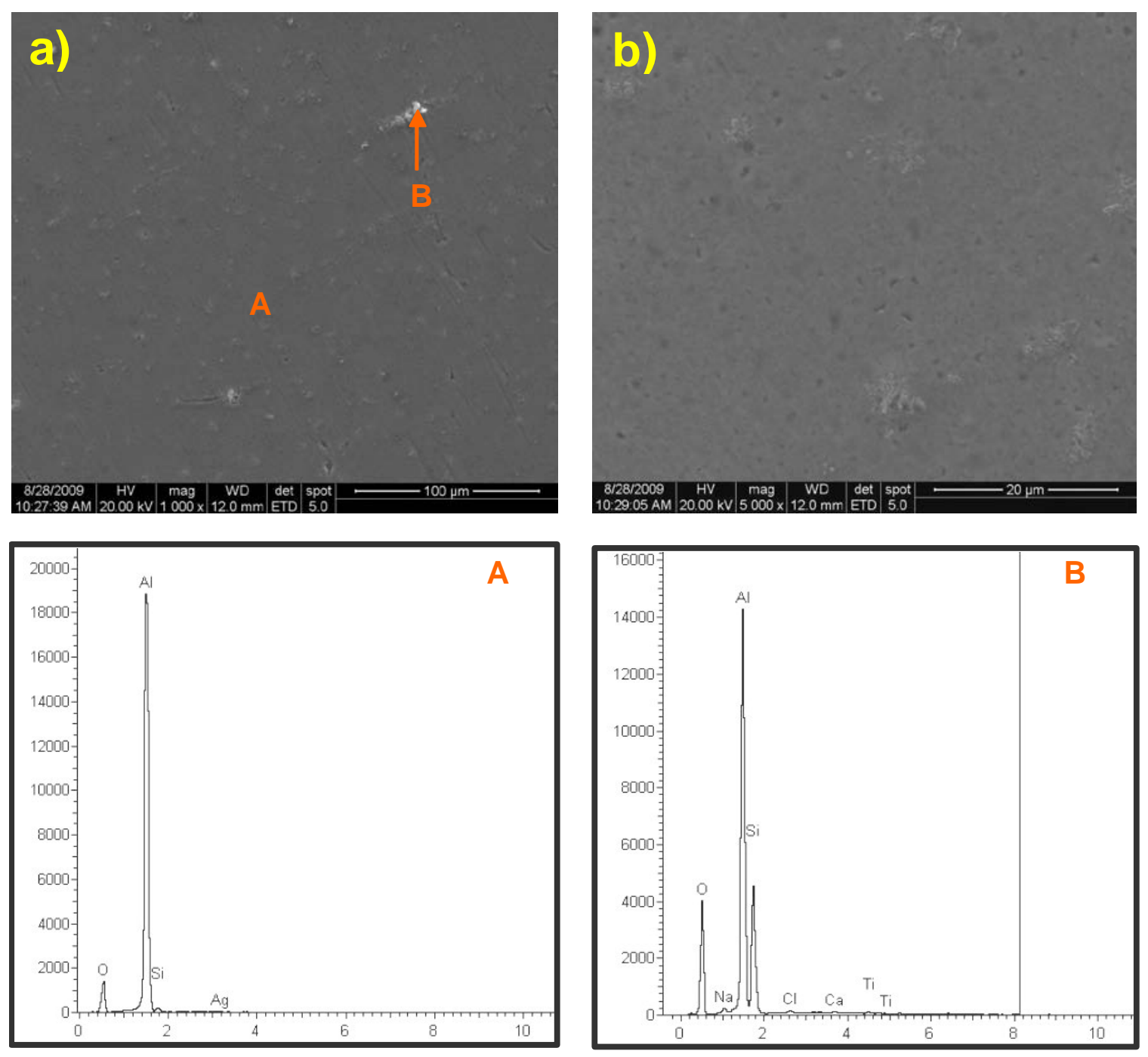

Figura 68 - Microscopia eletrônica de varredura com: a) ampliação de 1000x e b) ampliação de 5000x e espectro de energia dispersiva das regiões A e B de uma amostra tratada a plasma com tensão nominal de $250 \mathrm{~V}$. 

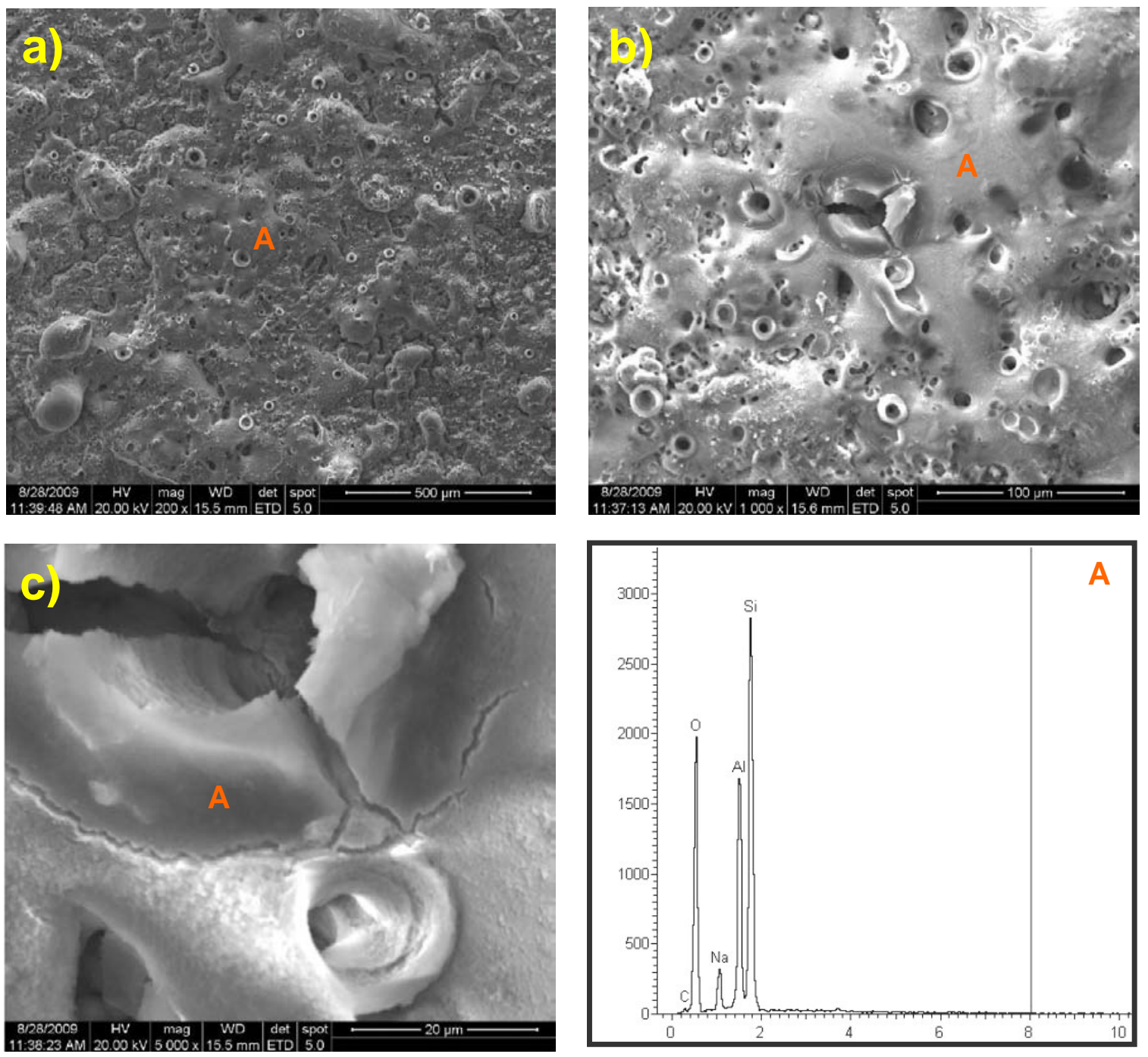

Figura 69 - Microscopia eletrônica de varredura com: a) ampliação de 200x, b) ampliação de 1000x e c) ampliação de 5000x e espectro de energia dispersiva da região apresentada em a), b) e c) de uma amostra tratada a plasma com tensão nominal de $275 \mathrm{~V}$. 

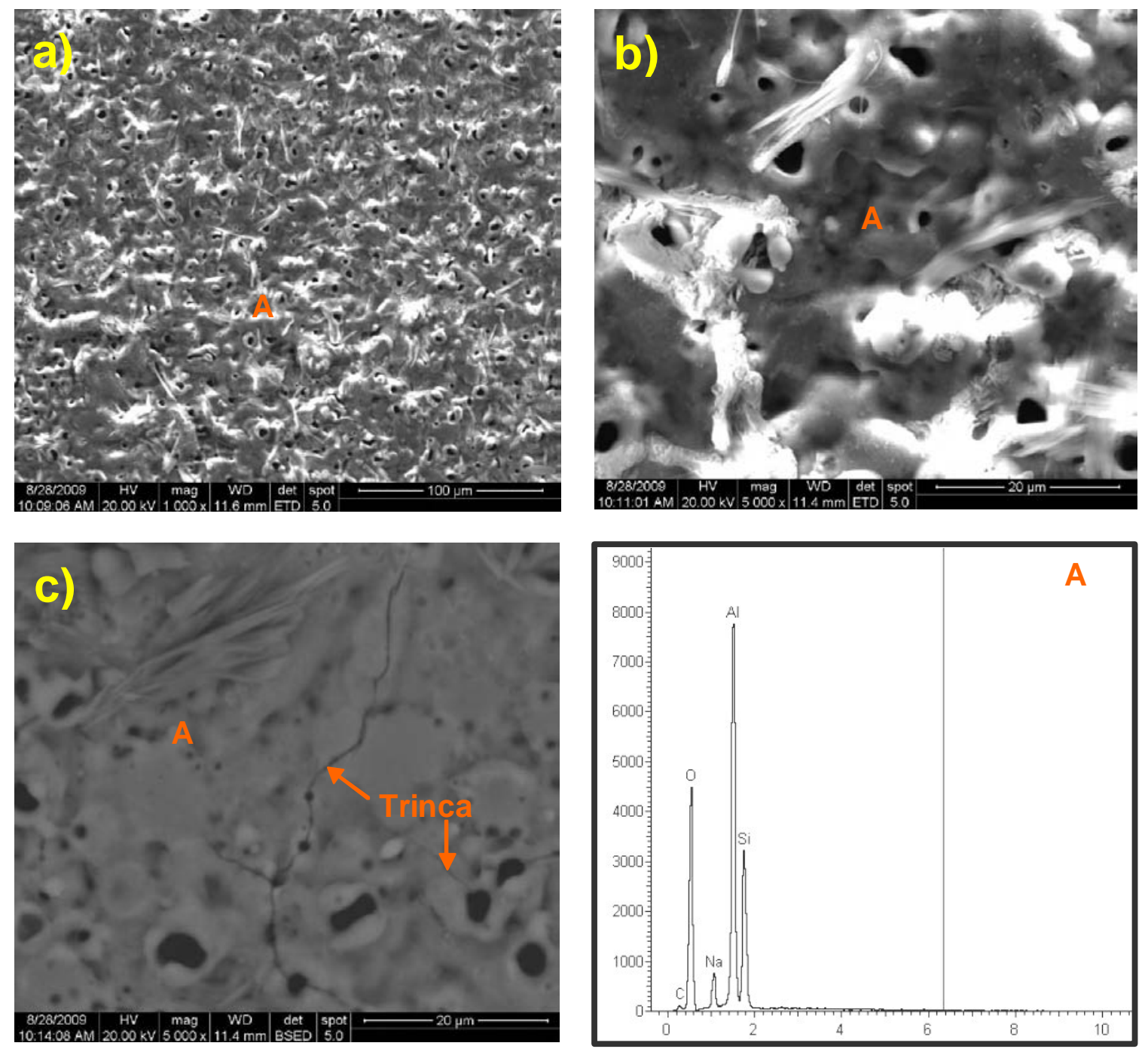

Figura 70 - Microscopia eletrônica de varredura com: a) ampliação de 1000x, b) e c) com ampliações de 5000x e espectro de energia dispersiva da região apresentada em a), b) e c) de uma amostra tratada a plasma com tensão nominal de $300 \mathrm{~V}$. 
A partir da micrografia das amostras, dá para se notar a presença de alguns resíduos brancos incorporados no filme. Os espectros destas regiões em substratos tratados entre 50 a $250 \mathrm{~V}$, denotam a presença de Si e O. Estes resíduos apresentam morfologia globular característica de óxidos.

A morfologia de "pé de galinha" apresentada na Figura 66, embora apresente aspecto diferente, possui a mesma composição química do restante da amostra. Os espectros apresentados sugerem uma tendência de aumento na concentração de Si para as amostras tratadas com tensões $\geq 250$ V. Esta característica confirma o desempenho das amostras nos testes de névoa salina e impedância.

A amostra tratada a $275 \mathrm{~V}$, apresenta uma topografia mais acentuada, com uma maior evidência de topos e vales. Em seu espectro pode-se verificar uma maior concentração de Na, Si e O presentes no filme. Já a amostra tratada com 300 V, embora apresente os mesmos elementos em quantidades ainda maiores, também apresenta uma topografia com maior quantidade de poros, notando-se inclusive a presença de trincas.

Durante o monitoramento do tratamento das amostras tratadas com $300 \mathrm{~V}$, em alguns instantes notou-se o repentino aparecimento de intensos arcos no tratamento. De acordo com os estudos conduzidos por Yerokhin [7], o aparecimento destes intensos arcos conduz a oscilações de corrente e pode causar danos ao revestimento como, por exemplo, o aparecimento de trincas.

\subsubsection{Análise da Estrutura Molecular por Espectroscopia no Infravermelho}

A Figura 71 apresenta os espectros de transmissão no infravermelho, IV, dos filmes depositados a plasma nas diferentes tensões nominais de tratamento. 


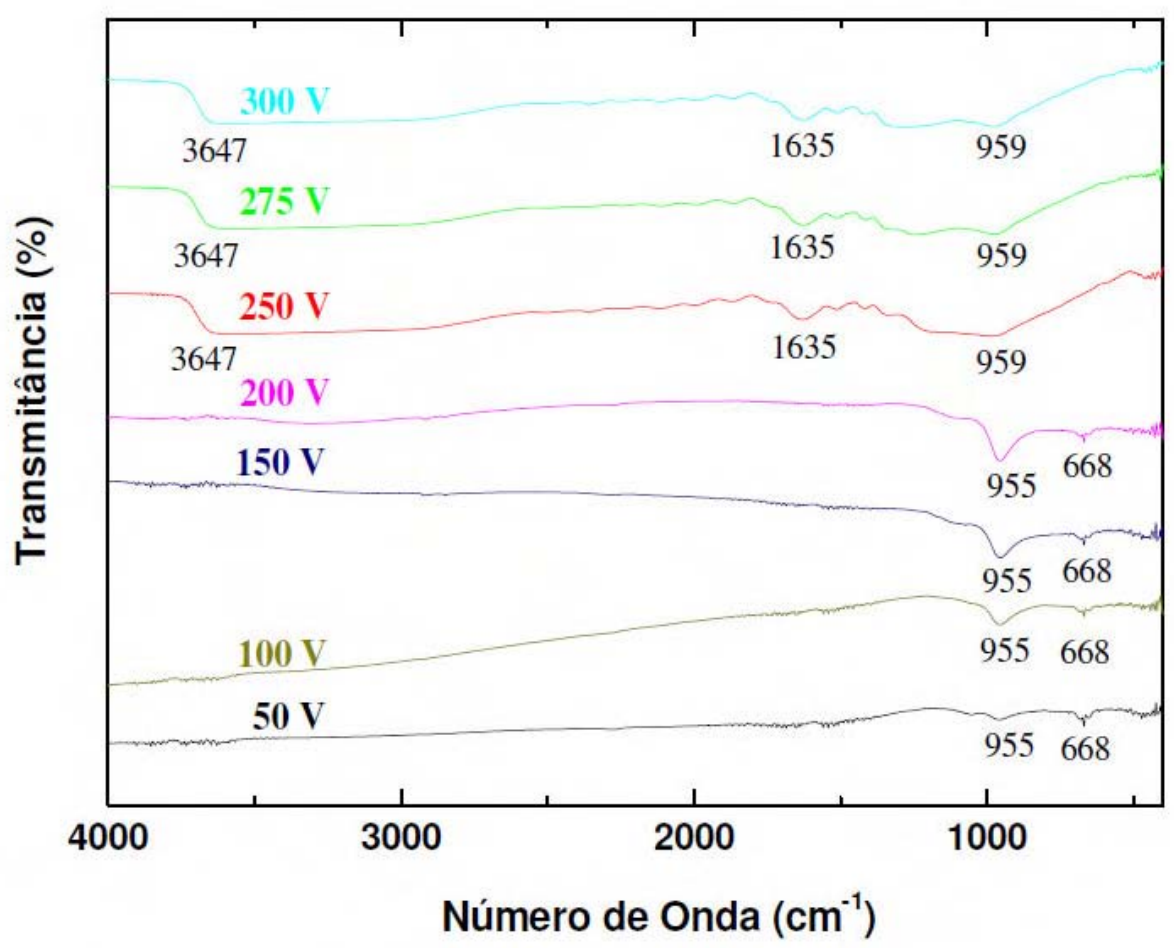

Figura 71 - Espectros de transmitância no infravermelho dos filmes depositados a plasma em diferentes tensões de tratamento.

A leitura dos resultados obtidos nas amostras deste trabalho foi efetuada pelo método IRRAS (InfraRed Reflectance - Absorbance Spectroscopy), que permite analisar filmes finos depositados sobre materiais refletores. Nesse método, o feixe incidente passa pelo filme e é refletido pela superfície metálica polida, de maneira tal que, o caminho percorrido pelo feixe é dobrado. Com isso, há uma diminuição na razão sinal/ruído e as absorções ficam mais claramente definidas.

Como pode ser observado a partir da Figura 71, bandas de absorção com picos variando entre $3000-3700 \mathrm{~cm}^{-1}$ são atribuídas a ligações de O-H [56]. Estas bandas provavelmente foram originadas de reações envolvendo vapor de água, durante o processamento. Segundo Lif [50], espectros que exibem bandas de absorção na região 
entre $3500-3800 \mathrm{~cm}^{-1}$ representam freqüências vibracionais de estiramento de grupos de hidroxila na alumina. Esta banda é observada somente em filmes depositados com tensões $\geq 250 \mathrm{~V}$.

O próximo pico observado a $1635 \mathrm{~cm}^{-1}$ pode ser principalmente devido ao modo vibracional de dobramento das moléculas residuais de água, sendo adsorvidas na superfície do óxido de alumínio [56, 57].

Os picos entre $920-970 \mathrm{~cm}^{-1}$ observados em todos os espectros apresentados, de acordo com Haanappel, são indicativos de ligações Al-O, considerados como característica de pico em filmes de alumina [56] com freqüências vibracionais de estiramento [59]. Brand [58] também atribui às faixas de vibração em torno de $960 \mathrm{~cm}^{-1}$ às ligações Al-O com freqüências vibracionais de estiramento. Segundo Brand [58], parte do crescimento da camada de óxido acontece em bandas ao redor de $950 \mathrm{~cm}^{-1}$.

Conforme Ortiz et al. [54], bandas localizadas entre 400 e $1000 \mathrm{~cm}^{-1}$ são características de filmes de $\mathrm{Al}_{2} \mathrm{O}_{3}$ e são compostas contribuição das vibrações de óxido de alumínio, o qual muda a forma, a posição dependendo da composição química da oxidação do alumínio [60].

\subsubsection{Discussões finais}

De acordo com as investigações realizadas, observado nos ensaios realizados, com o aumento da tensão, aumentava-se proporcionalmente, a quantidade e a intensidade dos micro-arcos durante o tratamento a plasma. Estes micro-arcos, conforme observado por Yerokhin [7] e investigado neste trabalho, proporcionam modificações na cinética do crescimento, na composição e na estrutura do revestimento, proporcionando maior sinterização do revestimento sobre a amostra. 
Como pôde ser visto nos resultados apresentados, a evolução da espessura do revestimento com tensões $\geq 150 \mathrm{~V}$, cresce consideravelmente. Para a configuração adotada neste equipamento, a cerca de $200 \mathrm{~V}$ o tratamento torna-se mais energético devido a presença dos micro-arcos.

É interessante mencionar que todos os filmes tratados apresentarem uma excelente estabilidade física de adesão ao substrato. Não foram observados pontos de descolamento do filme, o que comprometeria o desempenho das amostras nas investigações realizadas.

Conforme pode ser observado nas medições de rugosidade superficial das amostras antes e após a exposição ao plasma, todos os filmes conferiram ao material uma maior rugosidade superficial.

\section{CONCLUSÕES}

Através do desenvolvimento de um dispositivo para geração de plasma em meio aquoso proposto neste trabalho foi possível investigar o comportamento de filmes de óxido formados superficialmente em substratos de alumínio 2024. O processo utilizado foi o de oxidação via eletrólise, ou Plasma Eletrolítico de Oxidação, PEO.

Com os resultados obtidos foi possível verificar as propriedades conferidas aos substratos expostos ao PEO em diferentes faixas de tensão aplicadas e as características de barreira dos diferentes filmes formados para a proteção contra a corrosão oferecida à liga.

Através dos ensaios realizados, notou-se que houve tendência de diminuição nos valores do ângulo de contato à medida que a tensão nominal de tratamento era aumentada, tornando a superfície mais hidrofílica. Muito embora o filme torne a 
superfície mais hidrofílica, observou-se um expressivo aumento da resistência a corrosão do metal.

A estrutura e as propriedades dos filmes formados nos substratos de alumínio mostraram que a tendência de melhora da resistência a corrosão conferida pelo filme ao substrato aumenta em função da elevação da tensão de tratamento aplicada até determinados valores. Para tensões superiores a $300 \mathrm{~V}$, entretanto, observou-se o aparecimento de repentinos arcos intensos durante o tratamento e a presença de pequenas trincas na estrutura dos filmes depositados.

O filme formado em amostra com tensão nominal de $275 \mathrm{~V}$ foi o que apresentou a maior espessura, com média em torno de $24 \mu \mathrm{m}$.

Os filmes formados com tensões de tratamentos $\geq 250 \mathrm{~V}$ apresentaram um aumento significativo na proteção contra a corrosão acelerada. Através de ensaios de névoa salina verificaram-se aumentos na proteção conferida de até 145 vezes.

A partir dos testes de impedância eletroquímica e polarização, os filmes preparados com tensões de tratamento maiores que $200 \mathrm{~V}$ apresentaram boas propriedades de barreira, permitindo apontar o filme com tensão de $275 \mathrm{~V}$ como o mais efetivo para a proteção da liga de alumínio 2024.

Por fim, através deste trabalho foi possível promover a geração do plasma em meio aquoso e tratar a superfície de substratos de alumínio promovendo a estes excelentes características de proteção contra corrosão.

\section{TRABALHOS FUTUROS}

São sugestões para trabalhos futuros: 
- A investigação do desempenho ao desgaste de ligas de alumínio tratadas ao PEO;

- A variação na concentração da solução eletrolítica utilizada e a utilização de outros tipos de solução;

- A utilização de corrente pulsada na célula eletrolítica;

- Verificação da influência da variação de distância entre eletrodos no tratamento $\mathrm{PEO}$;

- O tratamento de outros materiais, como por exemplo, o aço carbono;

\section{REFERÊNCIAS}

[1]. STEVEnSON, M.F.J. Anodizing. In: Cotell, C.M., Sprague, J.A., Smidt, F.A.J. Surface Engineering. $9^{\text {th }}$ ed. ASM International Handbook Committee, v. 5, United States of America, p. 482-493, 1994.

[2]. DOMInGUES, L. et al. Anodização não poluente de ligas de alumínio. Corrosão e Protecção de Materiais, Lisboa, 2003. vol. 22 n 3.

[3]. GU, W. C. et al. Characterisation of ceramic coatings produced by plasma electrolytic oxidation of aluminium alloy. Materials Science and Engineering A 447, 2007. p.158-162.

[4]. ZHONG-AI, HU. et al. A Study on Water Treatment Induced by Plasma with Contact Glow Discharge Electrolysis. Plasma Science \& Technology, vol. $3 \mathrm{n}^{\circ}$ 5, 2001. p.927-932.

[5]. ATKINS, Peter; LORETTA Jones; tradução GARACELLI, Ignes. et. al. Princípios de química: questionando a vida moderna e o meio ambiente. Porto Alegre: Bookman, 2001. cap.12, p.603-634. 
[6]. MASTERTON, William L.; SLOWINSKI, Emil J.; STANITSKI, Conrad L.; tradução PEIXOTO, Jossyl de Souza. Princípios de Química. 6.ed. Rio de Janeiro: LTC, 1990. cap.12, p.253-274. cap.23, p.491-512.

[7]. YEROKHIN, A. L. et al. Plasma electrolysis for surface engineering. Surface and Coatings Technology 122, 1999. p.73-93.

[8]. ZIGLIO, A. C. Química Industrial e Inorgânica, Cloreto de Sódio e outros compostos de sódio. 2006. Instituto de Química de São Carlos - Universidade de São Paulo - USP, São Carlos, SP, 2006.

[9]. BOENING, H. V. Plasma science and technology. Cornell University Press, New York, 1982.

[10]. ROSSNAGEL, S.M.; CUOMO, J.J.; WESTWOOD, W.D. Handbook of plasma processing technology - fundamentals, etching, deposition and surface interactions. New Jersey, Noyes, 1989. 523p.

[11]. YASUDA, H. J. Plasma Polymerization. Academic Press. Inc, New York, 1985.

[12]. GUPTA, P. et al. Electrolytic plasma technology: Science and engineering - An overview. Surface and Coatings Technology 201, 2007. p.87468760.

[13]. Lieberman, M. A.; LICHTEnBERG, A. J. Principles of Plasma Discharges and Materials Processing. John Wiley and Sons, Inc., New York, 1994.

[14]. MOROSOFF, N. Plasma Deposition, Treatment and Etching of Polymers. Academic Press. Inc, New York. 1990.

[15]. YEROKHIN, A. L. et al. Spatial characteristics of discharge phenomena in plasma electrolytic oxidation of aluminium alloy. Surface and Coatings Technology 177-178, 2004. p.779-783. 
[16]. YASAKAU, K. A., et. al. Influence of inhibitor addition on the corrosion protection performance of sol-gel coatings on AA2024. Progress in Organic Coatings. V 63, 2008, 352.

[17]. PAULMIER T. et al. Development of a novel cathodic plasma electrolytic deposition technique - Part 1: Production of titanium dioxide coatings. Surface and Coatings Technology 201, 2007. p. 8761-8770.

[18]. YEROKHIN, A. L. et al. Phase formation in ceramic coatings during plasma electrolytic oxidation of aluminium alloys. Ceramics international 24 , 1997. p.1-6.

[19]. NIE, X. et al. Characteristics of a plasma electrolytic nitrocarburising treatment of stainless steel. Surface and Coatings Technology 139, 2001. p.135-142.

[20]. YEROKHIN, A. L. et al. Discharge characterization in plasma electrolytic oxidation of aluminium. Institute of physics publishing - Journal of physics D: Applied physics 36, 2003. p.2110-2120.

[21]. GUAN, Y. J. et al. Growth mechanism and corrosion behavior of ceramic coatings on aluminum produced by autocontrol AC pulse PEO. Surface and Coatings Technology 202, 2008. p. 4602-4612.

[22]. HALlidAY, D.; RESNiCK, R.; WALKER, J. Fundamentos de Física 3. 6 ed., Rio de Janeiro: LTC - Editora Livros Técnicos e Científicos, 1996.

[23]. Lei de Faraday da Eletrólise. Disponível em http://efisica.if.usp.br/eletricidade/basico/eletrolise. Acesso em 12/07/2008.

[24]. MILAN, M. T. et al. Metais, Uma visão objetiva. NEMAF - Núcleo de Ensaios de Materiais e Análise de Falhas - Departamento de Engenharia de 
Materiais, Aeronáutica e Automoblística (SMM) - Escola de Engenharia de São Carlos e USP.

[25]. AlUMiniUM ASSOCIATION, INC. Aluminium Alloy Selection and Applications. New York, 1998.

[26]. HUDA, Z. et. al. Characterization of 2024-T3: An aerospace aluminum alloy. Materials Chemistry and Physics. V 113, 2009, 516.

[27]. BURKARTER, E. Construção de Imagens por Padrões Hidrofóbicos/Hidrofílicos. 2006. Dissertação (Mestrado). Universidade Federal do Paraná, Curitiba, PR, 2006.

[28]. SILVA, G. Implantação iônica por imersão em plasma em ligas de alumínio. 2007. 148f. Dissertação (Mestrado) - ITA, São José dos Campos, 2007.

[29]. RANGEL, R. C. S. Aplicação da eletrocapilaridade na manipulação de microgotas. 2008. Dissertação (Mestrado). Universidade Estadual Paulista “Júlio de Mesquita Filho", Sorocaba, SP, 2008.

[30]. FOWKES , F. M. Ind. Eng. Chem., v. 56, p. 40, 1964.

[31]. OWEnS , D. K.; WEndT , R. C., J. Appl. Polym. Sci., v. 13, p. 1741, 1969.

[32]. ARYEH, B. N. Hydrophobic Interaction. New York: Plenum Press, 1980.

[33]. GEMELli, E. Corrosão de Materiais Metálicos e sua Caracterização. Rio de Janeiro. LTC - Livros Técnicos e Científicos Editora S.A., 2001, 96.

[34]. SKOOG, D. A.; HOLLER F. J.; NIEMAN T. A. Princípios de análise instrumental. 5 ed., Porto Alegre: Bookman, 2002, Cap. 16, p. 342-384. 
[35]. DELGADO, A. O. Estudo da Formação de Rastros Nucleares em Polímeros. 2007. 92f. Dissertação (Mestrado). Universidade de São Paulo, São Paulo, SP, 2007, 23.

[36]. CLARKE, A. R.; EBERHARDT, C. N. Microscopy Techniques for Materials Science. Waschington: Woodhead Publishing Limited and CRC Press LLC, $2002,362$.

[37]. REGONE, N. N. Anodização de Ligas de Alumínio por Corrente Pulsada. 2004. Tese (Doutorado). Universidade Estadual de Campinas, Campinas, SP, 2004

[38]. WOLYNEC, S. Técnicas Eletroquímicas em Corrosão. São Paulo: Editora da Universidade de São Paulo, 2003. 115-143.

[39]. MASCAGNI, D. B. T. Estudo das propriedades de barreira de filmes depositados a plasma sobre a liga de alumínio 2024. 2009. Dissertação (Mestrado). Universidade Estadual Paulista "Júlio de Mesquita Filho", Sorocaba, SP, 2009.

[40]. MANSFELD, F. et al. Recording and analysis of AC impedance data for corrosion studies. Corrosion, v.38, n. 11, 1982, p. 570-580.

[41]. OLIVEIRA, M. F. Estudo da influência de organo-silanos na resistência à corrosão de aço-carbono por meio de técnicas eletroquímicas. 2006. 276f. Tese (Doutorado). Universidade de São Paulo, São Paulo, 2006.

[42]. MANSFELD, F. Models for the impedance behavior of protective coatings and cases of localized corrosion. Electrochimica Acta, v. 38, n.14, 1993, p. 1891-1897.

[43]. WEI, C. B. et al. Anode current effects in plasma electrolytic oxidation. Surface and Coatings Technology 201, 2007. p.5021-5024. 
[44]. RANGEL, E. C. Polimerização em implantação iônica em filmes finos depositados por PECVD. 1999.144f. Tese (Doutorado). Universidade Estadual de Campinas, Campinas, 1999.

[45]. VILlAS BOAS, N.; DOCA, R. H.; BISCUOLA, G. J. Tópicos de Física - Vol. 3 - Eletricidade. 17ª ed. Rio de Janeiro: Saraiva, 2007.

[46]. Correntes de Foucault. Disponível em www.efisica.if.usp.br/eletricidade/basico/inducao. Acesso em 20/07/2009.

[47]. The Institute for Electronics and Measurement Technology Helmut Fischer. Disponível em www.helmut-fischer.com. Acesso em 20/07/2009.

[48]. SUNDARARAJAN, G.; KRISHNA, L. R. Mechanisms underlying the formation of thick alumina coatings through the MAO coating technology. Surface and Coatings Technology 167, 2003. p.269-277.

[49]. NIE, X. et al. Abrasive wear-corrosion properties and TEM analysis of $\mathrm{Al}_{2} \mathrm{O}_{3}$ coatings fabricated using plasma electrolysis. Surface and Coatings Technology 149, 2002. p. 245-251.

[50]. LIF, J. et al. Sintering of alumina-supported nickel particles under amination conditions: Support effects. Applied Catalysis A: General 317, 2007. p. 6269.

[51]. XUE, W. et al. Growth regularity of ceramic coatings formed by microarc oxidation on Al-Cu-Mg alloy. Thin Solid Films 372, 2000. p. 114-117.

[52]. THOMPSON, G.E. et al. Porous anodic alumina: fabrication, characterization and applications. Thin Solid Films 297, 1997. p. 192-201. 
[53]. TIAN, J. et al. Structure and antiwear behavior of micro-arc oxidized coatings on aluminum alloy. Surface and Coatings Technology 154, 2002. p. $1-7$.

[54]. ORTIS, A. et al. Characterization of amorphous aluminum oxide films prepared by the pyrosol process. Thin Solid Films 368, 2000. p. 74-79.

[55] KAWAKAMI, K. Estudo da corrosão do Ti-6Al-4V, com e sem depósito de TiO2, em solução de Hanks, através de técnicas eletroquímicas. 1992. Dissertação (Mestrado). Universidade Estadual de Campinas, Campinas, 1992.

[56]. HAANAPPEL, V. A. C. et al. Properties of alumina films prepared by low-pressure metal-organic chemical vapour deposition. Surface and Coatings Technology 72, 1995. p. 13-22.

[57]. RUHI, G. et al. Effect of sintering temperatures on corrosion and wear properties of sol-gel alumina coatings on surface pre-treated mild steel. Corrosion Science 50, 2008. p. 639-649.

[58]. BRAND, J. et al. Ageing of aluminium oxide surfaces and their subsequent reactivity towards bonding with organic functional groups. Applied Surface Science 235, 2004. p. 465-474.

[59]. SHIDING, M. et al. Synthesis and characterization of mesoporous aluminosilicate molecular sieve from K-feldspar. Microporous and Mesoporous Materials 83, 2005. p. 277-282.

[60]. SCHROEDER, R. A.; LYONS, L. L. Infra-red spectra of the crystalline inorganic aluminates. J. inorg. nucl. Chem. 28, 1966. p. 1155-1163. 